ISIS SANTOS COSTA

\title{
MODELAGEM DO ESCOAMENTO EM REATOR CATALÍTICO DE MEMBRANA CERÂMICA PARA HIDROGENAÇÃO PARCIAL TRIFÁSICA
}

São Paulo 
ISIS SANTOS COSTA

\section{MODELAGEM DO ESCOAMENTO EM REATOR CATALÍTICO DE MEMBRANA CERÂMICA PARA HIDROGENAÇÃO PARCIAL TRIFÁSICA}

Dissertação apresentada à Escola

Politécnica da Universidade de São

Paulo para obtenção do título de Mestre em Engenharia

Área de concentração:

Engenharia Química

Orientador:

Prof. Dr. Song Won Park

\section{São Paulo}


Este exemplar foi revisado e alterado em relação à versão original, sob responsabilidade única do autor e com a anuência de seu orientador.

São Paulo, 19 de janeiro de 2012.

Assinatura do autor

Assinatura do orientador

FICHA CATALOGRÁFICA

Costa, Isis Santos

Modelagem de hidrogenação parcial trifásica em reator catalítico de membrana cerâmica / I.S. Costa. -- ed.rev. -- São Paulo, 2012.

$138 \mathrm{p}$.

Dissertação (Mestrado) - Escola Politécnica da Universidade de São Paulo. Departamento de Engenharia Química.

1. Catalisadores 2. Reações heterogêneas 3. Simulação (Modelagem computacional) 4. Dinâmica dos fluidos I. Universidade de São Paulo. Escola Politécnica. Departamento de Engenharia Química II. t. 
DEDICATÓRIA

Dedico este trabalho aos meus pais, Graça e (in memoriam) Dudu, e a meus avós, Pergentina, Sr. Monteiro, Dona Laura e vovô. 


\section{AGRADECIMENTOS}

Agradeço imensamente a meu orientador, Prof. Song Won Park, pela abrangente orientação e pelo apoio absoluto na superação dos inúmeros obstáculos.

Agradeço ao Prof. Reihardt Schomäcker, Prof. Roberto Guardani e Dra. Andrea Schmidt, que contribuíram em trabalhos e etapas anteriores.

Dirijo meus agradecimentos também aos integrantes da banca de seminários semestrais e da Qualificação, Prof. Dr. Reinaldo Giudici, Prof. Dr. Augusto Câmara Neiva, Dra. Marilda Vianna e Prof. Ardson Vianna Jr., cujas observações direcionaram e lançaram luz quanto aos estudos realizados.

Sou grata pelo apoio da empresa onde trabalho, Thermojet do Brasil, que me possibilitou dedicação ao mestrado. Particularmente, agradeço ao meu chefe, Eng. ${ }^{\circ}$ Ricardo Leite Passos e ao diretor de Recursos Humanos, Antônio Carlos Rodgrs.

Agradeço à empresa ESSS, na pessoa de Ricardo Barros e Mariana Buchner Linardi, pela concessão de licença do ANSYS 13.0, e do Dr. Leonardo Rangel, pela ajuda com o uso do software.

Agradeço ao Prof. Dr. Darci Odloak e à Chefe do Serviço de Pós-Graduação da EPUSP, Fátima Domingues, pela concessão de novos prazos.

Agradeço ao Eng. ${ }^{\circ}$ Bruno Vidal, da Escola de Engenharia de Lorena, pela ajuda na caracterização da membrana.

Sou grata aos colegas do LSCP Daniel Ferreira, que me ajudou com tutoriais e ricas discussões, Giácoma Manhães, pela companhia e orientações, e Elsa Alvarez, pela ajuda com o texto. Menciono ainda as colegas Patrícia Pantoja, Patrícia Yasumura, Verônica e Deusanilde.

Foi de grande importância a colaboração de funcionários da USP, como a bibliotecária Maria Lucia Adamo Attar e o secretário Alexandre Oliveira.

Agradeço aos meus amigos, especialmente ao Marcelo Nogueira, pela ajuda no meu primeiro contato com o software FLUENT.

Agradeço também aos mais próximos, que acompanharam de perto todas as etapas: Graça, Tássio, Amilton e Pergentina. 
Pode-se superar os obstáculos do caminho caso se tenha determinação, coragem e vontade de trabalhar duro.

Sejam resolutos, mas nunca amargos.

Não permitam que ninguém os dissuada dos seus objetivos.

Não tenham medo de ser pioneiros e de se aventurar em terras desconhecidas.

Exijam e façam bom uso dos seus direitos, mas nunca deixem de realizar, com fé, suas obrigações e responsabilidades de cidadãos.

(Ralph J. Bunche) 


\section{RESUMO}

No presente trabalho, foi desenvolvido um modelo para o escoamento em reator de membrana do tipo contator ativo, através da abordagem de dinâmica dos fluidos computacional (CFD), utilizando o código comercial ANSYS FLUENT. O modelo incluiu todo o módulo de membrana constituído por uma membrana tubular e um casco metálico. A reação modelo estudada foi a hidrogenação parcial de 1,5ciclooctadieno, realizada pelo bombeamento da mistura reacional, dissolvida em nheptano, através da membrana, a partir das extremidades do tubo. Como catalisador, considerou-se a presença de nanopartículas de Pd impregnadas na membrana. O meio poroso foi aproximado por leito granular representado pela equação de Ergun, tendo como parâmetros a porosidade e o tamanho de grão da membrana de $\alpha-\mathrm{Al}_{2} \mathrm{O}_{3}$. O valor para o tamanho de grão foi adotado como equivalente ao diâmetro de partícula determinado com uso do código aberto de estereologia ImageJ, do instituto Nacional de Saúde dos Estados Unidos. O modelo de turbulência adotado foi o RNG $k-\varepsilon$. Um estudo de sensibilidade incluiu simulações comparando escoamento desprezando reações como escoamento reativo, variação da velocidade, alteração da saída do fluxo e ativação de modelo de turbulência no meio poroso. Foram realizadas simulações de defeitos estruturais na membrana, correspondendo a regiões de porosidade alterada, com e sem perda de sua uniformidade azimutal. Conclui-se que a presença de defeitos estruturais que afetem a uniformidade azimutal da membrana pode resultar em sensível alteração do escoamento em CMRs. 


\begin{abstract}
This study focused on the development of a model for the flow in a reactor membrane of the type active contactor, approached through computational fluid dynamics (CFD), using the commercial code ANSYS FLUENT. The model included the entire membrane module, consisted of a tubular membrane and a metal shell. The model reaction studied was the partial hydrogenation of 1,5-cyclooctadiene initiated by the pumping of the reaction mixture, dissolved in $n$-heptane, through the membrane, from the ends of the tube. As a catalyst, the study considered the presence of impregnated Pd nanoparticles in the membrane. The porous medium was approximated by a granular bed as represented by the Ergun equation, having as parameters the porosity and the grain size of the $\alpha-\mathrm{Al}_{2} \mathrm{O}_{3}$ membrane. The value for the grain size was adopted as equivalent to particle diameter determined through the open source stereology software ImageJ, of the National Institute of Health USA. The turbulence model used was the RNG k- $\varepsilon$. A sensitivity study included simulations of flow neglecting and including reactions, speed variation, change the flow outlet and activation of turbulence model in the porous media. Simulations of structural defects in the membrane were performed, defining regions of porosity changes with and without loss of azimuthal uniformity. The conclusion was that the presence of structural defects that affect the azimuthal uniformity of the membrane can result in marked alteration of the flow regime in CMRs.
\end{abstract}




\section{LISTA DE FIGURAS}

Figura 1: Hidrogenação de 1,5-ciclooctadieno 1

Figura 2: Ilustração de membrana catalítica impregnada com Pd...........................6

Figura 3: Geometria do reator: membrana e casco, vista lateral. Região ativa em

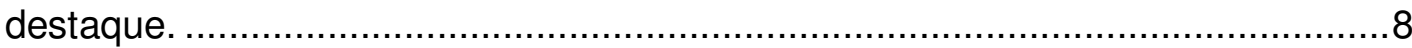

Figura 4: Geometria do reator: membrana e casco, corte transversal. .....................9

Figura 5: Fluxograma do reator de membrana modelado. ………........................12

Figura 6: Foto do reator de membrana utilizado...............................................13

Figura 7: Catálise e transporte de massa em meio poroso. Exemplo de reação consecutiva em membrana e em grão de catalisador.......................................21

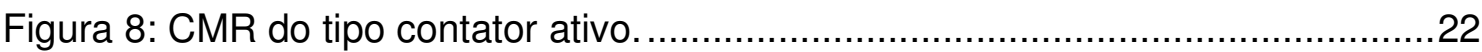

Figura 9: llustração de defeito localizado simulado no reator de membrana. ...........50

Figura 10: llustração de defeito generalizado simulado no reator de membrana......50

Figura 11: Desenho esquemático da geometria de casco equivalente ao

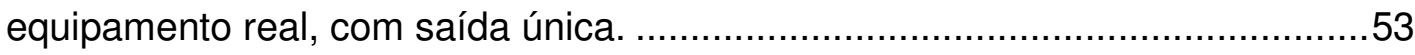

Figura 12: Desenho esquemático da geometria modificada de casco, com saída

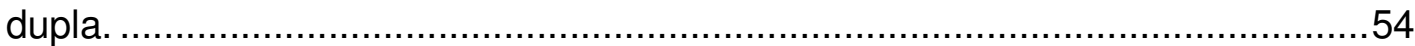

Figura 13: Geometria equivalente ao equipamento real, com saída única................54

Figura 14: Geometria modificada, com saída dupla.........................................55

Figura 15: Malha gerada por Park (2003) para estudo de reação WGS em CMR. ...56

Figura 16: Malha gerada no ANSYS Meshing,com 3.354.119 células para geometria equivalente ao equipamento real, com saída única. ........................................6

Figura 17: Malha gerada no ANSYS Meshing, com 1.477.391 células para geometria modificada, com saída dupla. 61

Figura 18: Resíduos em escala obtidos em simulação de reação e transporte de espécies no reator de membrana, com modelo $k-\omega$, descartado por divergir....65

Figura 19: Imagem de SEM do interior da membrana..........................................73

Figura 20: Imagem SEM do interior da membrana, após ajuste de bordas. .............73

Figura 21: Contagem do número de grãos da membrana.....................................74

Figura 22: Resíduos em escala, Caso M1 ..................................................... 82

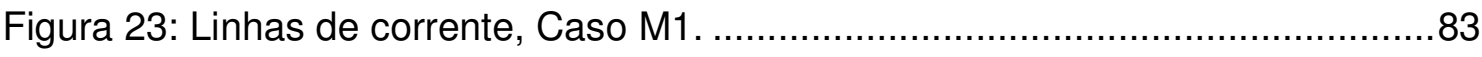

Figura 24: Perfil de velocidades no plano central, Caso M1. ..................................83

Figura 25: Perfil de velocidades no plano central, Caso M1 ......................................84 


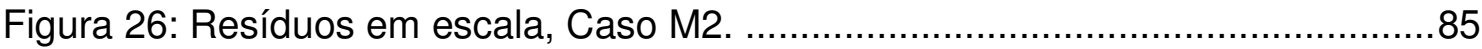

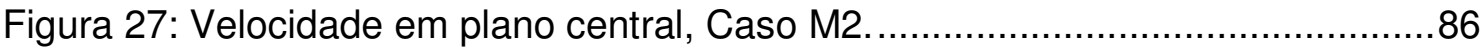

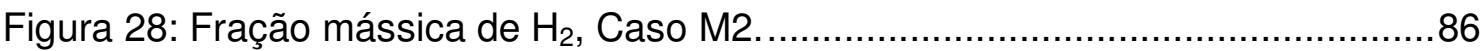

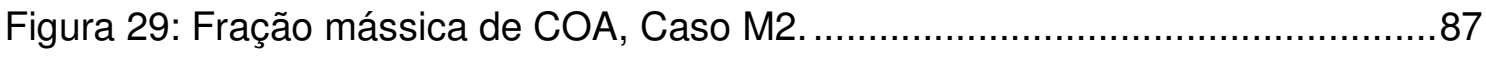

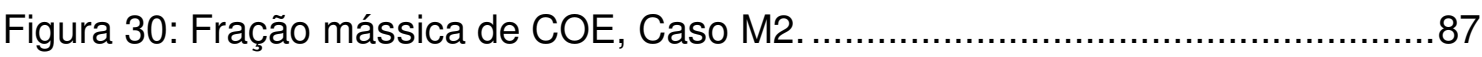

Figura 31: Fração mássica de COD, Caso M2 ..................................................8

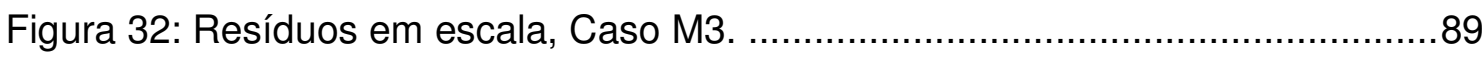

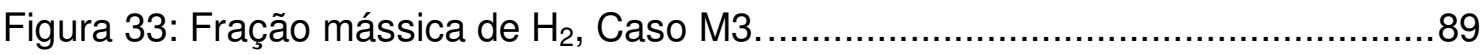

Figura 34: Fração mássica de COA, Caso M3....................................................

Figura 35: Fração mássica de COE, Caso M3......................................................

Figura 36: Fração mássica de COD, Caso M3...................................................

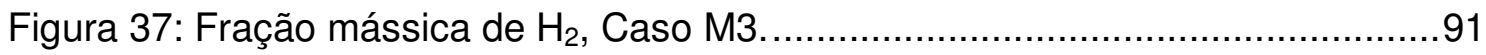

Figura 38: Fração mássica de COA, Caso M3...................................................92

Figura 39: Fração mássica de COE, Caso M3................................................

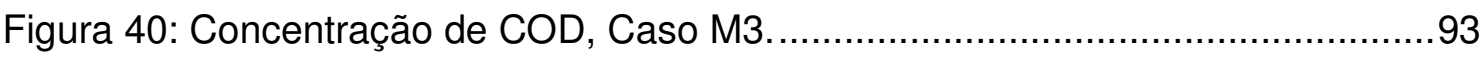

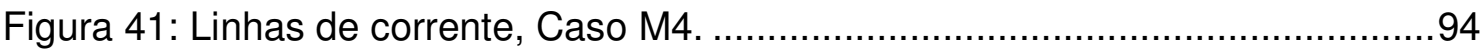

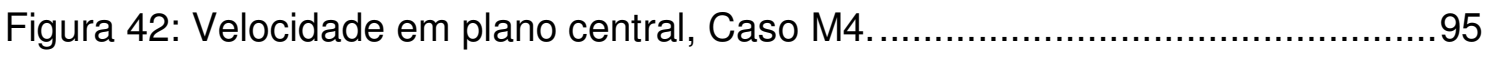

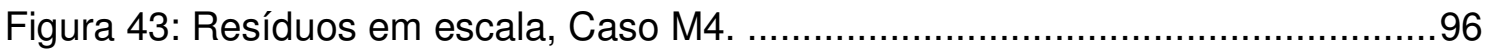

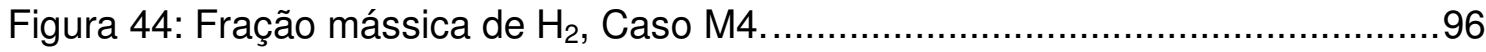

Figura 45: Fração mássica de COA, Caso M4 ...................................................

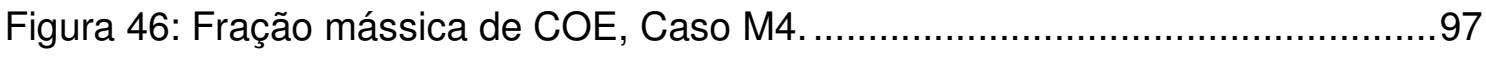

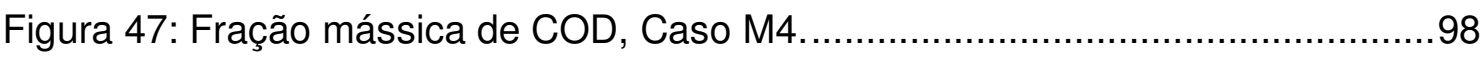

Figura 48: Linhas de corrente, Caso M5 - corte central........................................99

Figura 49: Linhas de corrente, Caso M5. ....................................................100

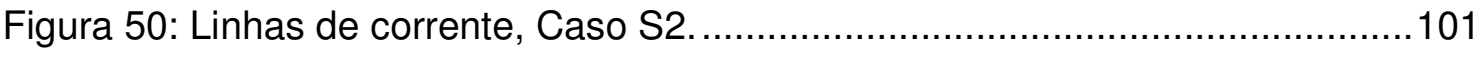

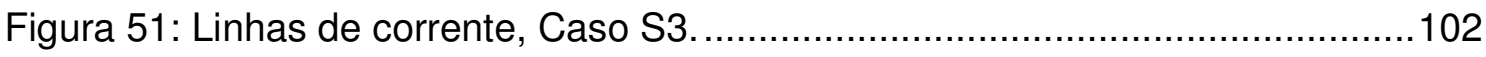

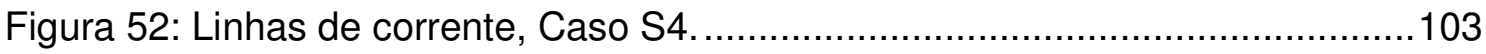




\section{LISTA DE TABELAS}

Tabela 1: Descrição física da membrana estudada. 8

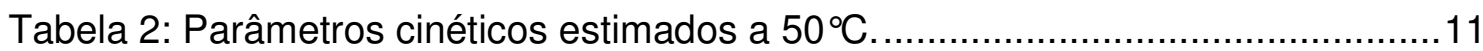

Tabela 3: Parâmetros cinéticos estimados a diferentes temperaturas. ....................11

Tabela 4: Experimentos em hidrogenação de COD no reator estudado..................14

Tabela 5: Sumário de casos preliminares simulados. ....................................47

Tabela 6: Sumário dos casos simulados para estudo de sensibilidade do modelo...48

Tabela 7: Sumário de simulações de defeito estrutural em membrana....................50

Tabela 8: Ferramentas de CFD utilizadas para modelagem e simulação .................51

Tabela 9: Subdomínios de malha e volume médio das células obtidas. ..................59

Tabela 10: Seleções nomeadas no caso para geometria real...............................61

Tabela 11: Seleções nomeadas no caso para geometria modificada. ....................63

Tabela 12: Propriedades dos compostos presentes no sistema estudado. ..............66

Tabela 13: Parâmetros adotados na definição da mistura reacional no código CFD 67

Tabela 14: Dados empregados na definição das reações no ANSYS FLUENT .......68

Tabela 15: Concentração inicial das espécies. ...............................................69

Tabela 16: Parâmetros de resistência porosa utilizados no modelo ........................74

Tabela 17: Parâmetros para definição de reação em zona de células no meio

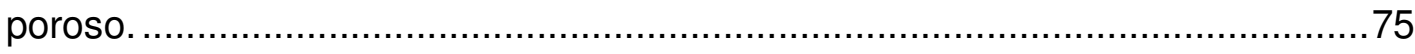

Tabela 18: Cálculo da velocidade de entrada ............................................... 77

Tabela 19: Cálculo da Intensidade de Turbulência .........................................78

Tabela 20: Critério de convergência adotado ................................................. 81 


\section{LISTA DE ABREVIATURAS E SIGLAS}

$\begin{array}{ll}\text { COA } & \text { Ciclooctano } \\ \text { COE } & \text { Cicloocteno } \\ \text { COD } & \text { 1,5-Ciclooctadieno } \\ \text { CFD } & \text { Dinâmica dos Fluidos Computacional (computational fluid dynamics) } \\ \text { CMR } & \text { Reator catalítico de membrana (catalytic membrane reactor) } \\ \text { FBR } & \text { Reator de leito fixo (fixed bed reator) } \\ \text { PISO } & \text { Pressão implícita com separação de operadores (pressure-implicit with } \\ & \text { spliting of operators) } \\ \text { RNG } & \text { Teoria do grupo de renormalização (ReNormalization Group Theory) } \\ \text { S } & \text { Seletividade } \\ \text { SIMPLE } & \text { Método semi-implícitos para equações acopladas de pressão (Semi- } \\ & \text { Implicit Method for Pressure Linked Equations) } \\ \text { WGS } & \text { Reação de deslocamento do vapor d'água (water shift gas) } \\ \mathbf{X} & \text { Conversão }\end{array}$




\section{SUMÁRIO}

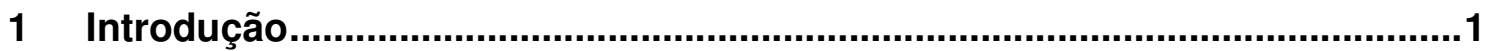

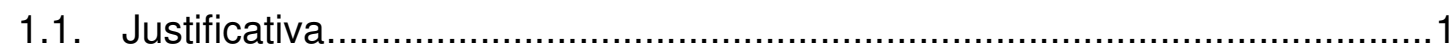

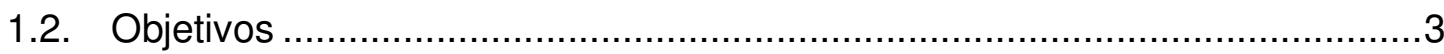

1.3. Considerações quanto à motivação do tema …………………..................

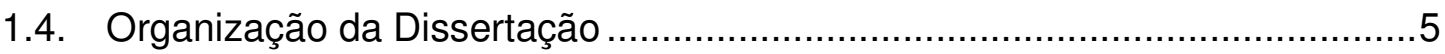

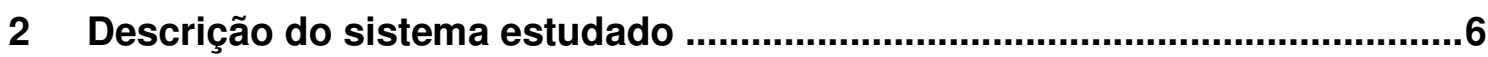

2.1. Membrana cerâmica............................................................................

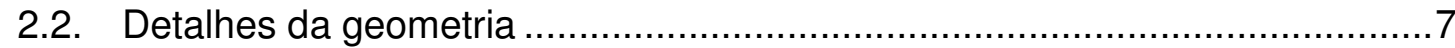

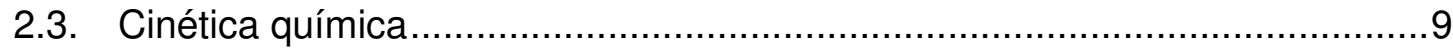

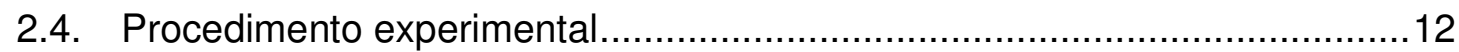

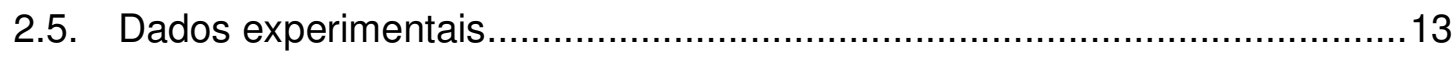

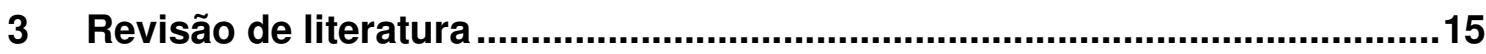

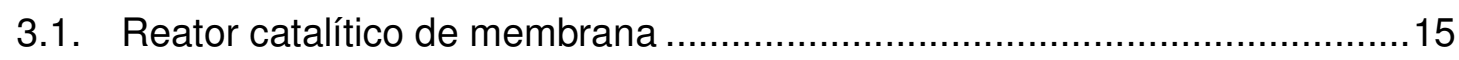

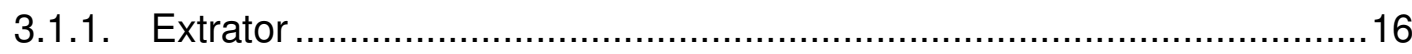

3.1.2. Distribuidor / Difusor ………...................................................... 17

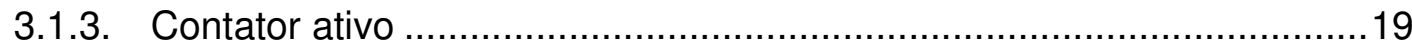

3.2. Modelagem e simulação de reatores catalíticos de membrana ....................26

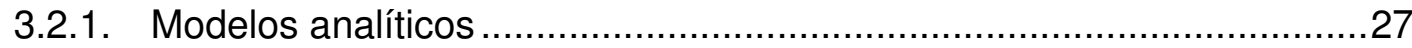

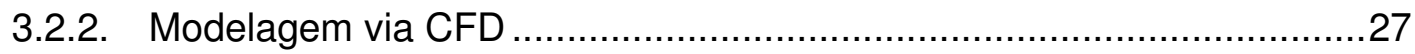

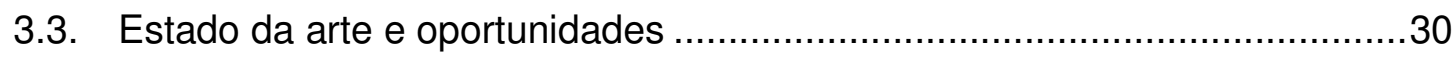

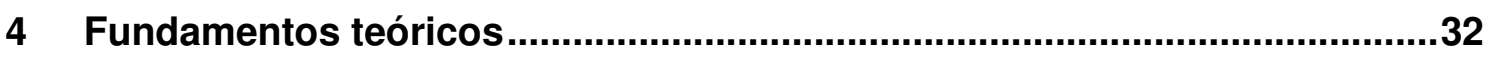

4.1. Reação com catálise heterogênea ........................................................

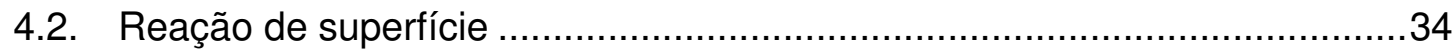

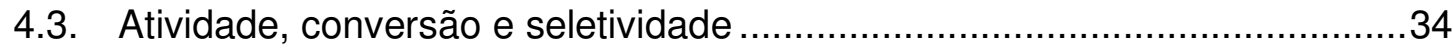

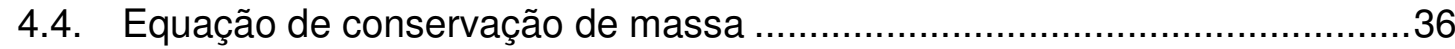

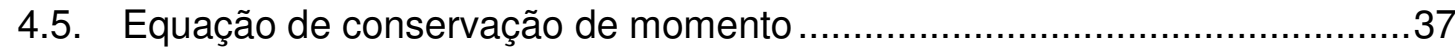

4.6. Balanço de reação-difusão para química de superfície ................................38

4.7. Regime de escoamento em membrana porosa .........................................39

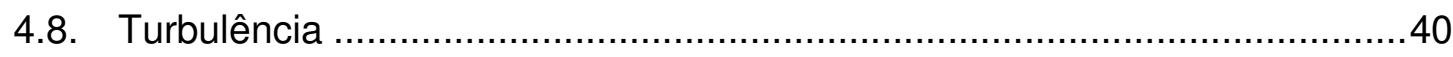

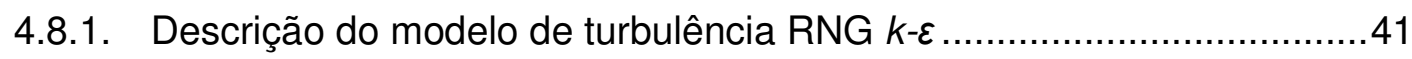

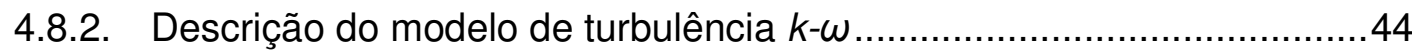

4.9. Métodos de solução do código comercial CFD ..........................................4 
5 Estratégias de modelagem CFD .45

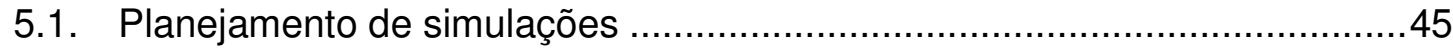

5.1.1. Casos simulados em estudo preliminar …….......................................45

5.1.2. Casos simulados para estudo de sensibilidade do modelo ...................47

5.1.3. Casos simulados de defeitos estruturais na membrana ........................49

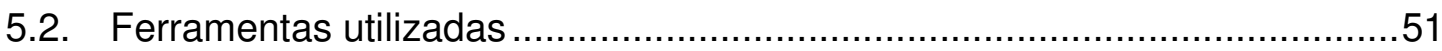

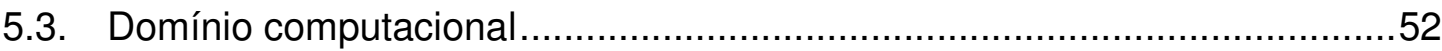

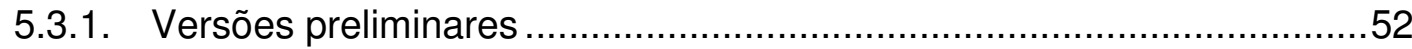

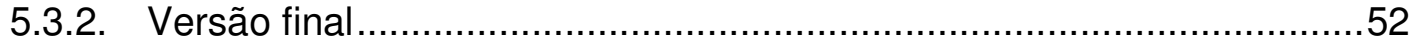

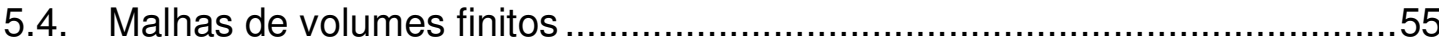

5.4.1. Comparação com malhas obtidas em literatura.....................................55

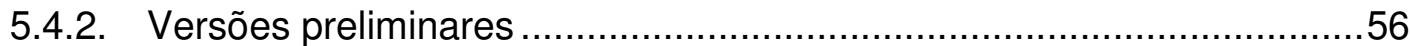

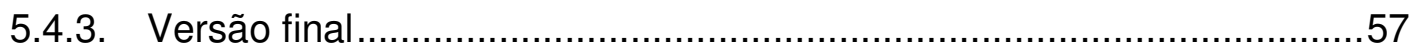

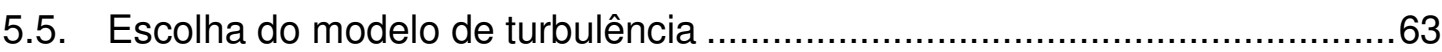

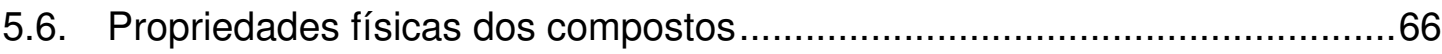

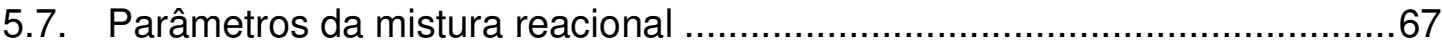

5.8. Definição das reações no código comercial de CFD......................................68

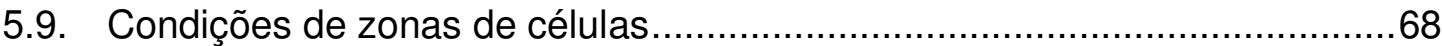

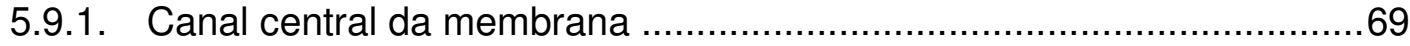

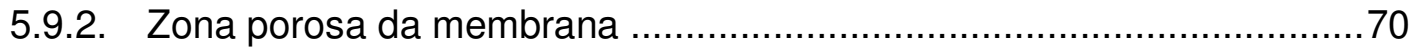

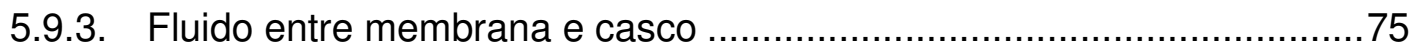

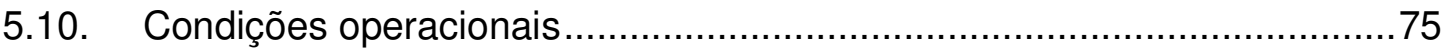

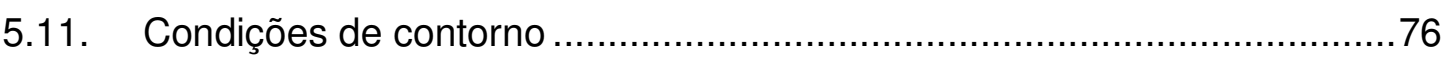

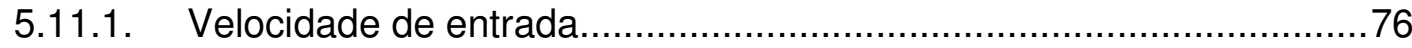

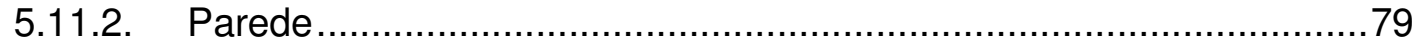

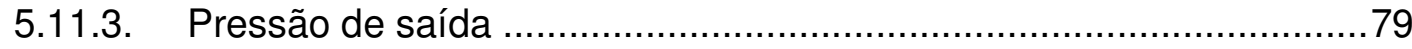

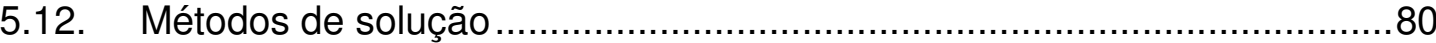

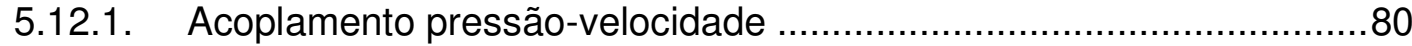

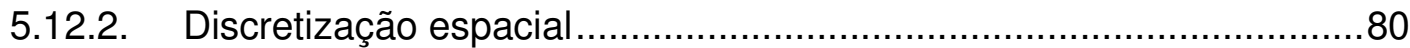

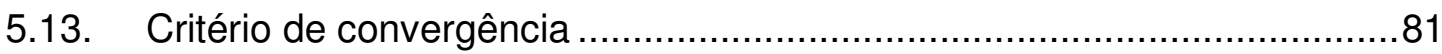

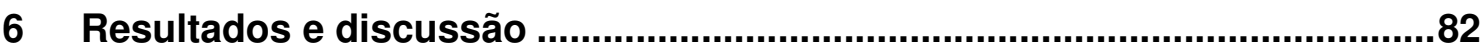

6.1. Caso M1 - Estudo de sensibilidade do modelo: somente escoamento .........82

6.2. Caso M2 - Estudo de sensibilidade do modelo: inclusão de reação ..............85

6.3. Caso M3 - Estudo de sensibilidade do modelo: variação da velocidade.......88 
6.4. Caso M4 - Estudo de sensibilidade do modelo: estudo da saída do

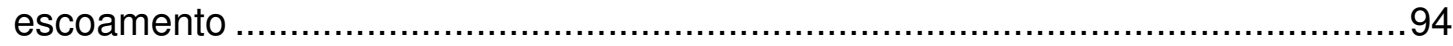

6.5. Caso M5 - Estudo de sensibilidade do modelo: ativação de turbulência no meio poroso .99

6.6. Caso S2 - Simulação de defeito estrutural sem perda de uniformidade azimutal: velocidade reduzida. 101

6.7. Caso S3 - Simulação de defeito estrutural sem perda de uniformidade azimutal: velocidade real 101

6.8. Caso S4 - Simulação de defeito estrutural com perda de uniformidade

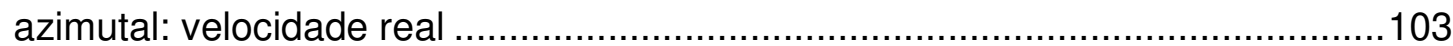

6.9. Verificação de consistência do modelo .................................................. 104

7 Conclusões e sugestões para trabalhos futuros .......................................105

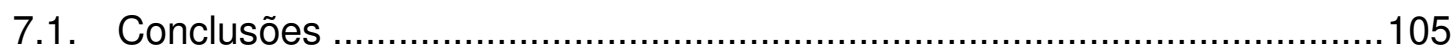

7.2. Sugestões de continuidade do trabalho ......................................... 106

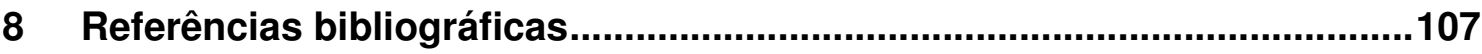

ANEXO 1 Experimentos utilizados na determinação da cinética.....................115 


\section{Introdução}

\subsection{Justificativa}

As reações de hidrogenação ocupam um papel central na indústria química. Exemplos típicos são a produção de amônia, margarina, metanol e hidrocarbonetos. Em geral, elas são realizadas por catálise heterogênea, devido à facilidade de separação do catalisador. No entanto, os processos mais utilizados implicam em dificuldades de separação ou em limitações de transporte de massa que, no caso de hidrogenações parciais, resultam em queda da seletividade para o produto desejado (Schmidt, 2007).

A reação de hidrogenação de COD, estudada no presente trabalho, resulta na formação de cicloocteno (COE), que, por sua vez, pode reagir com o hidrogênio disponível, sendo convertido ao produto saturado, ciclooctano (COA), conforme ilustrado na Figura 1.

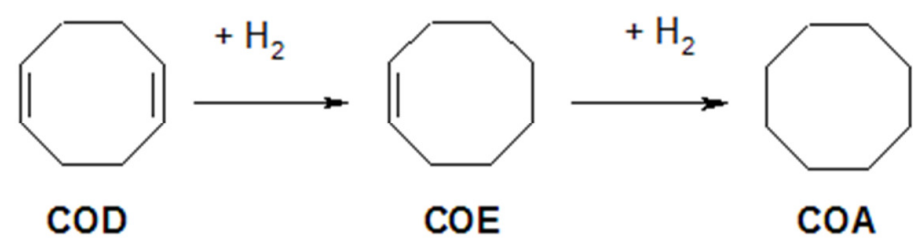

Figura 1: Hidrogenação de 1,5-ciclooctadieno

Segundo Bottino et al. (2002), o projeto de catalisador e reator deve ser voltado ao aumento de rendimento e produtividade dos produtos intermediários desejados, bem como resultar em um processo econômico que use efetivamente todos os sítios cataliticamente ativos.

Os reatores mais frequentemente utilizados em reações de hidrogenação são os reatores de leito fixo (FBR: fixed bed reator). Neles, o percurso realizado no interior dos poros dos grãos de catalisador prolonga o tempo de contato de produtos intermediários com os centros cataliticamente ativos, fazendo com que reajam novamente e, assim, a seletividade para produtos parcialmente hidrogenados seja diminuída. Se o sistema reacional produz uma grande quantidade de produtos 
indesejados, a separação e a subsequente purificação do produto desejado podem inviabilizar o processo (Schmidt, 2007).

$\mathrm{Na}$ indústria de química fina, a alternativa adotada é o uso de reatores de lama (slurry reators), cujas partículas finíssimas $(<200 \mu \mathrm{m})$ favorecem o transporte de massa, apresentando porém como incoveniente um elevado custo de separação.

No presente trabalho, realiza-se o estudo do escoamento em reatores do tipo CMR conforme abordagem adotada por Schmidt (2007) para o problema da seletividade em reações parciais. Essa abordagem baseia-se no controle do tempo de contato do produto desejado com o catalisador por meio de bombeamento da mistura reacional através de membranas porosas cataliticamente ativas, conforme apresentado por Schomäcker et al. (2005), resultando em aumento da taxa efetiva de reação e mitigação de reações indesejadas.

O desempenho do CMR está relacionado, entre outros fatores, com o movimento do fluido através da membrana. No CMR estudado são utilizadas membranas tubulares em que a mistura reacional é alimentada em ambas as extremidades, e reage à medida que a atravessa no sentido radial, sendo posteriormente realimentada para recirculação. Dessa forma, faz-se relevante estudar o escoamento da mistura reacional no percurso através da espessura da membrana, sua relação com o movimento de fluido no canal central, a camada limite de transporte, a ocorrência de transportes difusivos, bem como as interações físicas e químicas acontecendo em toda a superfície da membrana.

A partir de dados experimentais obtidos por Schmidt (2007) para a hidrogenação de 1,5-ciclooctadieno (COD) por catálise heterogênea com presença de três fases, sobre $\mathrm{Pd} / \alpha$-alumina, realiza-se o estudo do escoamento num reator catalítico de membrana (CMR) do tipo contator ativo com a finalidade de se desenvolver uma ferramenta de predição do desempenho do reator, para determinação das condições para ótima seletividade.

O estudo detalhado de reatores de membrana provê subsídios para a consolidação de uma tecnologia de produção de CMRs, o que, conforme mencionado por 
Criscuoli et al. (2001) contribui significativamente para sua aplicação em escala industrial.

A modelagem numérica de dinâmica dos fluidos computacional (CFD: Computational Fluid Dynamics) tem sido utilizada desde a década de 1960 pela indústria aeroespacial, tendo alcançado ampla abrangência em aplicações de Engenharia nos anos 90. No campo da Engenharia Química, CFD permite reproduzir detalhes locais do escoamento tridimensional e transiente em equipamentos das mais diversas geometrias, além de possibilitar a análise de complexos fenômenos físicos, como escoamentos multifásicos, turbulentos e reacionais. Dessa forma, CFD oferece uma abordagem adequada para a simulação numérica do fenômeno estudado.

\subsection{Objetivos}

No presente trabalho realiza-se a implementação de modelo de dinâmica dos fluidos computacional no software ANSYS FLUENT para a solução de escoamento reativo em meio poroso granular. Dentro do escopo desta dissertação, foram realizadas simulações com diferentes parâmetros de projeto e sob diversas condições operacionais, a fim de se obter uma visão qualitativa do comportamento do escoamento no interior do reator de membrana.

A primeira tarefa ao se selecionar um projeto apropriado de reator para uma reação em fase líquida (ou gasosa) catalisada sobre sólido é determinar uma dimensão apropriada do catalisador que permita a eficiente utilização desse custoso material. Em seguida, deve-se pensar no padrão de contato entre fases no nível do reator. Essas considerações determinam a distribuição do tempo de residência e a permanência das fases líquida e gasosa, e também a quantidade de catalisador sólido que pode ser carregada no reator.

\subsection{Considerações quanto à motivação do tema}

O presente trabalho baseia-se em estudo experimental realizado por Schmidt (2007), que adotou o conceito de reator catalítico de membrana (CMR) no estudo do aumento de seletividade de reações parciais de hidrogenação. 
A escolha do tema está relacionada à participação da autora da presente dissertação, auxiliando a então Doutoranda Andrea Schmidt nas fases iniciais do seu trabalho. No período de agosto a outubro de 2005, a atuação caracterizou-se pela elaboração de estudo de estágio intitulado "Espectro de aplicabilidade de um reator de membrana a reações de hidrogenação parcial'. O estudo incluiu a realização de experimentos para avaliação da aplicabilidade de um CMR à formação de citronelol, 1-octeno e estireno a partir de reações de hidrogenação parcial. A conversão $(X)$ e a seletividade $(S)$ para o produto desejado foram observadas para diferentes valores das seguintes variáveis:

- tamanho de poros das membranas (0.6, 1.8/1.9 e $3.0 \mu \mathrm{m})$;

- quantidade de catalisador depositado (0.4-31.8 mgPd);

- pressão inicial de hidrogênio (6.3-21.5 bar);

- vazão de reagentes (148-320 mL/min);

- temperatura $\left(40-55^{\circ} \mathrm{C}\right)$.

Para conversão completa de geraniol, 1-octino e fenil-acetileno, foram obtidas seletividades de $7 \%$ de citronelol, $90 \%$ de 1 -octeno e $71 \%$ de fenil-acetileno, respectivamente. Enquanto que para a maior parte dos fatores estudados foram obtidos resultados conclusivos, o impacto do tamanho de poro foi apontado como indeterminado.

No trabalho subsequente, denominado "Modelagem e simulação da hidrogenação de 1,5-ciclooctadieno em um reator catalítico de membrana do tipo contator ativo" e realizado como Trabalho de Conclusão de Curso pela presente autora na Graduação em Engenharia Química da Escola Politécnica da USP, foi apresentado um modelo matemático para simulação do desempenho do mesmo reator. Numa primeira abordagem, realizou-se análise preliminar a partir de modelo considerando apenas a formação do produto insaturado, cicloocteno. Em seguida, um aprimoramento do modelo foi realizado para incluir a formação de ciclooctano e, assim, permitir a avaliação do parâmetro de desempenho seletividade. Como resultado final foi obtido um código em MATLAB®, que permite a análise da variação da seletividade como resposta à alteração de parâmetros operacionais: temperatura, 
pressão inicial, concentração inicial, vazão volumétrica e diâmetro dos poros das membranas.

\subsection{Organização da Dissertação}

No capítulo 2, apresenta-se uma descrição detalhada do sistema estudado, como subsídio ao entendimento da modelagem realizada.

O capítulo 3 apresenta brevemente o conceito de reatores de membrana e suas possíveis aplicações e, em seguida, uma revisão do estado da arte nas abordagens dadas ao problema da modelagem de reatores catalíticos de membrana, em particular aquelas que se utilizam de ferramentas de CFD.

No capítulo 4 são apresentados os fundamentos aplicáveis à descrição via CFD do escoamento reativo em CMRs.

O desenvolvimento de modelo de CFD é apresentado em detalhes no capítulo 5, incluindo desde a geração de domínios computacionais e de malhas até a justificativa das condições de contorno e dos métodos adotados.

No capítulo 6, são discutidos os resultados obtidos para simulações classificadas em três grupos distintos: i) casos preliminares, para avaliação preliminar do escoamento para modelos amplamente simplificados; ii) casos para estudo de sensibilidade do modelo, nos quais se realiza estudo de sensibilidade do modelo à variação de parâmetros do equipamento, de condições operacionais e dos métodos de solução adotados e iii) breve estudo da ação de possíveis defeitos estruturais de membranas no escoamento e, consequentemente, nas taxas de reação.

Conclusões e sugestões de continuidade são apresentadas no capítulo 7, baseadas nos resultados e na experiência adquirida ao longo do desenvolvimento deste trabalho.

O capítulo 8 lista as referências bibliográficas adotadas e nos anexos são apresentados dados experimentais referentes ao sistema estudado. 


\section{Descrição do sistema estudado}

\subsection{Membrana cerâmica}

As membranas porosas de $\alpha$-alumina $\left(\mathrm{Al}_{2} \mathrm{O}_{3}\right)$ utilizadas na bancada experimental têm geometria tubular e comprimento de $25 \mathrm{~cm}$, diâmetro externo de 2,9 mm e diâmetro interno de $1,9 \mathrm{~mm}$. Cada extremidade das membranas tem $1,5 \mathrm{~cm}$ cobertos com vidro para se evitar sua quebra durante a montagem no reator. Com isso, temse comprimento ativo de $22 \mathrm{~cm}$ e área superficial de 0,002 $\mathrm{m}^{2}$, disponível para depósito do catalisador. Os diâmetros médios de poro das membranas utilizadas foram de $0,6 \mu \mathrm{m}, 1,9 \mu \mathrm{m}$ e $3,0 \mu \mathrm{m}$. A porosidade determinada foi de $30 \%$, resultando num volume de $4,4 \cdot 10^{-7} \mathrm{~m}^{3}$ para cada membrana. As membranas foram impregnadas com nanopartículas de Pd (Figura 2).

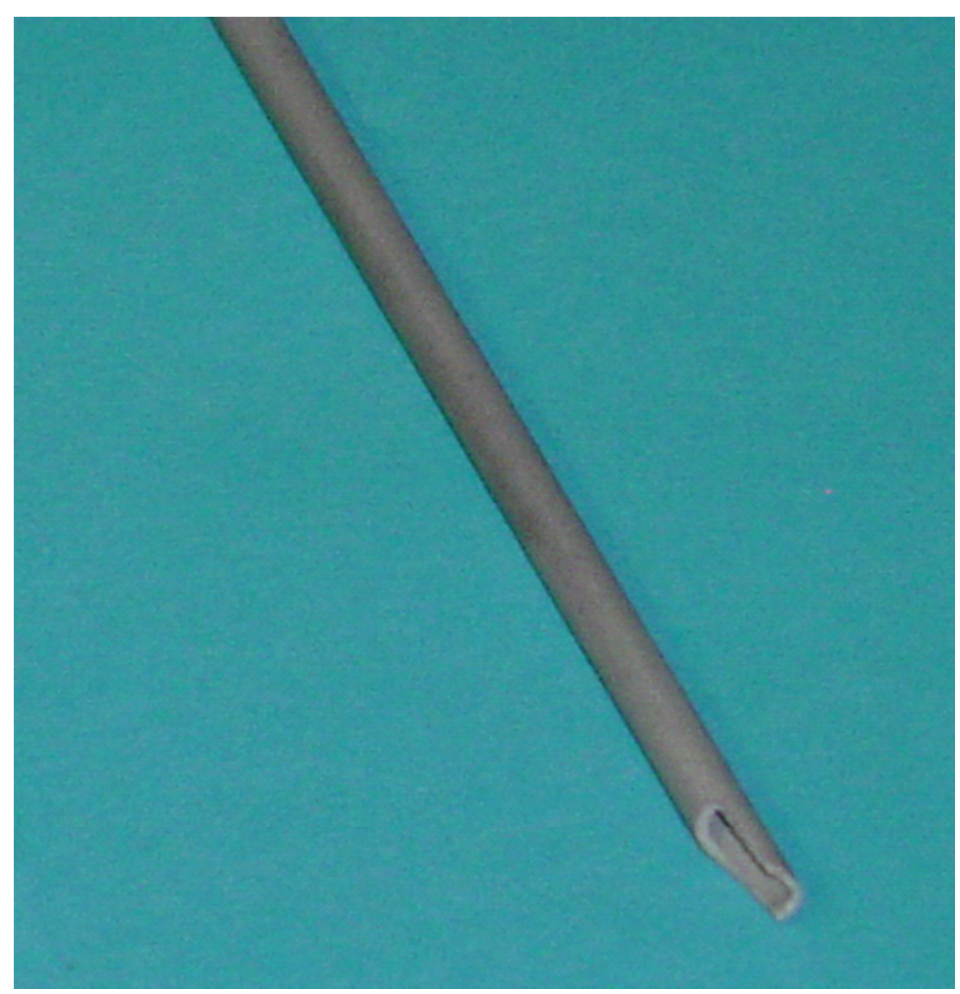

Figura 2: llustração de membrana catalítica impregnada com Pd.

Para o sistema estudado no presente trabalho, Schmidt (2007) avaliou a influência de diferentes parâmetros de processo e condições operacionais sobre a seletividade: 
- velocidade de escoamento

- tamanho de poro da membrana

- concentração de catalisador

- concentração de COD

- pressão de hidrogênio

- temperatura

Enquanto que para a maior parte dos fatores estudados foram obtidos resultados conclusivos, o impacto do tamanho de poro foi apontado como indeterminado. Em modelo matemático unidimensional desenvolvido por Schmidt (2007), os efeitos da velocidade de escoamento e concentração de catalisador apresentaram correspondência com dados experimentais. Por outro lado, uma melhor compreensão dos efeitos de tamanho de poro seria possibilitada, entre outros, pela simulação do escoamento através dessa camada porosa onde ocorre reação em fase heterogênea.

\subsection{Detalhes da geometria}

Conforme mencionado no item anterior, o presente trabalho tem sua origem relacionada aos estudos experimentais realizados por Schmidt (2007) na obtenção de maior seletividade para reações parciais de hidrogenação, utilizando reator catalítico com membrana impregnada de Pd (Figura 2). Particularmente para este trabalho, foi adotada a hidrogenação de ciclooctadieno como reação modelo. A região escolhida para simulação foi a membrana porosa juntamente com o casco, constituindo o chamado módulo de membrana. As dimensões mais relevantes para modelagem da membrana catalítica são apresentadas na Tabela 1, a seguir: 
Tabela 1: Descrição física da membrana estudada.

\begin{tabular}{c|c}
\hline Grandeza & Valor \\
\hline Diâmetro interno & $1,9 \times 10^{-3} \mathrm{~m}$ \\
\hline Diâmetro externo & $2,9 \times 10^{-3} \mathrm{~m}$ \\
\hline Comprimento ativo & $2,2 \times 10^{-1} \mathrm{~m}$ \\
\hline Área da membrana & $2,0 \times 10^{-3} \mathrm{~m}^{2}$ \\
\hline Diâmetro médio de poro & $1,9 \times 10^{-6} \mathrm{~m}$ \\
\hline Espessura da membrana & $0,5 \times 10^{-3} \mathrm{~m}$ \\
\hline Porosidade & $30 \%$ \\
\hline Tortuosidade & 2,0 \\
\hline Volume da membrana & $4,4 \times 10^{-7} \mathrm{~m}$ \\
\hline
\end{tabular}

A Figura 3 ilustra a montagem da membrana no módulo metálico que serve de suporte. Nota-se que o eixo da membrana e do módulo não coincidem, o que se deve ao fato de o módulo ser projetado para suporte de até três membranas. Dessa forma, na realização de reações com apenas uma membrana, obtém-se geometria assimétrica. Na Figura 4, observam-se os detalhes da tubulação de saída.

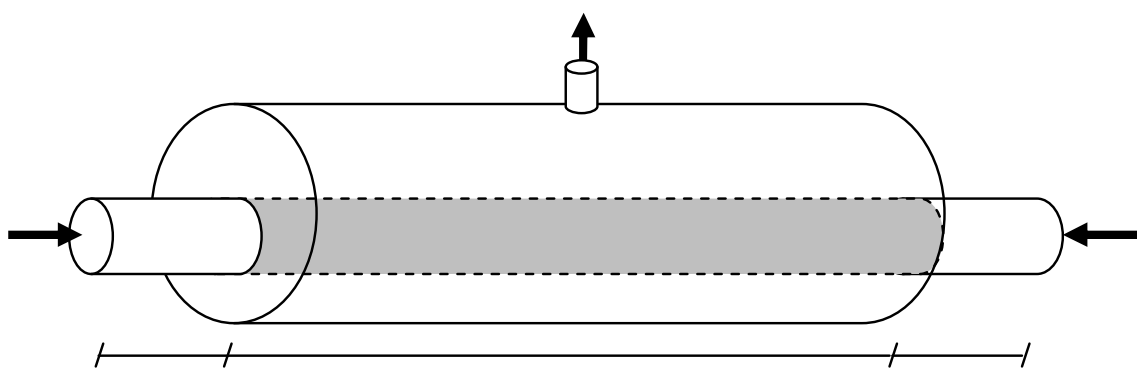

Região inativa: $15 \mathrm{~mm}$

Região ativa: $220 \mathrm{~mm}$

Região inativa: $15 \mathrm{~mm}$

Figura 3: Geometria do reator: membrana e casco, vista lateral. Região ativa em destaque. 


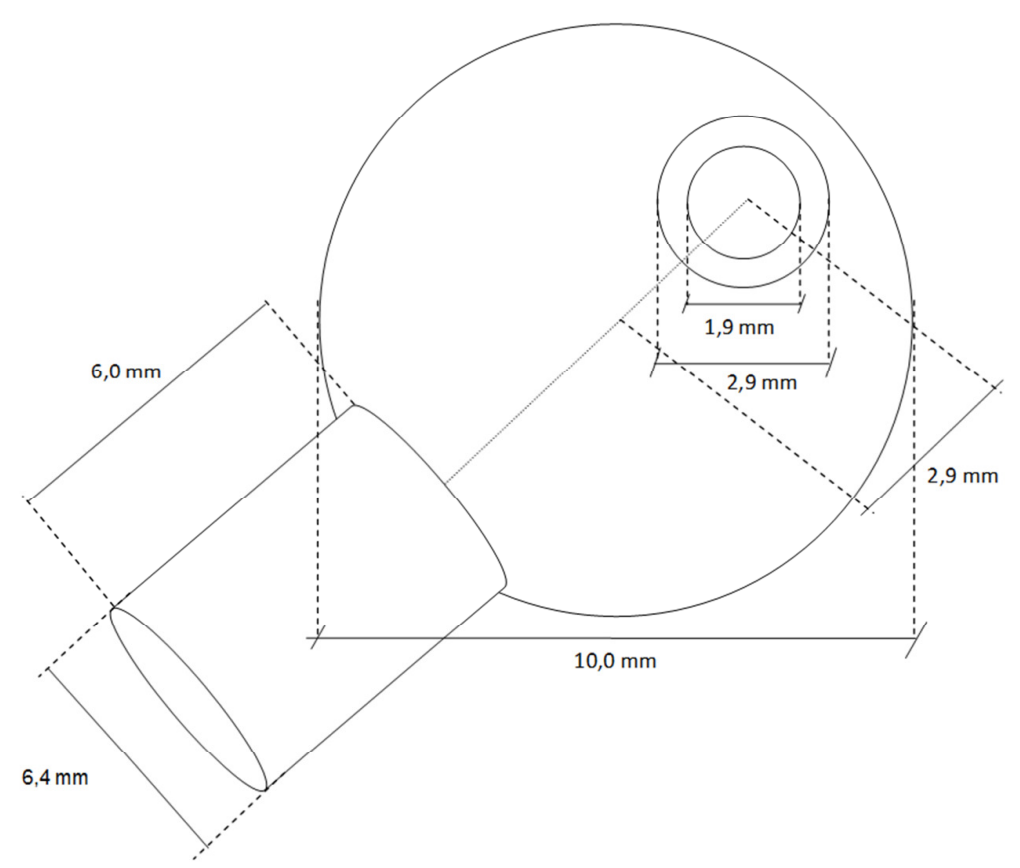

Figura 4: Geometria do reator: membrana e casco, corte transversal.

\subsection{Cinética química}

Adotou-se no presente trabalho a cinética de hidrogenação de 1,5-ciclooctadieno sobre Pd/alumina apresentada por Schmidt (2007), cujos parâmetros cinéticos foram determinados através da realização de experimentos com pó fino de $\mathrm{Pd} /$ alumina em reator de lama (slurry), a fim de se eliminar efeitos de difusão, obtendo-se a cinética intrínseca da reação.

Um fenômeno importante modelado na reação apresentada é a adsorção competitiva entre $\mathrm{COD}$ e $\mathrm{H}_{2}$ sobre a superfície catalítica, cujo efeito observável é a desaceleração da taxa de reação com o aumento da concentração de COD.

Nos experimentos realizados por Schmidt (2007), foi identificada uma relação linear entre a taxa de reação e a pressão inicial de hidrogênio. A cinética adotada, cujos parâmetros foram determinados com uso do software Berkeley Madonna ${ }^{\mathrm{TM}}$, da Universidade de Califórnia, é apresentada a seguir:

A primeira reação, de formação do produto insaturado, pode ser descrita pelas equações de (1) a (5): 


$$
\begin{gathered}
\mathrm{COD}+\mathrm{H}_{2} \stackrel{k_{1}}{\longrightarrow} \mathrm{COE} \\
r_{1}=k_{1} \cdot \theta_{\mathrm{H}_{2}} \cdot \theta_{C O D} \\
\theta_{\mathrm{H}_{2}}=\frac{K_{\mathrm{H}_{2}} c_{\mathrm{H} 2}}{\left(1+K_{C O D} c_{C O D}+K_{C O E} c_{C O E}+K_{\mathrm{H}_{2}} c_{H_{2}}\right)} \\
\theta_{C O D}=\frac{K_{C O D} c_{C O D}}{\left(1+K_{C O D} c_{C O D}+K_{C O E} c_{C O E}+K_{\mathrm{H}_{2}} c_{H_{2}}\right)} \\
\theta_{C O E}=\frac{K_{C O E} c_{C O E}}{\left(1+K_{C O D} c_{C O D}+K_{C O E} c_{C O E}+K_{H_{2}} c_{H_{2}}\right)} \\
r_{1}=k_{1} \frac{K_{C O D} c_{C O D} K_{\mathrm{H}_{2}} c_{\mathrm{H}_{2}}}{\left(1+K_{C O D} c_{C O D}+K_{C O E} c_{C O E}+K_{H_{2}} c_{H_{2}}\right)^{2}}
\end{gathered}
$$

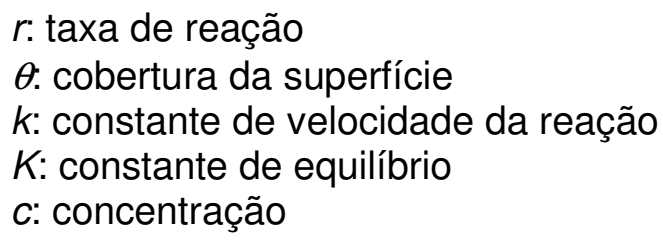

Analogamente, a segunda reação, que resulta na formação do indesejado produto saturado, é representada pelas equações (6) e (7):

$$
\begin{gathered}
\mathrm{COE}+\mathrm{H}_{2} \stackrel{k_{2}}{\longrightarrow} \mathrm{COA} \\
r_{2}=k_{2} \cdot \theta_{\mathrm{H}_{2}} \cdot \theta_{\mathrm{COE}} \\
r_{2}=k_{2} \frac{K_{\mathrm{COE}} c_{C O E} K_{\mathrm{H}_{2}} c_{\mathrm{H}_{2}}}{\left(1+K_{\mathrm{COE}} c_{\mathrm{COE}}+K_{\mathrm{COA}} c_{C O A}+K_{\mathrm{H}_{2}} c_{\mathrm{H}_{2}}\right)^{2}}
\end{gathered}
$$

Com as quatro equações diferenciais a seguir, (8)-(11), o avanço da reação pode ser descrito quando a solução permanece saturada com hidrogênio.

$$
\begin{gathered}
r_{\mathrm{H}_{2}}=\frac{d_{\mathrm{H}_{2}}}{d t}=-r_{1}-r_{2} \\
r_{C O D}=\frac{d_{C O D}}{d t}=-r_{1} \\
r_{C O E}=\frac{d_{C O E}}{d t}=+r_{1}-r_{2} \\
r_{C O A}=\frac{d_{C O A}}{d t}=+r_{2}
\end{gathered}
$$


Tabela 2: Parâmetros cinéticos estimados a $50^{\circ} \mathrm{C}$.

\begin{tabular}{c|c}
\hline Parâmetro & Valor \\
\hline$k_{1}$ & $1,8 \times 10^{-3} \mathrm{~mol} / \mathrm{mg}_{\mathrm{Pd}} \cdot \mathrm{s}$ \\
\hline$k_{2}$ & $3,4 \times 10^{-5} \mathrm{~mol} / \mathrm{mg}_{\mathrm{Pd}} . \mathrm{s}$ \\
\hline$K_{C O D}$ & $17,5 \mathrm{~L} / \mathrm{mol}$ \\
\hline$K_{C O E}$ & $10 \mathrm{~L} / \mathrm{mol}$ \\
\hline$K_{C O A}$ & $4 \mathrm{~L} / \mathrm{mol}$ \\
\hline
\end{tabular}

A variação da constante $k$ com a temperatura é descrita por uma modificação da lei de Arrhenius, conforme apresentado na equação (12):

$$
k=k_{0} \cdot e^{-\frac{E_{A}}{R T}}
$$

$k_{0}$ : fator pré-exponencial

$E_{A}$ : energia de ativação

$R$ : constante dos gases

$T$ : temperatura

Os valores encontrados por Schmidt (2007) para a energia de ativação foram os seguintes:

$$
\begin{aligned}
& E_{A 1}: 74 \mathrm{~kJ} / \mathrm{mol} \\
& E_{A 2}: 98 \mathrm{~kJ} / \mathrm{mol}
\end{aligned}
$$

A partir de valores medidos em outras temperaturas, pode-se, então, determinar o

\begin{tabular}{|c|c|c|c|c|c|}
\hline $\begin{array}{c}T \\
\left({ }^{\circ} \mathrm{C}\right)\end{array}$ & $\begin{array}{c}K_{C O D} \\
(\mathrm{~L} / \mathrm{mol})\end{array}$ & $\begin{array}{c}K_{C O E} \\
(\mathrm{~L} / \mathrm{mol})\end{array}$ & $\begin{array}{c}K_{C O A} \\
(\mathrm{~L} / \mathrm{mol})\end{array}$ & $\begin{array}{c}k_{1} \\
\left(\mathrm{~mol} / \mathrm{mg}_{\mathrm{Pd}} \cdot \mathrm{s}\right)\end{array}$ & $\begin{array}{c}k_{2} \\
\left(\mathrm{~mol} / \mathrm{mg}_{\mathrm{Pd}} \cdot \mathrm{s}\right)\end{array}$ \\
\hline 40 & 20,0 & 15,0 & 7,4 & $9,0 \times 10^{-4}$ & $5,8 \times 10^{-6}$ \\
\hline 50 & 17,5 & 10,0 & 4,0 & $1,8 \times 10^{-3}$ & $3,4 \times 10^{-5}$ \\
\hline 70 & 17,0 & 9,0 & 1,1 & $1,2 \times 10^{-2}$ & $2,3 \times 10^{-4}$ \\
\hline
\end{tabular}
fator pré-exponencial, ou fator de frequência:

Tabela 3: Parâmetros cinéticos estimados a diferentes temperaturas. 
Valor calculado para a reação $1: k_{1}=1,94 \times 10^{9} \mathrm{~mol} \cdot \mathrm{mg}_{\mathrm{Pd}}{ }^{-1} \cdot \mathrm{s}^{-1}$

Valor encontrado para a reação 2: $k_{2}=1,85 \times 10^{11} \mathrm{~mol} \cdot \mathrm{mg}_{\mathrm{Pd}^{-1}} \cdot \mathrm{s}^{-1}$

\subsection{Procedimento experimental}

Para a realização dos experimentos de hidrogenação, entre uma e três membranas de $\mathrm{Pd} / \mathrm{Al}_{2} \mathrm{O}_{3}$ são montadas no módulo de membrana (Figura 5). Inicialmente, adiciona-se o solvente (n-heptano) no tanque de saturação, acionando-se em seguida o banho termostático do tanque de saturação e a camisa de aquecimento do módulo de membrana. Atingida a temperatura desejada da reação a ser realizada sob condição isotérmica, ajusta-se a vazão ao valor selecionado e adiciona-se o reagente principal ao sistema. Uma amostra "zero" é nesse instante tomada para controle da evolução da reação.

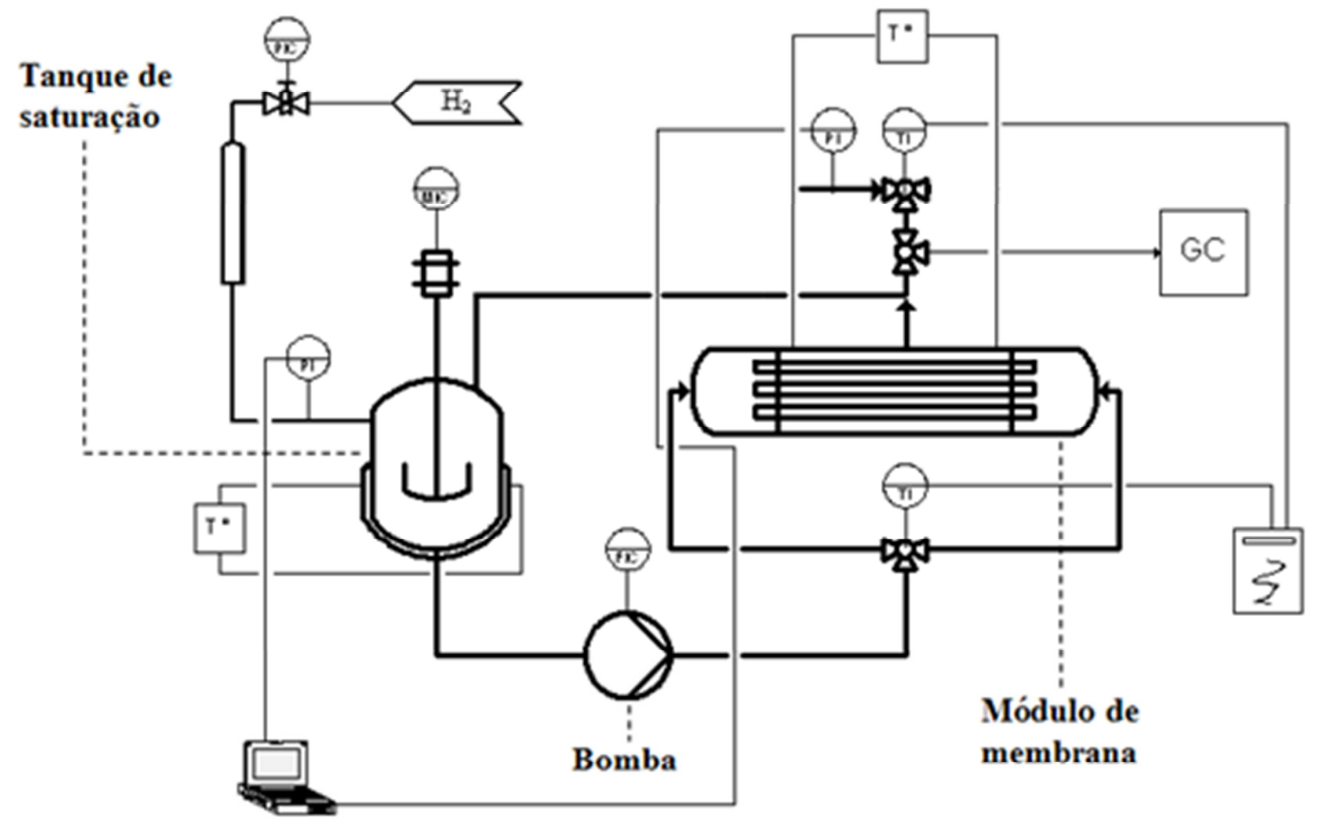

Figura 5: Fluxograma do reator de membrana modelado. 


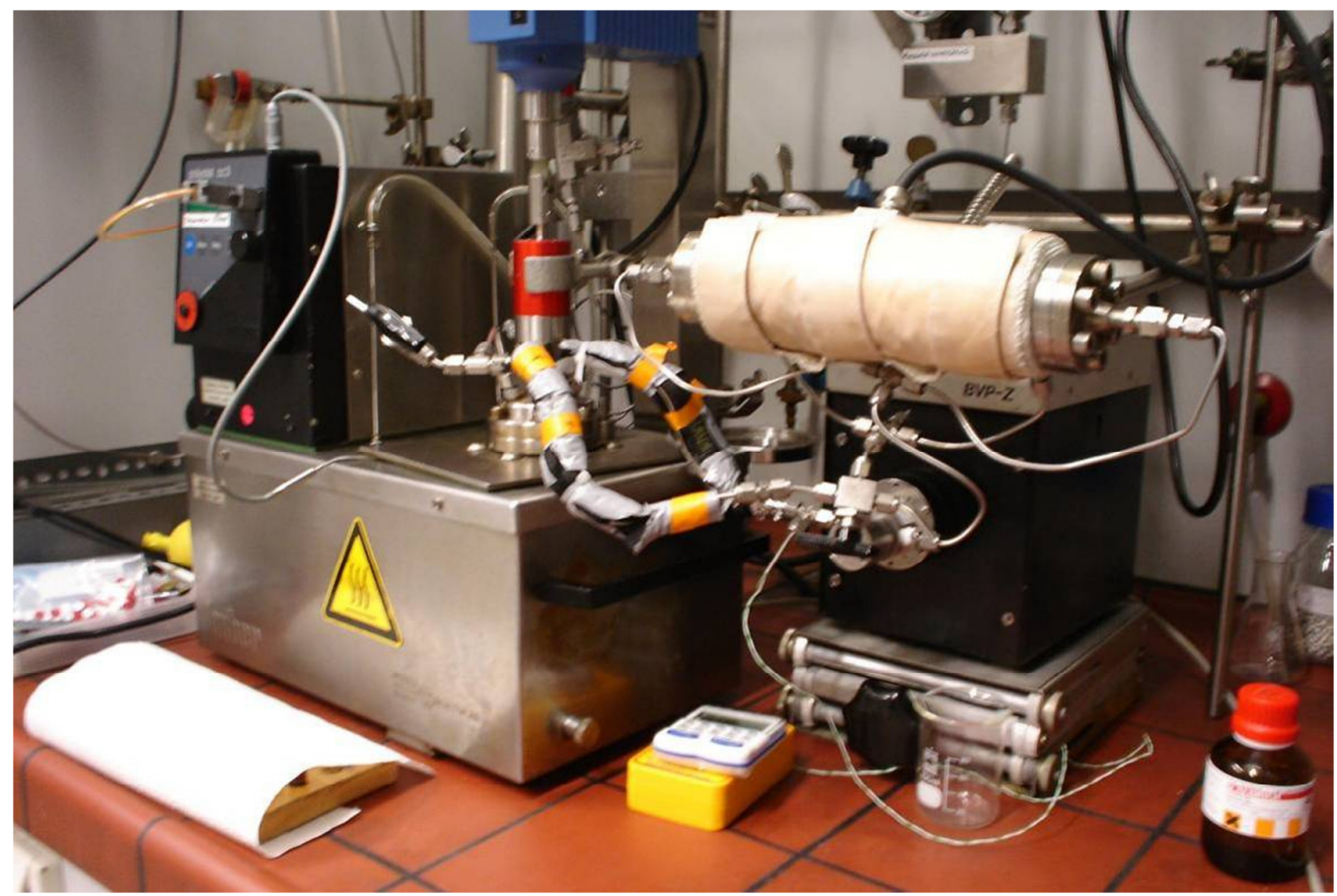

Figura 6: Foto do reator de membrana utilizado.

A reação é iniciada pela adição de hidrogênio $\left(\mathrm{H}_{2}\right)$ até se atingir a pressão inicial adotada. O sistema, ilustrado na Figura 6, é, então, fechado e a mistura reacional saturada de $\mathrm{H}_{2}$ passa em seguida a ser bombeada do tanque para o módulo de membrana, retornando ao tanque de saturação repetidas vezes, até que a reação se complete. A evolução da reação é acompanhada pela queda de pressão, cuja cessação foi adotada como indicador de estabilização na conversão máxima possível sob as condições adotadas.

\subsection{Dados experimentais}

Dados obtidos em quarenta e um experimentos, compilados na Tabela 4, já apresentados por Schmidt (2007), são referência para o modelo desenvolvido. Os valores mais frequentes ou os valores médios das variáveis acompanhadas nesses experimentos são adotados como parâmetros do modelo desenvolvido no presente trabalho. Na tabela, são apresentadas as seguintes variáveis:

- Volume inicial de solvente ( $\mathrm{n}$-heptano líquido): $\mathrm{V}_{0, \mathrm{n} \text {-heptano; }}$

- Volume inicial de 1,5-ciclooctadieno (líquido): $\mathrm{V}_{0, \mathrm{COD}}$; 
- Concentração inicial de 1,5-ciclooctadieno: [COD]0;

- Pressão inicial de hidrogênio: $P_{0}$;

- Temperatura: T;

- Vazão volumétrica: V;

- Massa de catalisador impregnado na membrana: $\mathrm{m}_{\mathrm{Pd}}$;

- Diâmetro nominal dos poros da membrana: $\varnothing_{\text {poro; }}$

- Conversão final: X;

- Seletividade para cicloocteno (COE): S.

A definição de conversão e seletividade é apresentada adiante, no item 4.3.

Tabela 4: Experimentos em hidrogenação de COD no reator estudado.

\begin{tabular}{|c|c|c|c|c|c|c|c|c|c|c|c|}
\hline$n^{0}$ & experimento & $V_{0, n}$-heptano & $\mathrm{V}_{0, \mathrm{COD}}$ & {$[\mathrm{COD}]_{0}$} & $P_{0}$ & $\mathrm{~T}$ & $\mathrm{~V}$ & $\mathrm{~m}_{\mathrm{Pd}}$ & $\emptyset_{\text {poro }}$ & $\mathrm{X}$ & $\mathrm{S}$ \\
\hline 1 & M45 ( $1^{\circ}$ experimento) & $90 \mathrm{ml}$ & $20 \mathrm{ml}$ & $0,41 \mathrm{~mol} / 1$ & 10 bar & $50^{\circ} \mathrm{C}$ & $140 \mathrm{ml} / \mathrm{min}$ & $1 \mathrm{mg}$ & $0,6 \mu \mathrm{m}$ & $63,1 \%$ & $99,97 \%$ \\
\hline 2 & M45 $\left(2^{\circ}\right.$ experimento $)$ & $90 \mathrm{ml}$ & $20 \mathrm{ml}$ & $0.41 \mathrm{~mol} / /$ & $10 \mathrm{bar}$ & $50^{\circ} \mathrm{C}$ & $140 \mathrm{ml} / \mathrm{min}$ & $1 \mathrm{mg}$ & $0.6 \mu \mathrm{m}$ & $35,9 \%$ & $99.98 \%$ \\
\hline 3 & M45 ( $3^{\circ}$ experimento) & $90 \mathrm{ml}$ & $20 \mathrm{ml}$ & $0,41 \mathrm{~mol} / 1$ & $10 \mathrm{bar}$ & $50^{\circ} \mathrm{C}$ & $140 \mathrm{ml} / \mathrm{min}$ & $1 \mathrm{mg}$ & $0,6 \mu \mathrm{m}$ & $28,4 \%$ & $99,97 \%$ \\
\hline 4 & M64 ( $1^{\circ}$ experimento $)$ & $104,5 \mathrm{ml}$ & $5,5 \mathrm{ml}$ & $0,41 \mathrm{~mol} / 1$ & $10 \mathrm{bar}$ & $50^{\circ} \mathrm{C}$ & $160 \mathrm{ml} / \mathrm{min}$ & $1 \mathrm{mg}$ & $1,9 \mu \mathrm{m}$ & $94,4 \%$ & $97,21 \%$ \\
\hline 5 & M82 $\left(1^{\circ}\right.$ experimento $)$ & $95 \mathrm{ml}$ & $5 \mathrm{ml}$ & $2.33 \mathrm{~mol} / 1$ & $10 \mathrm{bar}$ & $50^{\circ} \mathrm{C}$ & $100 \mathrm{ml} / \mathrm{min}$ & $2 \mathrm{mg}$ & $1.9 \mu \mathrm{m}$ & $15.3 \%$ & $100.00 \%$ \\
\hline 6 & M89 $\left(1^{\circ}\right.$ experimento $)$ & $95 \mathrm{ml}$ & $5 \mathrm{ml}$ & $2,33 \mathrm{~mol} / 1$ & $10 \mathrm{bar}$ & $50^{\circ} \mathrm{C}$ & $220 \mathrm{ml} / \mathrm{min}$ & $1 \mathrm{mg}$ & $1,9 \mu \mathrm{m}$ & $20,5 \%$ & $94,30 \%$ \\
\hline 7 & M89 (2० experimento $)$ & $104,5 \mathrm{ml}$ & $5,5 \mathrm{ml}$ & $0,41 \mathrm{~mol} / 1$ & $10 \mathrm{bar}$ & $50^{\circ} \mathrm{C}$ & $120 \mathrm{ml} / \mathrm{min}$ & $1 \mathrm{mg}$ & $1,9 \mu \mathrm{m}$ & $17,6 \%$ & $97,98 \%$ \\
\hline 8 & M107 ( $1^{\circ}$ experimento) & $90 \mathrm{ml}$ & $20 \mathrm{ml}$ & $2.33 \mathrm{~mol} / / \mathrm{s}$ & $20 \mathrm{bar}$ & $50^{\circ} \mathrm{C}$ & $140 \mathrm{ml} / \mathrm{min}$ & $1 \mathrm{mg}$ & $1.9 \mu \mathrm{m}$ & $81.8 \%$ & $90.25 \%$ \\
\hline 9 & M108 & $95 \mathrm{ml}$ & $5 \mathrm{ml}$ & $0,41 \mathrm{~mol} / 1$ & $10 \mathrm{bar}$ & $50^{\circ} \mathrm{C}$ & $120 \mathrm{ml} / \mathrm{min}$ & $1 \mathrm{mg}$ & $3,0 \mu \mathrm{m}$ & $15,6 \%$ & $88,18 \%$ \\
\hline 10 & $\mathrm{M} 113(1$ & $104,5 \mathrm{ml}$ & $5,5 \mathrm{ml}$ & $0,41 \mathrm{~mol} / 1$ & $10 \mathrm{bar}$ & $50^{\circ} \mathrm{C}$ & $220 \mathrm{ml} / \mathrm{min}$ & $1 \mathrm{mg}$ & $1,9 \mu \mathrm{m}$ & $98,6 \%$ & $94,88 \%$ \\
\hline 11 & M113 ( $2^{\circ}$ experimento) & $104.5 \mathrm{ml}$ & $5.5 \mathrm{ml}$ & $0.41 \mathrm{~mol} / \mathrm{l}$ & $10 \mathrm{bar}$ & $50^{\circ} \mathrm{C}$ & $180 \mathrm{ml} / \mathrm{min}$ & $1 \mathrm{mg}$ & $1.9 \mu \mathrm{m}$ & $76.6 \%$ & $98.73 \%$ \\
\hline 12 & M113 ( $3^{\circ}$ experimento) & $104,5 \mathrm{ml}$ & $5,5 \mathrm{ml}$ & $0,41 \mathrm{~mol} / 1$ & $10 \mathrm{bar}$ & $50^{\circ} \mathrm{C}$ & $220 \mathrm{ml} / \mathrm{min}$ & $1 \mathrm{mg}$ & $1,9 \mu \mathrm{m}$ & $81,6 \%$ & $98,15 \%$ \\
\hline 13 & M114 ( $1^{\circ}$ experimento) & $104,5 \mathrm{ml}$ & $5,5 \mathrm{ml}$ & $0,41 \mathrm{~mol} / 1$ & $10 \mathrm{bar}$ & $50^{\circ} \mathrm{C}$ & $190 \mathrm{ml} / \mathrm{min}$ & $1 \mathrm{mg}$ & $0,6 \mu \mathrm{m}$ & $29,8 \%$ & $89,23 \%$ \\
\hline 14 & M115 ( $1^{\circ}$ experimento) & $104,5 \mathrm{ml}$ & $5,5 \mathrm{ml}$ & $0.41 \mathrm{~mol} / 1$ & $10 \mathrm{bar}$ & $50^{\circ} \mathrm{C}$ & $160 \mathrm{ml} / \mathrm{min}$ & $1 \mathrm{mg}$ & $3,0 \mu \mathrm{m}$ & $36,7 \%$ & $90,58 \%$ \\
\hline 15 & M116 & $104,5 \mathrm{ml}$ & $5,5 \mathrm{ml}$ & $0,41 \mathrm{~mol} / 1$ & $10 \mathrm{bar}$ & $50^{\circ} \mathrm{C}$ & $160 \mathrm{ml} / \mathrm{min}$ & $1 \mathrm{mg}$ & $0,6 \mu \mathrm{m}$ & $98,1 \%$ & $89,94 \%$ \\
\hline 16 & M119 & $104,5 \mathrm{ml}$ & $5,5 \mathrm{ml}$ & $0,41 \mathrm{~mol} / 1$ & $10 \mathrm{bar}$ & $50^{\circ} \mathrm{C}$ & $160 \mathrm{ml} / \mathrm{min}$ & $1 \mathrm{mg}$ & $3,0 \mu \mathrm{m}$ & $49,4 \%$ & $97,17 \%$ \\
\hline 17 & M121 & $104,5 \mathrm{ml}$ & $5,5 \mathrm{ml}$ & $0,41 \mathrm{~mol} / 1$ & $10 \mathrm{bar}$ & $50^{\circ} \mathrm{C}$ & $160 \mathrm{ml} / \mathrm{min}$ & $1 \mathrm{mg}$ & $3,0 \mu \mathrm{m}$ & $76,7 \%$ & $98,58 \%$ \\
\hline 18 & M122 & $104,5 \mathrm{ml}$ & $5,5 \mathrm{ml}$ & $0,41 \mathrm{~mol} / 1$ & $10 \mathrm{bar}$ & $50^{\circ} \mathrm{C}$ & $160 \mathrm{ml} / \mathrm{min}$ & $1 \mathrm{mg}$ & $1,9 \mu \mathrm{m}$ & $95,1 \%$ & $96,65 \%$ \\
\hline 19 & M171 ( $1^{\circ}$ experimento) & $104,5 \mathrm{ml}$ & $5.5 \mathrm{ml}$ & $0.41 \mathrm{~mol} / 1$ & $10 \mathrm{bar}$ & $50^{\circ} \mathrm{C}$ & $200 \mathrm{ml} / \mathrm{min}$ & $1 \mathrm{mg}$ & $1.9 \mu \mathrm{m}$ & $67.6 \%$ & $98.28 \%$ \\
\hline 20 & $2^{\circ}$ experimento & $104.5 \mathrm{ml}$ & $5,5 \mathrm{ml}$ & $\mathrm{nol} / \mathrm{l}$ & $10 \mathrm{bar}$ & $50^{\circ} \mathrm{C}$ & $200 \mathrm{ml} / \mathrm{min}$ & $1 \mathrm{mg}$ & $1.9 \mathrm{\mu m}$ & $89.5 \%$ & $97,44 \%$ \\
\hline 21 & experimento) & $104.5 \mathrm{ml}$ & $5.5 \mathrm{ml}$ & $0.41 \mathrm{~mol} / \mathrm{/}$ & $10 \mathrm{bar}$ & $50^{\circ} \mathrm{C}$ & $200 \mathrm{ml} / \mathrm{min}$ & $1 \mathrm{mg}$ & $1.9 \mu \mathrm{m}$ & $100.0 \%$ & $90.19 \%$ \\
\hline 22 & M171 & $104.5 \mathrm{ml}$ & $5.5 \mathrm{ml}$ & $\mathrm{nol} / \mathrm{s}$ & $10 \mathrm{bar}$ & $50^{\circ} \mathrm{C}$ & $200 n$ & $1 \mathrm{mg}$ & $1.9 \mu \mathrm{m}$ & $93,5 \%$ & $95,52 \%$ \\
\hline 23 & $2\left(1^{\circ}\right.$ experi & $104,5 \mathrm{ml}$ & $5,5 \mathrm{ml}$ & nol/1/4 & $10 \mathrm{bar}$ & $50^{\circ} \mathrm{C}$ & 160 & $3 \mathrm{mg}$ & $1,9 \mu \mathrm{m}$ & $99,1 \%$ & $92,85 \%$ \\
\hline 24 & $2\left(2^{\circ}\right.$ experimento $)$ & $104,5 \mathrm{ml}$ & $5,5 \mathrm{ml}$ & 0,4 & $10 \mathrm{bar}$ & $50^{\circ} \mathrm{C}$ & 160 & $3 \mathrm{mg}$ & $1,9 \mu \mathrm{m}$ & $100,0 \%$ & $89,39 \%$ \\
\hline 25 & $182\left(3^{\circ}\right.$ experir & $104,5 \mathrm{ml}$ & $5,5 \mathrm{ml}$ & רol/1/ & $10 \mathrm{bar}$ & $50^{\circ} \mathrm{C}$ & 160 & $3 \mathrm{mg}$ & $1,9 \mu \mathrm{m}$ & $100,0 \%$ & $90,92 \%$ \\
\hline 26 & M180.181.182 (4 $4^{\circ}$ experimento) & $104,5 \mathrm{ml}$ & $5,5 \mathrm{ml}$ & $\mathrm{ol} / / \mathrm{l}$ & $10 \mathrm{bar}$ & $50^{\circ} \mathrm{C}$ & 160 & $3 \mathrm{mg}$ & $1,9 \mu \mathrm{m}$ & $44,2 \%$ & $98,21 \%$ \\
\hline 27 & M183 & $104,5 \mathrm{ml}$ & $5,5 \mathrm{ml}$ & nol/1/ & $10 \mathrm{bar}$ & $50^{\circ} \mathrm{C}$ & 200 & $1 \mathrm{mg}$ & $3,0 \mu \mathrm{m}$ & $98,3 \%$ & $94,18 \%$ \\
\hline 28 & M184 (1ํ experimento) & $104,5 \mathrm{ml}$ & $5,5 \mathrm{ml}$ & $\mathrm{mol} / \mathrm{l}$ & $10 \mathrm{bar}$ & $50^{\circ} \mathrm{C}$ & $200 n$ & $1 \mathrm{mg}$ & $0,6 \mu \mathrm{m}$ & $100,0 \%$ & $92,99 \%$ \\
\hline 29 & M186 ( $1^{\circ}$ experimento) & $104,5 \mathrm{ml}$ & $5,5 \mathrm{ml}$ & $0,41 \mathrm{~mol} / 1$ & $10 \mathrm{bar}$ & $60^{\circ} \mathrm{C}$ & $200 n$ & $1 \mathrm{mg}$ & $1,9 \mu \mathrm{m}$ & $98,4 \%$ & $87,50 \%$ \\
\hline 30 & M186 ( $2^{\circ}$ experimento) & $104,5 \mathrm{ml}$ & $5,5 \mathrm{ml}$ & $0,41 \mathrm{~mol} / 1$ & $10 \mathrm{bar}$ & $60^{\circ} \mathrm{C}$ & $200 \mathrm{ml} / \mathrm{min}$ & $1 \mathrm{mg}$ & $1,9 \mu \mathrm{m}$ & $100,0 \%$ & $86,63 \%$ \\
\hline 31 & M186 ( $3^{\circ}$ experimento) & $104,5 \mathrm{ml}$ & $5,5 \mathrm{ml}$ & $0,41 \mathrm{~mol} / 1$ & $10 \mathrm{bar}$ & $60^{\circ} \mathrm{C}$ & $200 \mathrm{ml} / \mathrm{min}$ & $1 \mathrm{mg}$ & $1,9 \mu \mathrm{m}$ & $100,0 \%$ & $83,86 \%$ \\
\hline 32 & M186 ( $4^{\circ}$ experimento) & $104,5 \mathrm{ml}$ & $5,5 \mathrm{ml}$ & $0,41 \mathrm{~mol} / 1$ & $10 \mathrm{bar}$ & $60^{\circ} \mathrm{C}$ & $180 \mathrm{ml} / \mathrm{min}$ & $1 \mathrm{mg}$ & $1,9 \mu \mathrm{m}$ & $100,0 \%$ & $85,87 \%$ \\
\hline 33 & M186 ( $5^{\circ}$ experimento) & $104,5 \mathrm{ml}$ & $5,5 \mathrm{ml}$ & $0,41 \mathrm{~mol} / 1$ & $10 \mathrm{bar}$ & $60^{\circ} \mathrm{C}$ & $180 \mathrm{ml} / \mathrm{min}$ & $1 \mathrm{mg}$ & $1,9 \mu \mathrm{m}$ & $100,0 \%$ & $90,09 \%$ \\
\hline 34 & M186 ( $6^{\circ}$ experimento) & $104,5 \mathrm{ml}$ & $5,5 \mathrm{ml}$ & $0,41 \mathrm{~mol} / 1$ & $10 \mathrm{bar}$ & $60^{\circ} \mathrm{C}$ & $180 \mathrm{ml} / \mathrm{min}$ & $1 \mathrm{mg}$ & $1,9 \mu \mathrm{m}$ & $100,0 \%$ & $89,77 \%$ \\
\hline 35 & M186 ( $7^{\circ}$ experimento) & $104,5 \mathrm{ml}$ & $5,5 \mathrm{ml}$ & $0,41 \mathrm{~mol} / 1$ & $10 \mathrm{bar}$ & $60^{\circ} \mathrm{C}$ & $180 \mathrm{ml} / \mathrm{min}$ & $1 \mathrm{mg}$ & $1,9 \mu \mathrm{m}$ & $99,8 \%$ & $88,81 \%$ \\
\hline 36 & M186 ( $8^{\circ}$ experimento) & $104,5 \mathrm{ml}$ & $5,5 \mathrm{ml}$ & $0,41 \mathrm{~mol} / 1$ & $10 \mathrm{bar}$ & $60^{\circ} \mathrm{C}$ & $180 \mathrm{ml} / \mathrm{min}$ & $1 \mathrm{mg}$ & $1,9 \mu \mathrm{m}$ & $99,6 \%$ & $90,77 \%$ \\
\hline 37 & M186 ( $9^{\circ}$ experimento) & $104,5 \mathrm{ml}$ & $5,5 \mathrm{ml}$ & $0,41 \mathrm{~mol} / \mathrm{l}$ & $10 \mathrm{bar}$ & $60^{\circ} \mathrm{C}$ & $180 \mathrm{ml} / \mathrm{min}$ & $1 \mathrm{mg}$ & $1,9 \mu \mathrm{m}$ & $98,7 \%$ & $92,83 \%$ \\
\hline 38 & M186 $\left(10^{\circ}\right.$ experimento) & $104,5 \mathrm{ml}$ & $5,5 \mathrm{ml}$ & $0,41 \mathrm{~mol} / 1$ & $10 \mathrm{bar}$ & $60^{\circ} \mathrm{C}$ & $180 \mathrm{ml} / \mathrm{min}$ & $1 \mathrm{mg}$ & $1,9 \mu \mathrm{m}$ & $98,5 \%$ & $93,69 \%$ \\
\hline 39 & M186 (11 ${ }^{\circ}$ experimento) & $104,5 \mathrm{ml}$ & $5,5 \mathrm{ml}$ & $0,41 \mathrm{~mol} / 1$ & $10 \mathrm{bar}$ & $60^{\circ} \mathrm{C}$ & $180 \mathrm{ml} / \mathrm{min}$ & $1 \mathrm{mg}$ & $1,9 \mu \mathrm{m}$ & $99,2 \%$ & $90,45 \%$ \\
\hline 40 & M186 (12 experimento) & $104,5 \mathrm{ml}$ & $5,5 \mathrm{ml}$ & $0,41 \mathrm{~mol} / 1$ & $10 \mathrm{bar}$ & $60^{\circ} \mathrm{C}$ & $180 \mathrm{ml} / \mathrm{min}$ & $1 \mathrm{mg}$ & $1,9 \mu \mathrm{m}$ & $99,0 \%$ & $91,45 \%$ \\
\hline 41 & $\mathrm{MP}$ & $104,5 \mathrm{ml}$ & $5,5 \mathrm{ml}$ & $0,41 \mathrm{~mol} / 1$ & $10 \mathrm{bar}$ & $50^{\circ} \mathrm{C}$ & $120 \mathrm{ml} / \mathrm{min}$ & $1 \mathrm{mg}$ & $1,9 \mu \mathrm{m}$ & $99,9 \%$ & $91,87 \%$ \\
\hline
\end{tabular}

Fonte: Schmidt (2007) 


\section{Revisão de literatura}

\subsection{Reator catalítico de membrana}

Os estudos pioneiros em reações com uso de membranas iniciaram-se no ano de 1866, em que Graham divulgou ao meio científico as vantagens quanto ao uso de membranas de $\mathrm{Pd}$ em reações de hidrogenação. Desde os anos 80 , os reatores catalíticos de membrana têm sido amplamente estudados por suas vantagens técnicas comparadas a reatores tradicionais, particularmente seu desenho modular e facilidade de aumento de escala (Tesser et al., 2005). A descoberta de que o hidrogênio emergido de membranas de $\mathrm{Pd}$ era muito mais ativo do que o gás alimentado diretamente junto à substância a ser hidrogenada atraiu a atenção de pesquisadores de diversos países (Gryaznov, 1999).

Desde então, o campo de estudo em membranas reativas se desenvolveu, abrangendo membranas densas, majoritariamente metais, que são quase que exclusivamente dedicados a reações de hidrogenação, e membranas porosas, que podem ser utilizadas em diversas aplicações, como o modo de escoamento forçado através da membrana (Dittmeyer et al., 2004).

O tipo mais frequente de aplicação são as reações de hidrogenação, principalmente de hidrocarbonetos, seguidas pelas reações de oxidação, também em sua maior parte aplicadas a hidrocarbonetos (Dittmeyer et al., 2004).

Segundo Dixon (2003), há três principais usos de reatores de membrana:

- o conceito mais comum de reator de membrana aplica-se à remoção de um produto do meio reacional de reação limitada por equilíbrio químico;

- o segundo conceito consiste da alimentação distribuída de reagente através do volume do reator, controlando, por exemplo, a taxa de reação para abrandamento da geração de calor em reações altamente exotérmicas; 
- e o terceiro é definido pelo uso da membrana para controlar a forma como os reagentes entram em contato uns com os outros.

De acordo com esses usos, o reator de membrana pode ser classificado como "extrator", "distribuidor" ou "contator ativo" (Schomäcker et al., 2005).

No presente trabalho, o contator ativo é estudado em detalhe. Não obstante, uma breve apresentação de cada um dos conceitos é realizada a seguir.

\subsubsection{Extrator}

O modelo mais utilizado de reator catalítico é o denominado extrator, que atua nas reações removendo um dos produtos formados, deslocando, principalmente, reações de equilíbrio.

Em experimento com reator de membrana catalítica do tipo extrator aplicado à reação trifásica de hidrogenação-isomerização competitiva de metilenociclohexano, Bottino et al. (2004) obtiveram melhor controle das condições operacionais, e possibilidade de exploração de ampla faixa de temperaturas, já que o processo global é controlado em regime cinético. Uma vantagem apontada em contraste com o tradicional reator de lama foi a possibilidade de se realizar hidrogenação sem a necessidade de se aplicar altas pressões para vencer limitações de transporte de massa. Como o intervalo de condições operacionais em que o reator opera em regime cinético é expandido, altas taxas globais de reação podem ser obtidas aumentando-se a temperatura. Finalmente, obtém-se facilidade no controle da seletividade de reações.

Num esforço conjunto envolvendo Eltron Research Inc., CoorsTek, Sud Chemie, Argonne National Laboratory e NORAM, foi desenvolvido um trabalho com foco em um método eficiente, econômico e ambientalmente positivo, para separação de hidrogênio a partir de misturas gasosas produzidas em operações industriais, como a gaseificação de carvão. O estudo envolveu quatro categorias de membranas densas: i) compósitos cerâmica/cerâmica, ii) compósitos cerâmica/metal (cermet), iii) cermets com metais permeáveis a hidrogênio, e iv) compósitos em camadas 
contendo ligas permeáveis a hidrogênio. Os resultados em taxas de permeação, estabilidade mecânica, e economia indicaram um grande potencial para aumento de escala e viabilidade comercial (Eltron Research Inc., 2005).

A desidrogenação oxidativa de ciclohexano pode ser realizada com alto rendimento quando uma membrana de paládio é usada para dividir o reator em seções de reação e separação. A fim de se determinar o efeito dos padrões de fluxo de gás quando um gás de varredura é usado para remover o hidrogênio permeado, cinco modelos de fluxo ideal foram analisados e comparados por N. Itoh, Y. e Shindo Haraya K. (Platinum Metals Review, 1991).

Itoh recentemente realizou a decomposição de ciclohexano para benzeno e hidrogênio utilizando um catalisador de $\mathrm{Pt}$ em $\mathrm{Al}$, em que o hidrogênio produzido era retirado do meio reacional por difusão através da parede de $\mathrm{Pd}$ do reator. Sob essas condições, a conversão atingida foi de 99,7\% (Platinum Metals Review, 1988).

Finalmente, no que diz respeito a reator catalítico de membrana do tipo extrator, uma inovação promissora é a idéia de acoplamento térmico para se tratar o problema do gerenciamento de energia térmica. A idéia consiste em realizar uma reação exotérmica em um dos lados da membrana e uma reação endotérmica no outro lado (Dixon, 2003).

\subsubsection{Distribuidor / Difusor}

Um segundo tipo de reator catalítico de membrana é o distribuidor / difusor, cujo princípio consiste em otimizar o contato entre os reagentes e a fase ativa de forma a explorar de maneira ótima as propriedades catalíticas intrínsecas do sistema (Dittmeyer, Svajda e Reif, 2004).

Reif e Dittmeyer (2003) aplicaram o conceito de distribuidor à remoção de nitrito e nitrato da água. Essa remoção tem particular relevância na Europa, onde o limite de $50 \mathrm{mg} / \mathrm{l}$ de nitrato em lençóis é excedido em diversas regiões, devido ao excesso de fertilização. Nessas reações, o tamanho de partículas de catalisador deve ser pequeno o suficiente para que se formem curtos caminhos de difusão. $O$ transporte 
difusivo pode ser evitado pelo uso de pós catalíticos de alguns mícrons. No entanto, em aplicações industriais torna-se complexo manusear e recuperar catalisadores tão finos. O conceito de difusor catalítico apresenta-se como solução mais adequada a esse problema. Em uma membrana cerâmica catalítica assimétrica, os metais catalíticos podem ser depositados nas finíssimas regiões porosas do topo da membrana. Dessa forma, o catalisador é imobilizado e fica dispensada a realização de processos de separação.

Em suma, os CMRs são, do ponto de vista de transporte, equivalentes a um reator do tipo slurry, com partículas extremamente finas, com a vantagem de não requererem um processo de separação do catalisador após a reação (Reif e Dittmeyer, 2003).

Membranas densas são às vezes utilizadas para fornecer hidrogênio em reações de hidrogenação. Exemplos são a hidrogenação de ciclopentadieno e 1,3-pentadieno (Gryaznov et al., 2001), e a hidrogenação de acetileno (Vincent e Gonzalez, 2002).

Dixon (2001) realizou um estudo comparativo do rendimento para produtos intermediários obtidos a partir de reator de membrana do tipo distribuidor e reatores convencionais de tubo de refrigeração com escoamento pistonado. Um modelo nãoisotérmico, não-adiabático de reator homogêneo unidimensional foi utilizado. A análise foi apresentada em termos dos grupos adimensionais usuais (número de Damköhler $\mathrm{Da}$, calor de reação parâmetro $\mathrm{B}$, o número de Peclet $\mathrm{Pe}$, etc.) (Dixon, 2003).

Num outro enfoque, muitas vezes a motivação para o uso de uma alimentação distribuída de oxigênio deve-se menos à perspectiva de ganho em seletividade do que à oportunidade de melhorias na operação estável do reator (Diakov e Varma, 2002). 


\subsubsection{Contator ativo}

Assim como no caso do distribuidor, o princípio do contator ativo consiste em otimizar o contato entre os reagentes e a fase ativa de forma a explorar de maneira ótima as propriedades catalíticas intrínsecas do sistema (Dittmeyer et al., 2004).

No difusor catalítico, mesmo com uma camada muito fina de membrana catalítica sobre um suporte cerâmico a limitação de transporte de massa por difusão nos poros pode ocorrer se a reação for muito rápida. A adição de dióxido de carbono pode diminuir os gradientes de $\mathrm{pH}$ na camada de membrana, mas não muda o gradiente de concentração dos reagentes. Ao se utilizar um catalisador em pó muito fino, é possível minimizar esses gradientes de concentração, mas tais pós finos são difíceis de serem separados e recuperados em uma escala industrial. Outra maneira de se minimizar a difusão nos poros é bombear toda a solução de reação através de uma membrana assimétrica cerâmica ou um suporte cerâmico revestido com metais cataliticamente ativos. Ao se ajustar a vazão da bomba, o tempo de contato com o catalisador pode ser variado e tempos de contato muito curtos podem ser alcançados (Reif e Dittmeyer, 2003).

Diversos estudos têm demonstrado um desempenho superior dos contatores de membrana porosa aplicados a processos catalíticos heterogêneos trifásicos: hidrogenação de metilestireno (Cini et al., 1991), hidrogenação de nitratos aquosos (Daub et al., 1999; Strukul et al., 2000) e oxidação de ciclohexano e de n-dodecano (Langhendries et al., 2000).

Os mesmos princípios motivaram o uso de membranas para a hidrogenação por Dittmeyer et al. (2001) e Centi e Perathoner (2003), que observaram que o hidrogênio tem baixa solubilidade em líquidos orgânicos. A membrana faz com que a interface gás-líquido fique em contato com o catalisador, a pressão mais baixa, já que o hidrogênio não precisa se dissolver no filme líquido e sim difundir através dele (Dixon, 2003).

Tesser et al. (2005) demonstraram vantagens no uso de contatores no estudo de reações gás-líquido e gás-líquido-sólido. 
Os contatores dividem-se em dois subtipos: interfaciais e de passagem através da membrana (forced through flow).

Reatores contatores do tipo interfacial caracterizam-se pela alimentação de dois ou mais reagentes distintos por lados opostos da espessura da membrana (Miachon e Dalmon, 2004).

Nos reatores do tipo contator de passagem através da membrana, os reagentes são previamente misturados e têm sua passagem forçada através da membrana, reagindo ao ficarem em contato eficiente com o catalisador. Essa configuração está se tornando uma terceira área da pesquisa em reatores catalíticos de membrana (Dixon, 2003).

De acordo com Dittmeyer et al. (2004), no caso mais provável para uma membrana porosa, haveria convecção dentro dos poros. Dessa condição de escoamento, resultaria um contato mais eficiente entre o fluido e a fase ativa sobre as paredes dos poros presentes, por exemplo, na forma de nanopartículas impregnadas. $O$ tamanho do poro de tais membranas seria escolhido na faixa de mícron ou submícron e o tempo de contato por ciclo seria curto; portanto, o arranjo pode ser visto como um micro-reator (ou até mesmo nano-reator) catalítico de curto tempo de contato.

Lambert e Gonzalez (1999) apresentam uma investigação da atividade e seletividade de uma membrana catalítica de $\mathrm{Pd} / \mathrm{Al}_{2} \mathrm{O}_{3}$ em reações de hidrogenação parcial de acetileno e 1,3-butadieno. Um resultado importante foi a obtenção de máxima seletividade ao se misturar previamente o hidrogênio gasoso à solução reagente líquida e então fazer a mistura gás-líquido atravessar a parede da membrana.

Para a minimização de limitações de transferência de massa num sistema gás / líquido / sólido, uma situação ótima pode ser idealizada quando gás e líquido são bem misturados e em seguida forçados a passar através de uma membrana porosa a uma vazão suficientemente alta (convectiva), promovendo um tempo de contato 
tão curto que nenhum consumo indesejado de reagente possa ocorrer (Dittmeyer et al., 2004).

A Figura 7, extraída de Schmidt et al. (2005), ilustra como processos de difusão resultam no prolongamento do tempo de permanência dos produtos formados em contato com os centros cataliticamente ativos. Nesse período, o produto desejado C pode ser convertido no produto consecutivo D.

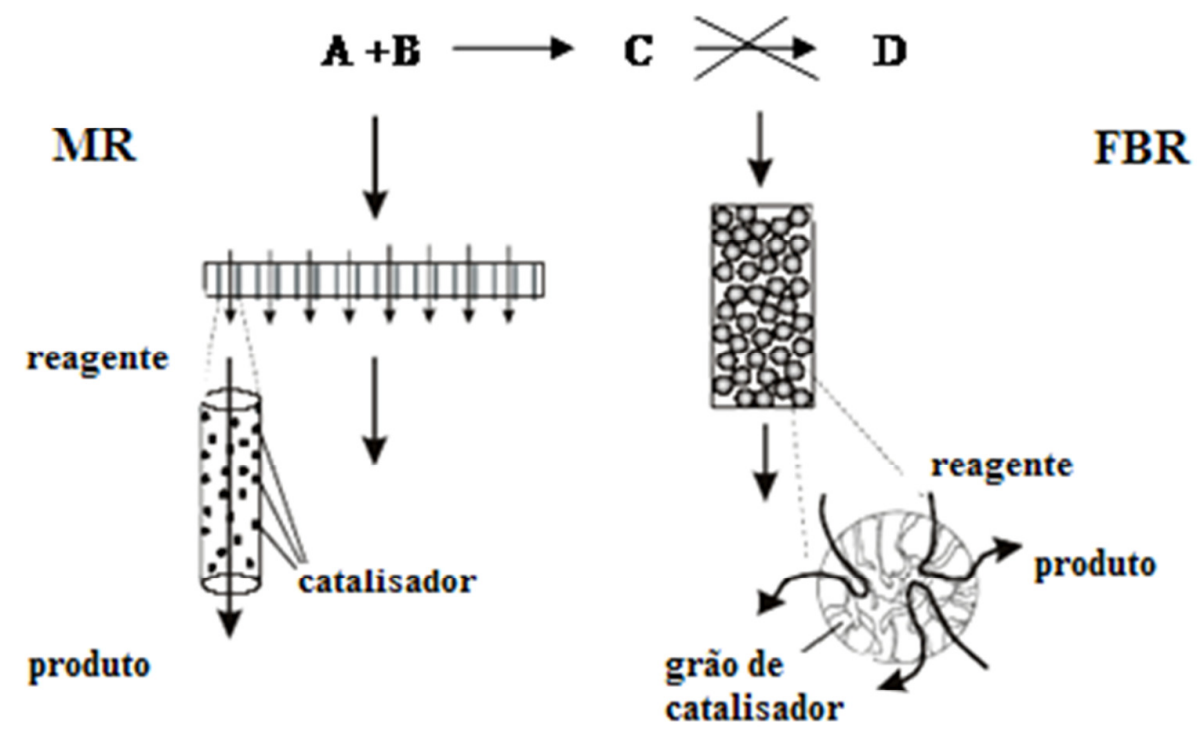

Figura 7: Catálise e transporte de massa em meio poroso. Exemplo de reação consecutiva em membrana e em grão de catalisador.

Nessa configuração de CMR (Figura 8), apresentada por Schmidt et al. (2005), a membrana não realiza separação, servindo apenas de superfície de contato entre catalisador e mistura reacional. A membrana pode ser constituída de material catalítico ou a ele servir de suporte. A mistura reacional é convertida ao atravessar a membrana. Dessa forma, o período de contato dos produtos intermediários com o catalisador é determinado pela vazão, que pode ser controlada de forma a evitar reações consecutivas (Schmidt et al., 2005).

Uma importante vantagem do CMR em comparação ao FBR (Fixed Bed Reactor, reator de leito fixo) seria um melhor controle do tempo de residência por variação do 
tamanho de poros e da vazão através dos poros da membrana (Schmidt et al., 2005).

Realizando-se diversas passagens a alta velocidade através da membrana, limitações por transporte de massa podem ser evitadas e o contato entre os reagentes dissolvidos na solução de reação e o catalisador no suporte poroso é intensificado. Como consequencia, tem-se uma maior atividade catalítica (Reif e Dittmeyer, 2003).
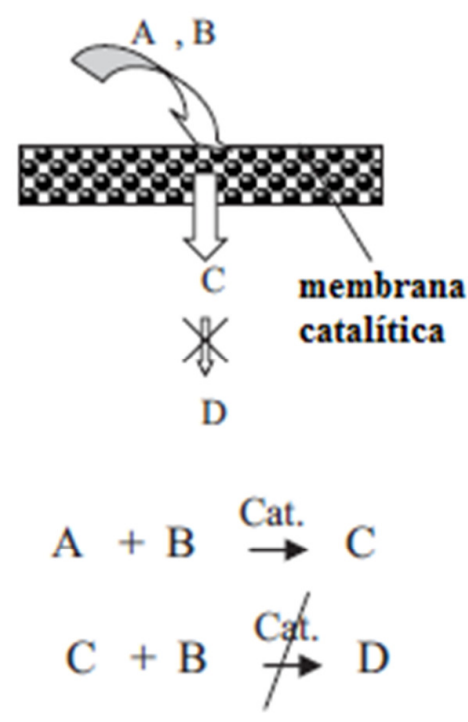

Figura 8: CMR do tipo contator ativo.

Para se minimizar limitações de transferência de massa em um sistema gás - líquido - sólido, uma situação ideal pode ser esperada quando o gás e o líquido são passados bem misturados através da membrana porosa, em fluxo suficientemente alto (isto é, com curto tempo de contato) para que o esgotamento dos reagentes seja evitado. Do ponto de vista da tecnologia de membranas, essa é uma forma natural de processamento de fluidos, por exemplo, na filtragem. Para a realização de uma reação no entanto, o conceito está inevitavelmente ligado ao reciclo de grandes fluxos de reagente, que impõe custos de energia e complica o projeto do reator, apesar de existirem muitas vezes situações em que os benefícios decorrentes de tal modo de operação, por exemplo, maiores taxas de reação, maior seletividade, maior 
qualidade do produto, e assim por diante, podem compensar as desvantagens (Dittmeyer et al., 2004).

No que se refere à questão da estabilidade, diversos experimentos mostraram que o fluxo forçado através de uma membrana pode ser mantido, se reagente flui do exterior para o interior da membrana e se houver um suficiente fluxo cruzado do lado retentado. Então, não ocorrerá obstrução dos poros da membrana (Reif e Dittmeyer, 2003).

Reif e Dittmeyer (2003) demonstraram que a atividade e a seletividade são dependentes do fluxo através da membrana. Em taxas de fluxo muito baixas a atividade do catalisador não é suficientemente alta. Com um aumento da vazão a atividade aumenta até que em determinado ponto limite um aumento adicional do fluxo não altera a atividade significativamente.

Fritsch e Bengtson (2006) aplicaram o conceito de membranas catalíticas porosas de alto fluxo constituídas de poli(éter-sulfona) e poli(amida-imida) à hidrogenação de óleos comestíveis. Essas membranas apresentaram-se estáveis sob efeitos de temperatura. Os reatores catalíticos foram desenvolvidos para operar no modo de passagem através da membrana sem qualquer perda de metal catalisador.

Gröschel (2004) estudou o uso de membranas catalíticas no aumento da seletividade de reações parciais, tendo como reação modelo a hidrogenação parcial em fase gasosa de propino a propeno.

Lange et al. (1998) prepararam membranas microporosas cataliticamente ativas de filmes finos por revestimento de imersão de membrana cerâmica assimétrica de suporte em $\mathrm{Na}_{2} \mathrm{PtCl}_{6}$ contendo sol com base em $\mathrm{Ti}(\mathrm{O} / \mathrm{Pr})_{4}$. Após a secagem e calcinação, a membrana (espessura da camada superior, 0,2-0,4 m) apresenta propriedades de separação típicas de membranas microporosas com baixo teor de defeitos (nanofiltração). Após a ativação com hidrogênio a $250^{\circ} \mathrm{C}$, as membranas apresentaram uma atividade de hidrogenação significativamente superior à dos catalisadores do tipo batelada aplicáveis à mesma finalidade. Nas condições de reação e de controle de limitação de disponibilidade de hidrogênio, 2-hexino é semi- 
hidrogenado com esse tipo de membrana com seletividade de $100 \%$ para cis-2hexeno. 1,3-hexadieno é semi-hidrogenado seletivamente para 1-hexeno. A seletividade acima da média observada é atribuída à prevenção de retro-mistura através da utilização do contator de membrana.

Purnama et al. (2006) aplicaram reator de passagem através da membrana à hidrogenação de $\alpha$-metilestireno.

Reif e Dittmeyer (2003) realizaram uma comparação entre o difusor e catalisador de passagem forçada através da membrana para a descloração de clorofórmio. A atividade para o reator de fluxo forçado através da membrana é significativamente maior do que com o difusor catalítico. Isso ocorre porque os efeitos de transporte de massa são eliminados e, pelo bombeamento através da estrutura porosa do catalisador, é intensificado o contato entre catalisador e reagentes dissolvidos e, assim, uma intensificação de processo é realizada.

Segundo Reif e Dittmeyer (2003), para o conceito de fluxo forçado através da membrana, um nível suficientemente elevado de reciclo é necessário para se evitar o bloqueio dos poros e manter a operação. Este alto fluxo turbulento envolve um elevado consumo de energia. Uma solução apropriada para o conceito de contator de fluxo forçado pode ser projetado com filtro de discos rotativos que proporcionam elevadas velocidades de fluxo cruzado com um consumo de energia consideravelmente reduzido em comparação a sistemas convencionais.

Westermann e Melin (2009) apresentaram uma ampla revisão dos princípios e aplicações de reatores de membrana de passagem forçada. As aplicações foram divididas em três categorias: Reatores Integrais de Conversão Completa, Reatores Integrais Seletivos e Reatores Diferenciais Seletivos.

Zhang et al. (1998) estudaram a hidrogenação de cinamaldeído em reatores de membrana com catalisadores de $\mathrm{Pd} / \mathrm{C}$.

Schmidt e Schomäcker (2007b) realizaram a hidrogenação parcial de óleo de girassol em um reator de passagem forçada através da membrana usando n- 
heptano como solvente. $\mathrm{O}$ reator consistiu de uma membrana porosa- $\mathrm{Al}_{2} \mathrm{O}_{3}$ impregnada com $\mathrm{Pd}$ ou $\mathrm{Pt}$ como catalisador ativo e foi construído tendo dois módulos: um reator de saturação e módulo de membranas. Experimentos de hidrogenação foram realizados em diferentes temperaturas, pressões de hidrogênio e metais nobres como catalisadores. Os experimentos no reator de membrana foram comparados a experimentos em um reator de lama (slurry) com catalisador em pó, para benchmarking. O teor de ácido esteárico para um valor de iodo (IV, iodine value) de cerca de 80 foi de $10-15 \%$ no reator de membrana e de $45 \%$ no reator slurry. A seletividade obtida para os ácidos graxos monoeno foi melhorado com a diminuição das pressões de hidrogênio. $O$ teor de ácidos graxos trans para IV $\approx 80$ foi de $30-45 \%$ no reator com membrana, enquanto que no reator slurry $12 \%$ foram obtidos. Para a formação de isômeros trans, a influência da pressão de hidrogênio e da temperatura no reator de membrana foi bastante baixa. Pd apresentou maior atividade e seletividade em relação à $\mathrm{Pt}$, mas promoveu a isomerização trans em maior medida.

Schmidt e Schomäcker (2007a) investigaram ainda a cinética intrínseca da reação de hidrogenação de 1,5 ciclooctadieno (COD) para cicloocteno (COE) e do COE para ciclooctano (COA) numa ampla gama de condições de reação: $40-70{ }^{\circ} \mathrm{C}, 0,2-1$ $\mathrm{MPa}$ de pressão de hidrogênio e concentração inicial de COD variando entre 0,41$0,82 \mathrm{~mol} / \mathrm{L}$ com um pó fino de catalisador $\mathrm{Pd} / \mathrm{R}-\mathrm{Al}_{2} \mathrm{O}_{3}$ (100 $\mu \mathrm{m}$ de tamanho de grão) em um reator de lama (s/urry). Foi identificado que as taxas de reação dependem das concentrações de COD, COE e hidrogênio de acordo com um mecanismo cinético do tipo Langmuir-Hinshelwood. Constantes de velocidade e energia de ativação foram determinadas a partir do ajuste do modelo cinético aos dados experimentais. Energias de ativação de $74 \mathrm{~kJ} / \mathrm{mol}$ para a reação do COD para o COE e de $98 \mathrm{~kJ} / \mathrm{mol}$ para a reação do COE para COA foram determinados.

No mesmo trabalho, Schmidt e Schomäcker (2007a) empregaram o modelo obtido de cinética intrínseca ao estudo de um reator catalítico de membrana do tipo passagem forçada. Os dados desse trabalho são referência para o presente estudo. 


\subsection{Modelagem e simulação de reatores catalíticos de membrana}

A modelagem e simulação de CMRs apresentam importantes tarefas a serem realizadas (Saracco et al., 1999). Com respeito à compreensão e capacidade de predição dos mecanismos de transporte altamente seletivos, investigações teóricas relevantes são realizadas há mais de dez anos (Tsotsis et al., 1993; Dalmon, 1997; Saracco et al., 1999; Bernstein, Agarwalla e Lund, 1993; Lu et al., 1997; Langhendries, Baron e Jacobs, 1999.). No entanto, os modelos desenvolvidos nesses estudos estão limitados por estarem fortemente atrelados à experiência acumulada na modelagem de FBRs (Eigenberger, 1997).

Os modelos originais de CMR geralmente apresentam consideráveis simplificações, dentre as quais algumas são aqui mencionadas:

- os modelos são essencialmente unidimensionais (1-D), ou seja, gradientes perpendiculares à direção principal de transporte são desprezadas;

- concentração e temperatura em reatores multifásicos em geral não sofrem distinção para as diversas fases (modelos pseudo-homogêneos);

- modelos isotérmicos são normalmente adotados;

- taxas de reação efetivas são adotadas.

Para o projeto de diversos equipamentos que envolvem escoamento em meios porosos, é necessário um conhecimento de como a vazão varia em função da diferença de pressão a jusante e a montante do meio. A determinação desta relação só é possível conhecendo-se alguma grandeza física que represente a resistência do meio poroso ao escoamento (Lisboa, 2000).

Segundo Dittmeyer et al. (2004), a modelagem matemática como uma ferramenta para entender as limitações de um determinado sistema combinada com experiências específicas, com algumas notáveis exceções, ainda não é utilizada de forma suficiente em reatores catalíticos de membrana. Tal observação é válida desde as estimativas simples e até estudos de modelagem mais avançados, que poderiam ajudar a avaliar os potenciais benefícios decorrentes da combinação de transferência de massa através de uma membrana e uma reação catalítica em 
condições de operação não-estacionária (reversão do fluxo, oscilações periódicas da pressão transmembrana ou potencial aplicado, etc.). Este campo não tem recebido muita atenção até agora, apenas alguns estudos relatam ter tratado com tais princípios.

Porém, à medida que o tema reatores de membrana catalítica se desenvolve, o nível de sofisticação de estudos experimentais e modelagem vêm aumentando. Modelos mais detalhados estão sendo desenvolvidos, incluindo 0 uso de modelos bidimensionais do reator e a avaliação de concentração e gradientes de temperatura. Os pesquisadores estão se voltando para anecessidade de um melhor entendimento da cinética de reação e das sutilezas do projeto de reator de membrana. Em particular, há um corpo crescente da opinião de que é necessário desenvolver a concepção do reator e do catalisador em conjunto, levando em conta as interações entre eles. Não é suficiente apenas colocar os tubos de membrana no projeto e operação do habitual reator de leito fixo (Dixon, 2003).

\subsubsection{Modelos analíticos}

Schmidt (2007) desenvolveu um modelo matemático para a hidrogenação de COD em reator de membrana de passagem forçada. O modelo pressupõe de que o fluxo líquido através da membrana seja do tipo plug-flow. Os perfis de concentração de hidrogênio na membrana foram simulados através da resolução de balanços de massa, incluindo leis de cinética obtidas a partir de experimentos em reatores de lama. Como uma primeira abordagem, o modelo foi utilizado para a previsão da evolução de reação sob diferentes condições de operação. O modelo representou os efeitos da taxa de fluxo da circulação e da quantidade de Pd sobre o processo de hidrogenação de forma compatível com os experimentos realizados. O trabalho concluiu, no entanto, que a influência do tamanho dos poros da membrana não era adequadamente explicada por esse modelo.

\subsubsection{Modelagem via CFD}

Contribuições nessa área são encontradas nos trabalhos de Itoh et al. (1994), Koukou et al. (1997) e Hou et al. (2001). Itoh et al. (1994) estudaram os perfis de 
pressão parcial de hidrogênio formada ao longo do reator de membrana de Pd do tipo leito recheado. Simulação usando um modelo radial de difusão foi comparada a simulação com modelo de vazão ideal. O estudo evidenciou gradiente de hidrogênio na direção radial devido à permeação radial através da membrana.

Koukou et al. (1997) desenvolveram um modelo não-isotérmico para um reator de membrana de leito recheado. O modelo matemático desenvolvido foi aplicado na investigação da desidrogenação endotérmica de ciclohexano. Efeitos de se desprezar fenômenos térmicos nas predições do campo de temperatura e conversão foram apresentados.

Hou et al. (2001) desenvolveram um modelo matemático para previsão da concentração radial e perfis de temperatura num reator de membrana de leito fixo. $A$ influência dos perfis radiais de concentração no rendimento e na seletividade foi estudada. O modelo é postulado como apropriado até mesmo para aumento de escala dos reatores de membrana da escala de laboratório para a escala de plantapiloto, e para estudos preliminares de aplicação industrial.

Lapkin et al. (2002) desenvolveram um modelo no nível mesoscópico de reator catalítico de membrana do tipo contator.

Dixon (2003) destacou a importância da modelagem bi-dimensional enfatizada por Brinkmann et al. (2001) e Pedernera et al. (2002). Koukou et al. (2001) analisaram os efeitos de fluxo não-ideal (dispersão) em um modelo bidimensional de um reator com membrana adiabática em larga escala para a reação de water shift gas (WGS). Eles resolveram uma equação de equilíbrio do momento para ambas as componentes axial e radial da velocidade, com queda de pressão dada pela equação de Ergun pontual, e considerando uma abordagem pseudo-homogênea. Eles descobriram que havia acentuados perfis radiais de hidrogênio, o que reduziu as taxas aparentes de transporte de hidrogênio através da membrana, em comparação com aquelas que seriam calculadas assumindo um escoamento do tipo pistonado, ou fluxo unidimensional. Inclinações e tendências semelhantes foram encontradas para os perfis de temperatura radial. 
Hou et al. (2001) utilizaram um modelo bidimensional da concentração e temperatura, e mostraram que o perfil radial de concentrações afeta a seletividade e a produtividade em um reator de desidrogenação oxidativa de propano. O sistema estudado consistiu de um CMR do tipo distribuidor. O modelo 2-D adotado partiu das seguintes hipóteses:

- Condições isobáricas.

- Simetria cilíndrica.

- Velocidade do gás com duas componentes em qualquer ponto: axial e radial.

- Componente axial independente da posição radial (essa hipótese corresponde a desprezar a perda de carga por atrito à parede, o que implica em perfil linear da compenente radial em função do raio, desprezando-se a variação de volume decorrente da reação).

- Transporte radial de massa por dois mecanismos: difusão e convecção.

- Transporte de massa por difusão desprezível na componente axial, em comparação com o transporte convectivo.

- Lei do gás ideal (aplicável devido às condições adotadas, de alta temperatura e baixa pressão).

- Modelo pseudo-homogêneo adotado para a seção catalítica.

O modelo previu adequadamente o efeito da variação do diâmetro do reator em seu desempenho final.

Hara et al. (1999) demonstraram que em um reator de remoção de $\mathrm{H}_{2}$ em membrana de $\mathrm{Pd}$, a presença de $\mathrm{CO}$ pode impedir a permeação de hidrogênio através da membrana, em baixas temperaturas. Eles atribuíram este efeito de polarização por concentração do $\mathrm{H}_{2}$ e também à restrição por adsorção de $\mathrm{CO}$ na superfície da membrana. Observa-se que eles precisaram desenvolver um modelo de tubo de membrana bidimensional para explicar esses efeitos.

Sousa et al. (2002) avaliaram o surgimento de acentuado gradiente axial, e introduziram métodos numéricos para a solução dos seus modelos unidimensionais baseados na análise wavelet. 
Nekhamkina et al. (2000) investigaram o aparecimento de padrões espaçotemporais para reatores reagentes distribuídos, mostrando um comportamento complexo sob determinadas condições.

Menciona-se, finalmente, quanto à questão da produção acumulada em modelagem de reatores catalíticos de membrana, que as principais tarefas que permanecem como desafio são as seguintes (Saracco et al., 1999):

- modelagem complexa de módulos de reatores de membrana de grande escala;

- definição de critérios gerais para otimização do projeto e condições operacionais de reatores de membrana, como, por exemplo, seu tamanho, os padrões de vazão adotados, e o número de estágios / reciclos / alimentações intermediárias a ser realizado.

\subsection{Estado da arte e oportunidades}

Do levantamento realizado neste capítulo, conclui-se que embora haja interesse industrial e acadêmico na análise de reatores de membrana em suas escalas meso e micro, conforme, por exemplo, sugestão de Schmidt (2007) mencionada no item 3.2.1, dificuldades intrínsecas à modelagem de tais sistemas justificam o número reduzido de publicações relativas ao tema.

Em estudo da permeabilidade longitudinal em meios porosos fibrosos, Lisboa (2000) menciona que a complexidade dos meios porosos reais impõe barreiras à descrição precisa de sua geometria. Segundo o autor, a complexidade das equações analíticas que definem o espaço entre os poros inviabiliza sua direta aplicação para fins práticos. Aproximações geométricas são então consideradas, de modo a viabilizar o estudo do meio, obtendo-se resultados próximos aos reais.

Adicionalmente, Dixon et al. (2006) mencionam que simplificações em escoamentos intersticiais vieram sendo motivadas no passado por conta da necessidade de 
economia em custo computacional, o que tem se tornado cada vez menos relevante, graças ao aumento significativo da capacidade de processamento em dispositivos cada vez mais compactos.

No caso das membranas tubulares empregadas usualmente nos reatores do tipo contator de passagem forçada, há um aspecto adicional que dificulta a modelagem: a alta razão de aspecto intrínseca à geometria da membrana. No CMR do tipo contator, espessuras típicas são da ordem dos milímetros, de forma que, mesmo para uma membrana de poucos centímetros de comprimento tem-se uma razão cem vezes entre o comprimento da membrana e sua espessura. Decorre que no caso em que deseje estudar efeitos bidimensionais, faz-se necessária uma malha suficientemente fina para observação dos gradientes no sentido radial, ainda que uma malha relativamente mais grosseira permitisse a análise dos gradientes em sentido axial.

Mencione-se finalmente que, em reatores de membrana de passagem forçada, espera-se que efeitos de turbulência devam ser levados em consideração. Isso decorre do fato de que os fluxos da corrente reacional devem ser altos para que haja uma efetiva eliminação dos efeitos de transporte de massa.

O pequeno número de documentos sobre condições turbulentas em CMR leva a inferir que a modelagem em condições de turbulência é difícil. A falta de um modelo de turbulência para CMRs é observável e os pesquisadores ainda não concordam sobre a validade dos atuais modelos comerciais propostos, em meio à grande variedade de aplicações. Na verdade, a aplicação a CMRs exige a resolução de equações mais complexas e malhas muito finas. Por conseguinte, o uso de computadores mais rápidos e com maior quantidade de memória faz-se necessário e os tempos de processamento devem ser mais longos.

Não obstante as dificuldades mencionadas, muitos autores têm sido atraídos por modelar condições turbulentas em membranas, pois muitos processos trabalham com número de Reynolds elevado. Diversos trabalhos têm sido publicados recentemente sobre este tema, o que pode levar a novas oportunidades no desenvolvimento de processos de membrana (Ghidossi et al., 2006). 


\section{Fundamentos teóricos}

\subsection{Reação com catálise heterogênea}

Nos parágrafos a seguir, são apresentadas as equações que descrevem reação heterogênea no código comercial utilizado, por ser essa a abordagem adotada para a obtenção dos resultados apresentados. Uma descrição abrangente do equacionamento de reações heterogêneas é apresentada por Fogler (2006) e particularidades da modelagem matemática de membranas encontram-se em Seidel-Morgenstern (2010) e Li (2007).

Uma reação de superfície $r$, pode ser representada pela expressão (13), a seguir:

$$
\sum_{i=1}^{N_{g}} g_{i, r}^{\prime} G_{i}+\sum_{i=1}^{N_{b}} b_{i, r}^{\prime} B_{i}+\sum_{i=1}^{N_{g}} s_{i, r}^{\prime} S_{i} \stackrel{K_{r}}{\longleftrightarrow} \sum_{i=1}^{N_{g}} g_{i, r}^{\prime \prime} G_{i}+\sum_{i=1}^{N_{b}} b_{i, r}^{\prime \prime} B_{i}+\sum_{i=1}^{N_{g}} s_{i, r}^{\prime \prime} S_{i}
$$

onde $G_{i}, B_{\mathrm{i}}$ e $S_{i}$ representam as espécie em fase gasosa, as espécies bulk e as espécies adsorvidas sobre a superfície (ou sítios), respectivamente. $N_{g}, N_{b}$ e $N_{s}$ são os números totais dessas espécies. $g_{i, r}^{\prime} \quad b_{i, r}^{\prime}$ e $s_{i, r}^{\prime}$ são os coeficientes estequiométricos para cada série de produtos $i . K_{r}$ é a constante de taxa de reação direta. Destaca-se que o solver adotado não apresenta modelos para reações reversíveis de superfície.

Os somatórios da equação acima incluem todas as espécies químicas no sistema, mas somente espécies envolvidas como reagentes ou produtos terão coeficientes estequiométricos não-nulos. A taxa da r-ésima equação é apresentada na equação (14):

$$
R_{r}=k_{f, r}\left(\prod_{i=1}^{N_{g}}\left[G_{i}\right]_{\text {parede }}^{\eta_{i, r, r}^{\prime}}\right)\left(\prod_{j=1}^{N_{s}}\left[S_{i}\right]_{\text {parede }}^{\eta_{j, s, r}^{\prime}}\right)
$$

onde [ ]parede representa as concentrações molares de espécies adsorvidas superficialmente na parede. $\eta_{i, g, r}^{\prime}$ é o coeficiente de taxa para a i-ésima espécie 
gasosa como reagente na reação e $\eta_{j, s, r}^{\prime}$ é o coeficiente de taxa da j-ésima espécie sobre sítio como reagente na reação. Assume-se que a taxa de reação não depende das concentrações de espécies bulk.

A partir disso, a taxa líquida molar de produção ou consumo de cada espécie i é dada pela equação (15):

$$
\begin{array}{rl}
\widehat{R}_{i, g a s}=\sum_{r=1}^{N_{m n}}\left(g_{i, r}^{\prime \prime}-g_{i, r}^{\prime}\right) R_{r} & i=1,2,3, \ldots, N_{g} \\
\widehat{R}_{i, b u l k}=\sum_{r=1}^{N_{m m}}\left(b_{i, r}^{\prime \prime}-b_{i, r}^{\prime}\right) R_{r} & i=1,2,3, \ldots, N_{b} \\
\hat{R}_{i, \text { site }}=\sum_{r=1}^{N_{r m}}\left(s_{i, r}^{\prime \prime}-s_{i, r}^{\prime}\right) R_{r} & i=1,2,3, \ldots, N_{s}
\end{array}
$$

A constante de taxa de reação direta $r, k_{f, r}$ é computada usando a expressão de Arrhenius (16),

$$
k_{f, r}=A_{r} T^{\beta_{r}} e^{-E_{r} / R T}
$$

onde,

$$
\begin{aligned}
& A_{r} \quad=\text { fator pré-exponencial ( unidades consistentes) } \\
& \beta_{r} \quad=\text { coeficiente de temperatura (adimensional) } \\
& E_{r} \quad=\text { energia de ativação para a reação }(\mathrm{J} / \mathrm{kg} \cdot \mathrm{mol}) \\
& R \quad=\text { constante universal dos gases }(\mathrm{J} / \mathrm{kg} \cdot \mathrm{mol}-\mathrm{K})
\end{aligned}
$$

No presente trabalho, não se considerou a distribuição de sítios ativos. Somente os parâmetros da equação de Arrhenius foram informados para definição das duas reações de hidrogenação que ocorrem no sistema, conforme valores calculados no item 2.3. 


\subsection{Reação de superfície}

Não obstante esse fenômeno não esteja sendo considerado no modelo apresentado a seguir, apresenta-se aqui o equacionamento correspondente, para entendimento e inclusão em trabalhos futuros.

O software de CFD adotado disponibiliza a opção de se modificar a taxa de reação de superfície como função da cobertura da espécie. Nesses casos, a constante de taxa de reação direta para a r-ésima reação é avaliada como se apresenta na equação (17):

$$
k_{f, r}=A_{r} T^{\beta_{r}} e^{-E_{r} / R T} \prod_{k_{\text {sfiio }}}\left(10^{Z_{k} \eta_{k, r}}\right)\left(Z^{\mu_{k, r}}\right)\left(e^{-\varepsilon_{k, r} Z_{r} / R T}\right)
$$

$\mathrm{Na}$ equação acima, os três parâmetros de modificação da taxa de reação de cobertura de superfícies para a espécie $k$ na reação $r$ são $\eta_{k, r}, \mu_{k, r}$ e $\varepsilon_{k, r}$. Tais parâmetros são nulos para espécies de reação cujo percentual de cobertura de superfície não se modifica. A fração de superfície coberta, $Z_{k}$, é a fração de superfície coberta pela espécie $k$, e é definida pela equação (18):

$$
Z_{k}=\left[S_{k}\right] / \rho_{\text {sitio }}
$$

$\left[S_{k}\right]=$ concentração de superfície

$\rho_{\text {sitio }}=$ densidade de superfície.

\subsection{Atividade, conversão e seletividade}

Atividade catalítica é expressa em termos das taxas de reação, preferencialmente normalizada à área superficial da fase ativa. Essas áreas superficiais podem ser calculadas através de técnicas adequadas de quimissorção. Como alternativa a essas taxas por unidade de área, pode-se também utilizar taxas específicas, normalizadas à massa de catalisador. Uma medida prontamente disponível da atividade catalítica é o rendimento espaço-tempo, expresso em unidades da quantidade de produto convertido no reator por unidade de tempo e unidade de volume do reator (Knözinger e Kochloefl, 2005). 
Dados de conversão ou gráficos de conversão versus tempo não são suficientes como uma medida de atividade catalítica. Seletividade pode ser definida como a quantidade de produto desejado obtida por quantidade de reagente consumido. Valores de seletividade são melhor avaliados se a conversão correspondente é também informada. Uma forma simples de medição da seletividade é o rendimento (rendimento $=$ seletividade $\times$ conversão). Seletividades podem também ser utilizadas para indicar as taxas relativas de duas ou mais reações competindo; competição pode ocorrer quando diversos reagentes formam produtos em paralelo (tipo I):

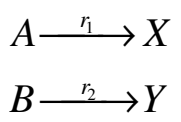

quando um reagente se converte em diversos produtos em paralelo (tipo II):

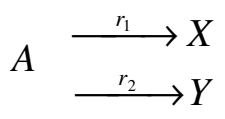

ou reações consecutivas (tipo III):

$$
A \stackrel{r_{1}}{\longrightarrow} X \stackrel{r_{2}}{\longrightarrow} Y
$$

A seletividade é definida como a razão entre a taxa líquida de formação do produto desejado e taxa de consumo da matéria inicial. Portanto, as seletividades para o produto $X$ para reações de primeira ordem (a título de ilustração) são as seguintes:

Tipos I e II: $\frac{r_{1}}{r_{1}+r_{2}}$

Tipo III: $\quad \frac{r_{1}-r_{2}}{r_{1}}$ 
No caso das reações dos tipos I ou II, seletividade para $X$ ou $Y$ é independente da conversão da matéria inicial.

Em reações do tipo III, a seletividade para $X$ é inicialmente 100\%, decresce gradualmente com o aumento da conversão, e cai a zero a $100 \%$ de conversão. $A$ uma conversão intermediária, há um rendimento máximo de $X$, que depende da razão das constantes de velocidade $k_{1}$ e $k_{2}$ das taxas $r_{1}$ e $r_{2}$. As equações de velocidade integradas são as seguintes:

$$
\begin{gathered}
{[A]=\exp \left(-k_{1} t\right)} \\
{[X]=\frac{k_{1}}{k_{2}-k_{1}}\left[\exp \left(-k_{1-} t\right)-\exp \left(-k_{2} t\right)\right]}
\end{gathered}
$$

Onde $[A]$ é a concentração de $A$ não convertido, $[X]$ a concentração de $A$ convertido a $X$, e $t$ o tempo. O rendimento máximo é atingido no instante indicado pela equação a seguir:

$$
t=\left(k_{1}-k_{2}\right)^{-1} \ln \left(\frac{k_{1}}{k_{2}}\right)
$$

Nessa mesma notação, pode-se expressar a seletividade como segue:

$$
S=\frac{[X]}{[A]_{0}-[A]}
$$

Com $[A]_{0}$ sendo a concentração inicial de $A$ (Knözinger e Kochloefl, 2005).

\subsection{Equação de conservação de massa}

A equação de conservação de massa, ou equação da continuidade, $\frac{\partial \rho}{\partial t}+\nabla \cdot(\rho \vec{v})=0$, foi adaptada neste software comercial para incorporar termo fonte $S_{m}$ proveniente de reação ou geração, escrita conforme equação (23):

$$
\frac{\partial \rho}{\partial t}+\nabla \cdot(\rho \vec{v})=S_{m}
$$


A equação acima é a forma adaptada da equação de conservação de massa e é válida tanto para fluidos compressíveis quanto incompressíveis. A fonte $S_{m}$ é a massa de uma segunda fase dispersa adicionada à fase contínua (por exemplo, devido à vaporização de gotículas líquidas) e quaisquer outras fontes definidas livremente.

Para geometrias bidimensionais e assimétricas, a equação da continuidade é dada pela equação (24):

$$
\frac{\partial \rho}{\partial t}+\frac{\partial}{\partial x}\left(\rho v_{x}\right)+\frac{\partial}{\partial r}\left(\rho v_{r}\right)+\frac{\rho v_{r}}{r}=S_{m}
$$

onde $x$ é a coordenada axial, $r$ a coordenada radial, $v_{x}$ é a velocidade axial e $v_{r}$ é a velocidade radial.

\subsection{Equação de conservação de momento}

A conservação de momento em um referencial inercial é descrita pela equação (25):

$$
\frac{\partial}{\partial t}(\rho \vec{v})+\nabla \cdot(\rho \vec{v} \vec{v})=-\nabla p+\nabla \cdot(\overline{\bar{\tau}})+\rho \vec{g}+\vec{F}
$$

onde $p$ é a pressão estática, $\bar{\tau}$ é o tensor tensão (descrito abaixo) e $\rho \vec{g}$ e $\vec{F}$ são a força gravitacional de corpo e as forças externas de corpo (por exemplo, que aparece da interação com a fase dispersa), respectivamente. $\vec{F}$ também contém outras fontes dependentes do modelo, como meio poroso e fontes definidas pelo usuário.

O tensor de tensão é aqui dado pela equação (26):

$$
\overline{\bar{\tau}}=\mu\left[\left(\nabla \vec{v}+\nabla \vec{v}^{T}\right)-\frac{2}{3} \nabla \cdot \vec{v} I\right]
$$


Onde $\mu$ é a viscosidade molecular, $I$ é o tensor unitário e o segundo termo da direita corresponde ao efeito de dilatação volumétrica.

Para geometrias assimétricas bidimensionais em coordenadas cilíndricas, a conservação dos momentos radial e axial é dada pelas equações (27) e (28):

$$
\begin{aligned}
\frac{\partial}{\partial t}\left(\rho v_{r}\right) & +\frac{1}{r} \frac{\partial}{\partial x}\left(r \rho v_{x} v_{r}\right)+\frac{1}{r} \frac{\partial}{\partial r}\left(r \rho v_{r} v_{r}\right)= \\
& -\frac{\partial p}{\partial r}+\frac{1}{r} \frac{\partial}{\partial x}\left[r \mu\left(\frac{\partial v_{r}}{\partial x}+\frac{\partial v_{x}}{\partial r}\right)\right] \\
& +\frac{1}{r} \frac{\partial}{\partial r}\left[r \mu\left(2 \frac{\partial v_{r}}{\partial r}-\frac{2}{3}(\nabla \cdot \vec{v})\right)\right] \\
& -2 \mu \frac{v_{r}}{r^{2}}+\frac{2}{3} \frac{\mu}{r}(\nabla \cdot \vec{v})+\rho \frac{v_{z}^{2}}{r}+F_{r}
\end{aligned}
$$

onde

$$
\nabla \cdot \vec{v}=\frac{\partial v_{x}}{\partial x}+\frac{\partial v_{r}}{\partial r}+\frac{v_{r}}{r}
$$

onde $v_{z}$ é a velocidade de turbilhão.

\subsection{Balanço de reação-difusão para química de superfície}

Reações de superfície modificam espécies em fase gasosa, espécies adsorvidas à superfície e espécies bulk. Em superfícies reagentes, o fluxo de massa de cada espécie gasosa devido à difusão e convecção para ou da superfície é balanceada pela sua taxa de consumo/produção na superfície, conforme equação (29):

$$
\begin{array}{rr}
\rho_{\text {parede }} D_{i} \frac{\partial Y_{i, \text { parede }}}{\partial n}-\dot{m}_{\text {dep }} Y_{i, \text { parede }}=M_{w, i} \widehat{R}_{i, g a s} & i=1,2,3, \ldots N_{g} \\
\frac{\partial\left[S_{i}\right]_{\text {parede }}}{\partial t}=\widehat{R}_{i, \text { sitio }} & i=1,2,3, \ldots N_{s}
\end{array}
$$


A fração de massa na parede $Y_{i, \text { parede }}$ está relacionada à concentração pela equação (30):

$$
\left[G_{i}\right]_{\text {parede }}=\frac{\rho_{\text {parede }} Y_{i, \text { parede }}}{M_{w, i}}
$$

$\dot{m}_{\text {dep }}$ é a taxa líquida de deposição de massa como resultado da reação em superfície, como mostra a equação (31):

$$
\dot{m}_{\text {dep }}=\sum_{i=1}^{N_{b}} M_{w, i} \widehat{R}_{i, b u l k}
$$

$\left[S_{i}\right]_{\text {parede }}$ é a concentração de espécie na parede, definida pela equação (32):

$$
\left[S_{i}\right]_{\text {parede }}=\rho_{\text {sitio }} Z_{i}
$$

Embora tenham sido apresentadas no item 2.3 as equações relativas ao percentual de cobertura de superfícies, os parâmetros apresentados consideram reação sem consideração das taxas de cobertura. Dessa forma, efeitos da concentração de cobertura de superfície estão inativos no presente trabalho.

\subsection{Regime de escoamento em membrana porosa}

Embora a maior parte dos estudos de dinâmica dos fluidos computacional aplicada a membranas, particularmente nos campos de ultrafiltração e osmose reversa, tenha se desenvolvido considerando-se condições laminares, alguns pesquisadores demonstraram a necessidade de se levar em conta efeitos de turbulência na operação (Ghidossi et al., 2006).

Pellerin et al. (1994) formularam e implementaram simulação numérica de diferenças finitas de escoamento de um componente para modelagem 2-D do transporte turbulento em módulos de membrana. Nesse estudo, confirmaram a partir da comparação de dados de simulação turbulenta e laminar com dados experimentais que, nos casos em que condições de contorno relacionadas à pressão sejam relevantes para os resultados avaliados, particularmente para números de Reynolds 
acima de 2.500, simulações de escoamento membrana devem considerar efeitos de turbulência.

De acordo com Dittmeyer et al. (2004), no caso mais provável para uma membrana porosa em CMR do tipo contator, haveria convecção dentro dos poros, resultando em um contato altamente eficiente entre o líquido e a fase ativa nas paredes dos poros presente, por exemplo, na forma de partículas nanométricas impregnadas, como é o caso no presente trabalho. O tamanho dos poros das membranas seria escolhido na faixa de mícron ou sub-mícron e os tempo de contato por passagem seriam curtos. Dessa forma, o arranjo pode ser visto como um microreator (ou mesmo nano) catalítico de curto tempo de contato.

Ghidossi et al. (2006) mencionam que baixo referenciamento bibliográfico sobre condições turbulentas em membranas leva a concluir que a modelagem em condições de turbulência necessita de um número maior de parâmetros do que os modelos aplicados a domínios não-porosos ou abertos.

No presente trabalho, duas diferentes abordagens são consideradas para cada uma das geometrias estudadas. São realizadas simulações com modelo de turbulência ativado e desativado na zona porosa.

\subsection{Turbulência}

Escoamentos turbulentos são caracterizados velocidade, temperaturas, pressões e outros campos flutuantes. No estudo de tais escoamentos, as grandezas de interesse prático correspondem à média temporal dos valores flutuantes. Para se obter essas médias, as equações de escoamento laminar não-estacionário são convertidas em equações médias temporais para escoamento turbulento através de uma operação matemática que tem como pressuposto flutuações rápidas e aleatórias dos valores a cada instante em torno de um valor médio (Patankar, 1980). As equações modificadas contêm novas variáveis de valor desconhecido e para sua determinação são necessários modelos de turbulência (ANSYS 12.0 Theory Guide). 


\subsubsection{Descrição do modelo de turbulência RNG $k-\varepsilon$}

No ano de 1974, Launder e Spalding lançaram artigo sobre escoamentos turbulentos, defendendo que a solução simultânea de equações de transporte para o cálculo da magnitude da energia cinética turbulenta $(k)$ e da sua taxa de dissipação $(\varepsilon)$ resultaria na melhor condição do balanço entre economia computacional, faixa de aplicabilidade e sentido físico.

Desde então, os modelos $k-\varepsilon$ têm sido extensivamente utilizados para aplicações de engenharia, resultando numa profusão de variações para resolver limitações específicas do método padrão. Dentre essas versões, destaca-se aqui a aplicação da rigorosa técnica estatística teoria do grupo de renormalização, ReNormalization Group Theory, que resultou no modelo RNG $k-\varepsilon$, com aplicabilidade a escoamentos sob baixo número de Reynolds e sujeitos a deformações bruscas.

Assim como os demais modelos dessa classe, o RNG $k-\varepsilon$ é um modelo semiempírico, desenvolvido sobre o fundamento de considerações fenomenológicas e abordagem envolvendo aspectos de empirismo. 
As equações de transporte utilizadas no modelo RNG $k-\varepsilon$ são similares àquelas utilizadas no $k-\varepsilon$ padrão, apresentando diferenças somente no termo referente ao transporte de $k$ ou $\varepsilon$ por difusão, como pode ser observado nas equações (33) e (34), respectivamente (Versteeg e Malalasekera, 2007):

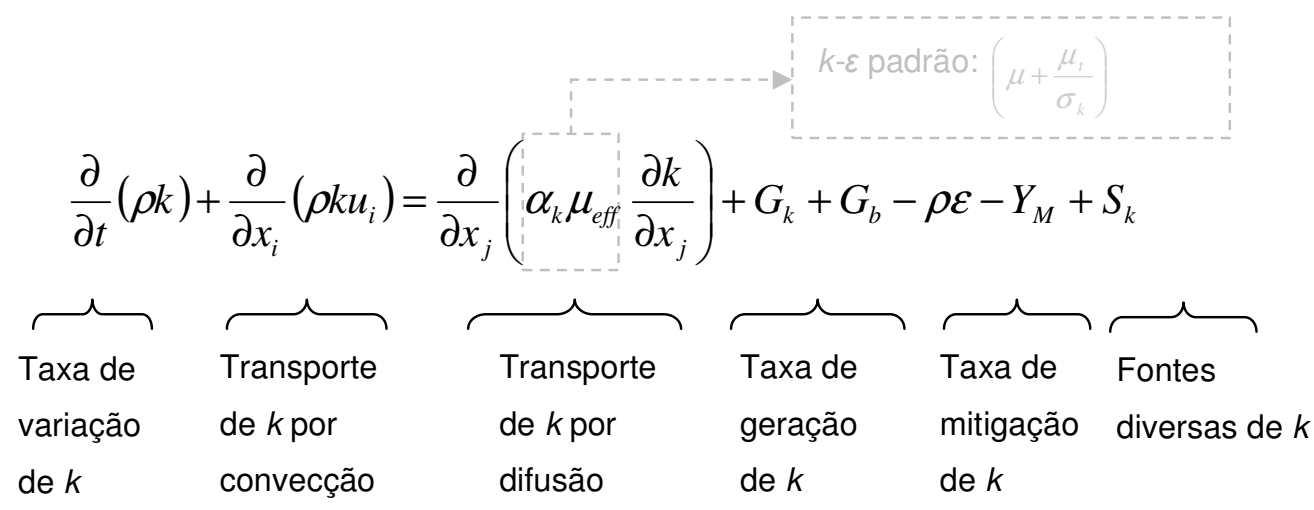

$$
\frac{\partial}{\partial t}(\rho \varepsilon)+\frac{\partial}{\partial x_{i}}\left(\rho \varepsilon u_{i}\right)=\frac{\partial}{\partial x_{j}}\left(\alpha_{\varepsilon} \mu_{e f f} \frac{\partial \varepsilon}{\partial x_{j}}\right)+C_{1 \varepsilon} \frac{\varepsilon}{k}\left(G_{k}+C_{3 \varepsilon} G_{b}\right)-C_{2 \varepsilon} \rho \frac{\varepsilon^{2}}{k}-R_{\varepsilon}+S_{\varepsilon}
$$

\begin{tabular}{|c|c|c|c|c|c|}
\hline $\begin{array}{l}\overbrace{\text { vaxa de }}^{\text {variação }} \\
\text { des }\end{array}$ & $\begin{array}{l}\overbrace{\text { Transporte }} \\
\text { de } \varepsilon \text { por } \\
\text { convecção }\end{array}$ & $\begin{array}{l}\overbrace{\text { Transporte de }} \\
\varepsilon \text { por difusão }\end{array}$ & $\begin{array}{l}\text { Taxa de } \\
\text { geração de } \varepsilon\end{array}$ & $\overbrace{\begin{array}{l}\text { Taxa de } \\
\text { mitigação de } \varepsilon\end{array}}$ & $\begin{array}{l}\overbrace{\text { Fontes }} \\
\text { diversas de } \varepsilon\end{array}$ \\
\hline
\end{tabular}

Nas simulações realizadas, os parâmetros para modelo de turbulência foram mantidos em seu valor padrão, conforme sugeridos no código adotado, a saber:

$$
\begin{aligned}
& \mathrm{C}_{\mu}=0,0845 \\
& \mathrm{C}_{1 \varepsilon}=1,42 \\
& \mathrm{C}_{2 \varepsilon}=1,42 \\
& \alpha=0,85
\end{aligned}
$$

O modelo RNG $k-\varepsilon$ inserido no código comercial utilizado disponibiliza uma opção para uso de fórmula diferencial para a viscosidade efetiva $\mu_{\text {eff }}$ para dar conta dos efeitos de baixo número de Reynolds: Differential Viscosity Model. Essa equação, 
apresentada na equação (35) descreve a forma como o transporte turbulento varia com o número de Reynolds efetivo (ou escala de turbilhão, eddy scale) e foi mantida ativa em todas as simulações realizadas neste trabalho.

com

$$
d\left(\frac{\rho^{2} k}{\sqrt{\varepsilon \mu}}\right)=1,72 \frac{\widehat{v}}{\sqrt{\hat{v}^{3}-1+C_{v}}} d \hat{v}
$$

$$
\begin{aligned}
& \widehat{v}=\mu_{\text {eff }} / \mu \\
& C_{v} \approx 100
\end{aligned}
$$

Nas proximidades das paredes, estabelecem-se altos gradientes das variáveis de solução além de o transporte de momento e outros escalares ocorrer de forma mais vigorosa. Para o tratamento das condições de escoamento nessas regiões, 0 software empregado no presente trabalho disponibiliza o denominado Near-Wall Treatment, vulgarmente denominado Lei de Parede.

Em suma, há duas abordagens básicas para o tratamento de regiões de proximidade às paredes. Na primeira, denominada Wall Function Approach, a região afetada pela viscosidade é tratada de forma isolada, não sendo incluída na solução geral, mas sim substituída por funções de parede que conectam a região de escoamento bulk à superfície circundante. Essa opção resulta em maior rapidez para convergência, porém apresentando riscos para baixo número de Reynolds.

Na segunda abordagem, Near-Wall Model Approach, toda região é incluída na solução geral do modelo. Em decorrência, essa alternativa é somente aplicável caso o modelo de turbulência adotado seja válido para toda a região de proximidade à parede.

No presente trabalho, foi adotado Near-Wall Model Approach, já que o modelo RNG $k-\varepsilon$ é proposto para uma faixa ampla de números de Reynolds. 


\subsubsection{Descrição do modelo de turbulência $k-\omega$}

No modelo $k-\varepsilon$, a viscosidade cinemática de turbilhão $v_{t}$ é expressa como o produto entre uma escala de velocidade $\vartheta=\sqrt{k}$ e uma escala de comprimento $\ell=k^{3 / 2} / \varepsilon$. A taxa de dissipação da energia cinética de turbulência $\varepsilon$ não é a única variável possível par determinação do comprimento de escala. De fato, muitos outros modelos de duas equações foram postulados. A alternativa de maior destaque é o modelo $k-\omega$ proposto por Wilcox (1988, 1993a, b, 1994 apud Versteeg e Malalasekera, 2007), o qual utiliza a frequência de turbulência $\omega=\varepsilon / k$ (de dimensão $\mathrm{s}^{-1}$ ) como segunda variável. Caso se adote essa variável, a escala de comprimento se torna $\ell=\sqrt{k} / \omega$. A viscosidade de turbilhão é, então, dada pela equação (36):

$$
\mu_{t}=\rho k / \omega
$$

Os desdobramentos das equações do tipo $k-\omega$ decorrem das hipóteses mencionadas acima e são descritos por Versteeg e Malalasekera (2007).

\subsection{Métodos de solução do código comercial CFD}

Os métodos de solução empregados no presente trabalho, conforme disponíveis no software comercial utilizado, são descritos em detalhes por Versteeg e Malalasekera (2007) e na documentação ANSYS:

- Acoplamento pressão-velocidade PISO

- Acoplamento pressão-velocidade SIMPLE

- Discretização espacial de gradiente Least Squares

- Discretização espacial de pressão PRESTO!

- Discretização espacial de pressão Standard

- Discretização espacial de momento First Order Upwind

- Discretização espacial de energia cinética turbulenta First Order Upwind

- Discretização espacial de taxa de dissipação de turbulência First Order Upwind

- Discretização espacial de espécies First Order Upwind

- Discretização espacial de energia First Order Upwind 


\section{Estratégias de modelagem CFD}

Neste capítulo são apresentadas e justificadas as estratégias adotadas no desenvolvimento do modelo do reator estudado, juntamente com uma visão global das simulações realizadas.

\subsection{Planejamento de simulações}

No decorrer do presente trabalho, foram simulados casos com diferentes definições de parâmetros e geometrias, visando à compreensão de algumas das relações entre alterações no escoamento e o resultado final em termos de conversão de reagentes e seletividade para o produto esperado.

Num primeiro estudo, realizou-se simulação somente do escoamento, sem ativação do modelo de reação e transporte de espécies. Essa primeira abordagem teve por objetivo avaliar o comportamento no fluido nas diferentes regiões do reator e revisar o modelo, preparando-o para a inclusão de fatores de maior complexidade.

Os parágrafos a seguir descrevem a caracterização de cada caso simulado e os resultados obtidos, comparando-os entre si, conforme foi realizado para a definição de próximos estudos.

Os principais casos simulados são aqui apresentados, classificados em três grupos: casos para estudo preliminar, com identificação iniciada por "P", casos para estudo de sensibilidade do modelo, iniciados por "M" e algumas simulações para avaliação do impacto de possíveis defeitos estruturais de membranas do padrão final de escoamento, iniciados por "S".

\subsubsection{Casos simulados em estudo preliminar}

\subsubsection{Caso P1 - Estudo preliminar: $2-D$}

O primeiro estudo preliminar consistiu de modelo 2-D com malha desenhada em GAMBIT e simulada com FLUENT, apenas para visualização primária do 
comportamento geral do escoamento da membrana. A malha adotada foi consideravelmente grosseira e o número de iterações permaneceu abaixo de 200. A conclusão que se pôde obter, de qualquer forma, desse estudo foi o fato de que as dimensões envolvidas apresentaram valores extremamente baixos, o que dificultou a visualização de resultados.

\subsubsection{Caso P2 - Estudo preliminar: 3-D}

No segundo estudo preliminar, foi desenvolvido modelo 3-D, porém em escala reduzida: o comprimento foi encurtado em cem vezes a fim de se contornar o problema da razão de aspecto e assim se obter malha grosseira, conveniente para as primeiras avaliações.

Como resultado do campo de velocidades, obteve-se escoamento ocorrendo quase que totalmente pelas extremidades das membranas: tão logo o fluido entrava no canal da membrana já se dirigia de imediato para atravessar a membrana, retornando, em seguida, no sentido contrário ao da alimentação.

Desse padrão de escoamento, deduziu-se que o problema poderia estar relacionado à definição dos parâmetros da membrana, que provavelmente estaria permitindo uma passagem do fluxo quase que livre de resistência. Tal explicação seria plenamente aplicável, já que à ocasião, não se havia ainda definido parâmetros realistas para o meio poroso: os valores aplicados nas primeiras simulações não correspondiam às membranas estudadas, sendo os efeitos do meio poroso representados por valores hipotéticos, obtidos em literatura para meios diferentes do estudado.

\subsubsection{Caso P3 - Estudo preliminar: 3-D, revisada resistência da} membrana

Das observações realizadas no Caso P2, decidiu-se pela execução de teste de diferentes parâmetros para a resistência da membrana, sendo que a adoção de valores mais altos de resistência da membrana ao escoamento corrigiu a inconsistência observada no caso anterior. 
Tabela 5: Sumário de casos preliminares simulados.

\begin{tabular}{l|l|l}
\hline Caso & Tipo de domínio & $\begin{array}{l}\text { Resistência da } \\
\text { membrana ao } \\
\text { escoamento }\end{array}$ \\
\hline P1 & 2-D & Baixa \\
\hline P2 & 3-D & Baixa \\
\hline P3 & 3-D & Intermediária \\
\hline
\end{tabular}

5.1.2. Casos simulados para estudo de sensibilidade do modelo

5.1.2.1. Caso M1 - Estudo de sensibilidade do modelo: somente escoamento

O primeiro caso foi desenvolvido adotando-se a geometria modificada, com duas saídas de fluido a partir do casco, em vez de apenas uma. A escolha foi feita pelo fato de essa geometria resultar em malha mais grosseira, já que foi adotada a hipótese de simetria na direção axial. Um desenho esquemático da geometria utilizada neste caso é apresentado na Figura 12, o resultado da definição do domínio computacional é ilustrado pela Figura 14 e a malha utilizada apresenta-se na Figura 17. Neste primeiro modelo manteve-se inativa a ferramenta de cálculo de reação e transporte de espécies. A definição de meio poroso já estava adequada, conforme modelo de leito fixo adotado, com parâmetros determinados por estereologia, conforme descrito no item 5.9.2.1, "Parâmetros de porosidade".

5.1.2.2. Caso M2 - Estudo de sensibilidade do modelo: inclusão de reação

O segundo caso apresentado ilustra a inclusão de reação química e transporte de espécies no modelo. 
5.1.2.3. Caso M3 - Estudo de sensibilidade do modelo: variação da velocidade

No terceiro caso, realiza-se uma diminuição expressiva do valor da velocidade relativamente aos valores praticados na bancada real, a fim de compensar a ausência de recirculação no modelo, que resulta em baixíssima conversão final observada.

5.1.2.4. Caso M4 - Estudo de sensibilidade do modelo: estudo da saída do escoamento

No quarto caso, retoma-se a magnitude original de velocidade idêntica aos casos M1 e M2 para incluí-la no modelo desenvolvido para observação dos efeitos da saída do casco no padrão de escoamento do reator.

5.1.2.5. Caso M5 - Estudo de sensibilidade do modelo: turbulência no meio poroso

Este último caso foi desenvolvido para se estudar o efeito da ativação e desativação na região porosa do modelo de turbulência adotado, RNG $k-\varepsilon$.

Tabela 6: Sumário dos casos simulados para estudo de sensibilidade do modelo

\begin{tabular}{|c|c|c|c|c|}
\hline Caso & Geometria & $\begin{array}{l}\text { Reação e } \\
\text { espécies }\end{array}$ & $\begin{array}{l}\text { Velocidade de } \\
\text { entrada }\end{array}$ & $\begin{array}{l}\text { Escoamento } \\
\text { no meio } \\
\text { poroso }\end{array}$ \\
\hline M1 & $\begin{array}{l}\text { Modificada } \\
\text { (2 saídas) }\end{array}$ & $\begin{array}{l}\text { Modelo } \\
\text { inativo }\end{array}$ & $\begin{array}{l}\text { Real: } \\
1 \mathrm{~m} / \mathrm{s}\end{array}$ & Laminar \\
\hline M2 & $\begin{array}{l}\text { Modificada } \\
\text { ( } 2 \text { saídas) }\end{array}$ & $\begin{array}{l}\text { Modelo } \\
\text { ativo* }^{*}\end{array}$ & $\begin{array}{l}\text { Real: } \\
0,9405278 \mathrm{~m} / \mathrm{s}\end{array}$ & Laminar \\
\hline M3 & $\begin{array}{l}\text { Modificada } \\
\text { ( } 2 \text { saídas) }\end{array}$ & $\begin{array}{l}\text { Modelo } \\
\text { ativo* }^{*}\end{array}$ & $\begin{array}{l}\text { Reduzida: } \\
1 \mathrm{e}-06 \mathrm{~m} / \mathrm{s}\end{array}$ & Laminar \\
\hline M4 & $\begin{array}{l}\text { Real } \\
\text { (1 saída) }\end{array}$ & $\begin{array}{l}\text { Modelo } \\
\text { ativo* }^{*}\end{array}$ & $\begin{array}{l}\text { Real: } \\
0,9405278 \mathrm{~m} / \mathrm{s}\end{array}$ & Laminar \\
\hline
\end{tabular}




\begin{tabular}{l|l|l|l|l}
\hline M5 & Real & Modelo & Real: & Turbulento \\
& (1 saída) & ativo* & $0,9405278 \mathrm{~m} / \mathrm{s}$ & \\
\hline
\end{tabular}

* Para os casos M2, M3, M4 e M5 as simulações incluíram modelo de reação e transporte de espécies.

\subsubsection{Casos simulados de defeitos estruturais na membrana}

A fim de se avaliar a aplicação de dinâmica dos fluidos computacional ao estudo de escoamentos não-ideais no interior de membranas, três simulações de casos hipotéticos de possíveis defeitos estruturais em membranas são apresentados a seguir. A faixa de variabilidade da porosidade da membrana foi adotada com base em caracterizações realizadas por Han et al. (2011).

5.1.3.1. Caso S2 - Simulação de defeito estrutural: faixa longitudinal de alta porosidade, baixa velocidade ${ }^{1}$

Um primeiro tipo de defeito introduzido foi a definição de porosidade $33 \%$ maior que o valor padrão na localização de um quarto do diâmetro total da membrana, posicionada no ponto mais distante da saída, conforme ilustrado na Figura 9:

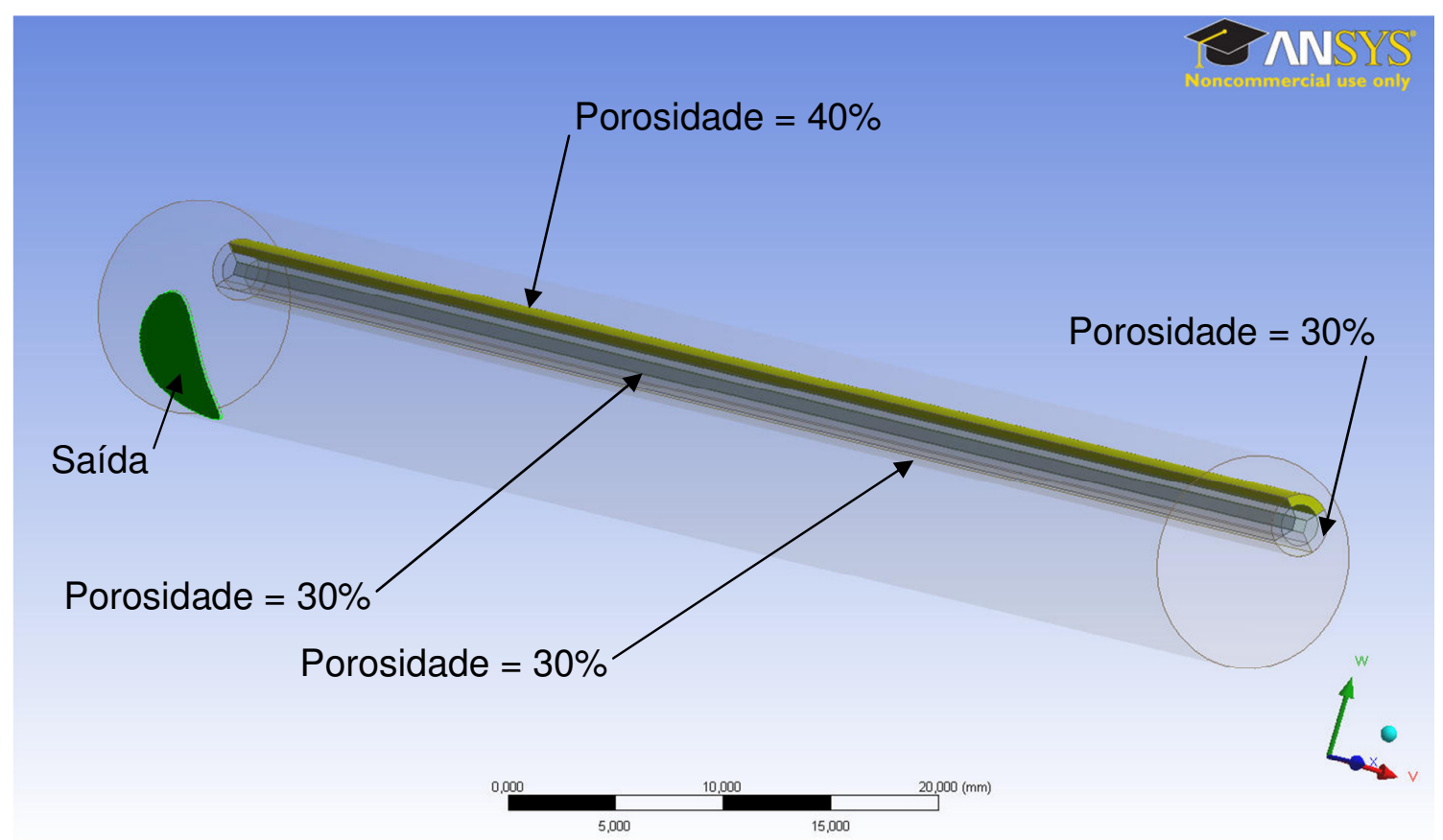

${ }^{1}$ Caso $\mathrm{S} 1$ foi descartado. 
Figura 9: llustração de defeito localizado simulado no reator de membrana.

5.1.3.2. Caso S3 - Simulação de defeito estrutural: faixa longitudinal de alta porosidade, velocidade real

No segundo caso, simulou-se, o mesmo defeito apresentado no caso anterior, porém com velocidade idêntica à adotada em experimentos de bancada.

5.1.3.3. Caso S4 - Simulação de defeito estrutural: variação generalizada de porosidade

No caso S4, similarmente ao ilustrado para o caso anterior, foram definidas localizações da membrana com porosidade fora da especificação. A porosidade definida variou entre $20 \%$ e $40 \%$. A principal diferença para o caso anterior foi o fato de haver dois valores diferentes de porosidade para uma mesma distância radial, conforme ilustrado na Figura 10.

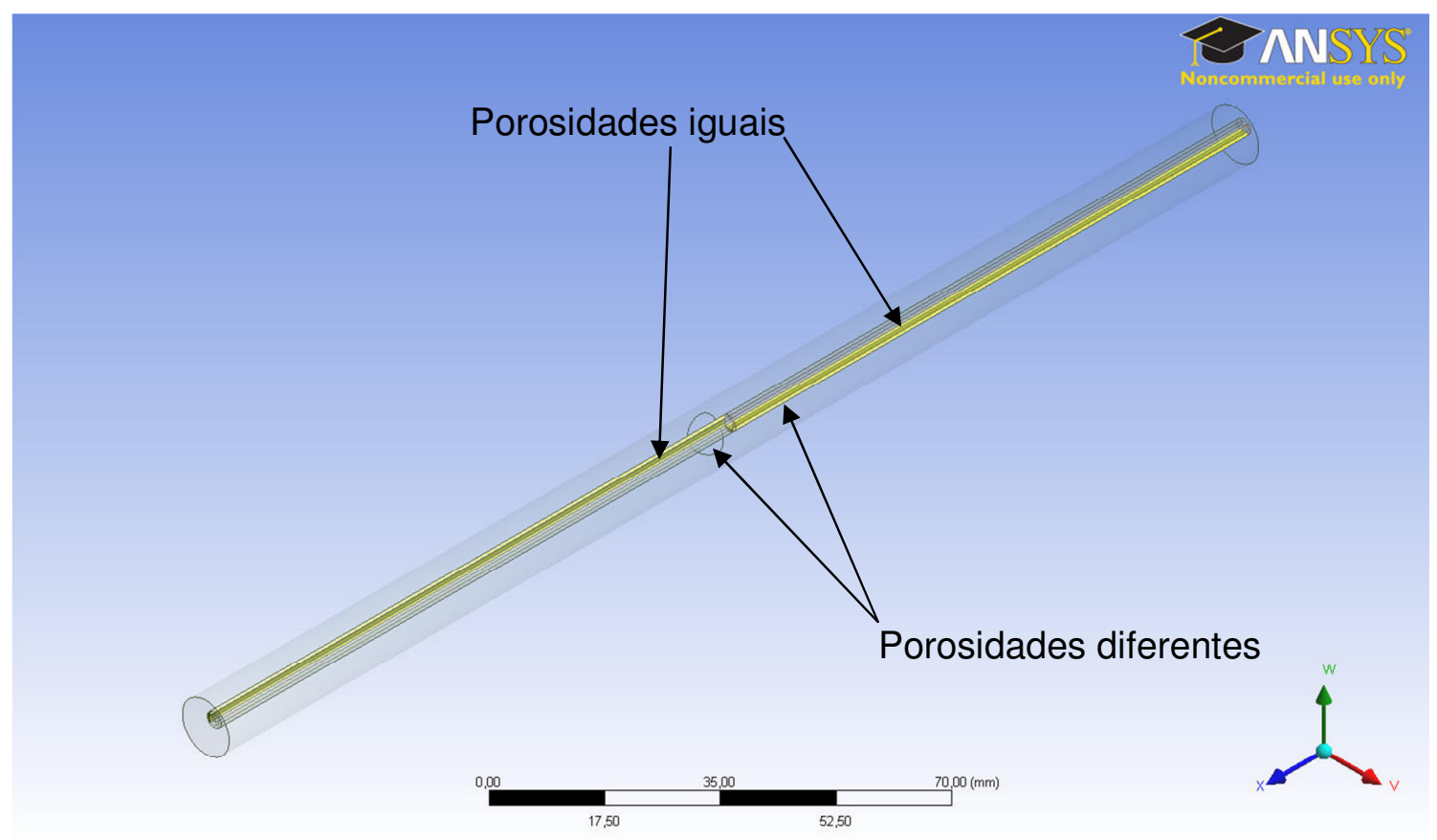

Figura 10: llustração de defeito generalizado simulado no reator de membrana.

Tabela 7: Sumário de simulações de defeito estrutural em membrana.

\begin{tabular}{l|l|l|l}
\hline Caso & Geometria & $\begin{array}{l}\text { Velocidade de } \\
\text { entrada }\end{array}$ & Tipo de defeito \\
\hline
\end{tabular}




\begin{tabular}{l|l|l|l}
\hline S2 & $\begin{array}{l}\text { Real } \\
\text { (1 saída) }\end{array}$ & $\begin{array}{l}\text { Reduzida: } \\
1 \mathrm{e}-12 \mathrm{~m} / \mathrm{s}\end{array}$ & $\begin{array}{l}\text { Localização em 1/4 do diâmetro da membrana com } \\
\text { porosidade de 40\%, ou seja, 33\% maior do que o } \\
\text { restante da membrana. Posicionada na região mais } \\
\text { distante da saída. }\end{array}$ \\
\hline S3 & $\begin{array}{l}\text { Modificada } \\
\text { (2 saídas) }\end{array}$ & $\begin{array}{l}\text { Real: } \\
0,9405278 \mathrm{~m} / \mathrm{s}\end{array}$ & $\begin{array}{l}\text { Localização em 1/4 do diâmetro da membrana com } \\
\text { porosidade de 40\%, ou seja, 33\% maior do que o } \\
\text { restante da membrana. Posicionada na região mais } \\
\text { distante da saída. }\end{array}$ \\
\hline S4 & $\begin{array}{l}\text { Real } \\
\text { (1 saída) }\end{array}$ & $\begin{array}{l}\text { Real: } \\
0,9405278 \mathrm{~m} / \mathrm{s}\end{array}$ & $\begin{array}{l}\text { Distribuição de defeitos resultando em 8 regiões } \\
\text { distintas, distribuídas axial e angularmente, com } \\
\text { porosidade variando entre 20\% e 40\%. }\end{array}$ \\
\hline
\end{tabular}

\subsection{Ferramentas utilizadas}

Todo o desenvolvimento de modelo físico e as simulações CFD foram realizados através das ferramentas disponibilizadas no Workbench do código comercial CFD, conforme apresentado na Tabela 8.

Tabela 8: Ferramentas de CFD utilizadas para modelagem e simulação

\begin{tabular}{c|c|c}
\hline Etapa & Atividade & Ferramenta \\
\hline Pré-processamento & Geometria & ANSYS DesignModeler \\
\hline Pré-processamento & Geração de malhas & ANSYS Meshing \\
\hline Pré-processamento & Definição do modelo físico & ANSYS FLUENT \\
\hline Pré-processamento & Definição de parâmetros do \\
solver & ANSYS FLUENT \\
\hline Processamento & Solução de equações & ANSYS FLUENT \\
\hline Pós-processamento & Visualização de resultados & ANSYS CFD-Post \\
\hline
\end{tabular}

O modelo foi simulado em equipamento HP Z800 Workstation, com dois processadores Intel® Xeon® CPU X5550, sistema operacional de 64 Bits, memória instalada (RAM) de $12 \mathrm{~GB}$, operando na plataforma Windows 7 Professional. 
Estudos preliminares de definição de malha foram realizados com uso do préprocessador GAMBIT v. 2.1.6 e um caso preliminar 2-D foi simulado no programa FLUENT v. 6.0 .

\subsection{Domínio computacional}

\subsubsection{Versões preliminares}

Como estudo preliminar, havia sido tomada em consideração somente a região da membrana, incluindo apenas meio poroso e canal central, desprezando efeitos do módulo de membrana. Nessa etapa, foram feitos alguns testes de malhas, principalmente em decorrência do desafio colocado pelas dimensões em questão: além de apresentar intrinsecamente uma alta razão de aspecto em sua geometria, os valores a serem observados são em escala consideravelmente reduzida.

Foi desenvolvido também modelo em 2-D, somente para uma visualização inicial do comportamento geral do reator e da adequação dos primeiros parâmetros adotados, tais como a verificação de adequação da velocidade às dimensões da membrana.

Embora tenham sido realizados esses estudos preliminares, desprezando casco e variações angulares, destaca-se aqui que um modelo tridimensional é de fundamental importância para a observação dos fenômenos que afetam o escoamento e, em consequência, a reação sobre membrana, conforme é apresentado no item 6 .

\subsubsection{Versão final}

Nesta etapa do pré-processamento, tem-se por objetivo definir uma geometria que represente adequadamente o sistema real em estudo para a definição do domínio computacional em que o problema é calculado.

Conforme mencionado anteriormente, o reator estudado consiste de uma membrana porosa tubular com entrada por ambas as extremidades do canal central e saída 
através dos poros para um casco metálico, o qual apresenta saída única no centro longitudinal do reator.

A membrana reativa tem seu eixo posicionado de forma não-coincidente com o eixo do casco, pois este é projetado para o suporte de até três membranas.

Para avaliação dos efeitos da condição de saída no escoamento no interior da membrana foram desenvolvidos modelos para duas geometrias de casco diferentes:

- Geometria de casco equivalente ao equipamento real, com saída única no centro do reator (Figura 11);

- Geometria modificada de casco, com saída dupla, sendo cada uma das saídas localizada próxima ao centro longitudinal do reator (Figura 12).

Em ambos os casos, a saída, representada no modelo como um orifício, foi posicionada à máxima distância diagonal até a membrana, conforme ilustrado na Figura 4.

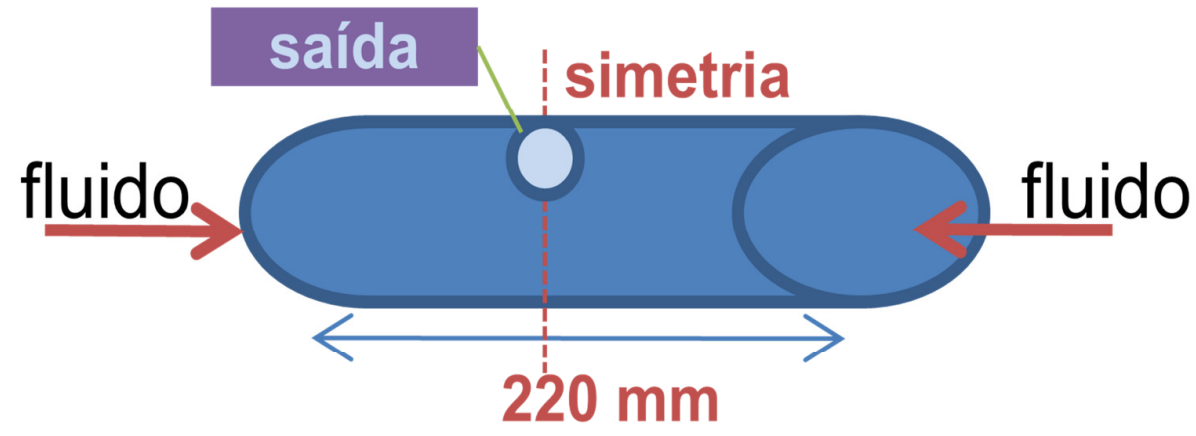

Figura 11: Desenho esquemático da geometria de casco equivalente ao equipamento real, com saída única. 


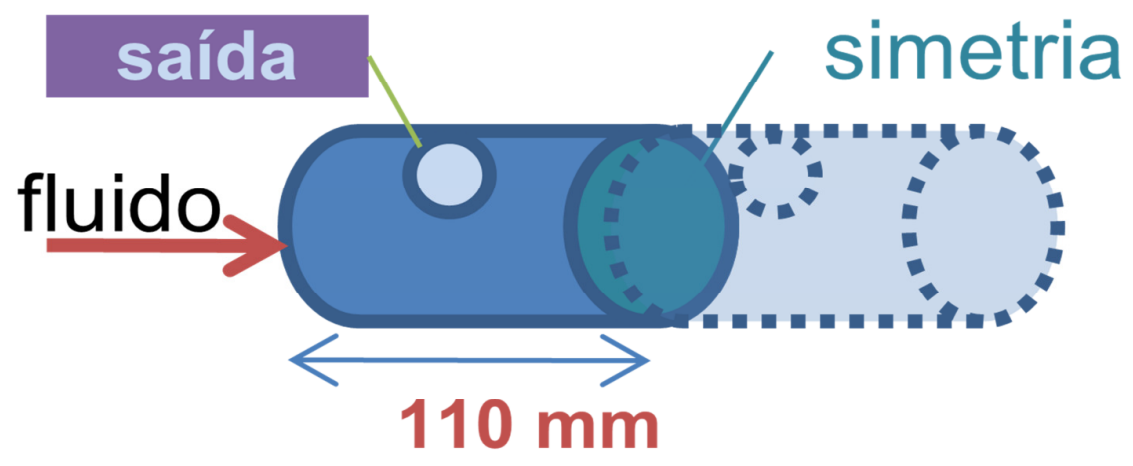

Figura 12: Desenho esquemático da geometria modificada de casco, com saída dupla.

A geometria obtida no ANSYS DesignModeler para o caso equivalente ao equipamento real e para o caso modificado são apresentadas na Figura 13 e Figura 14, respectivamente:

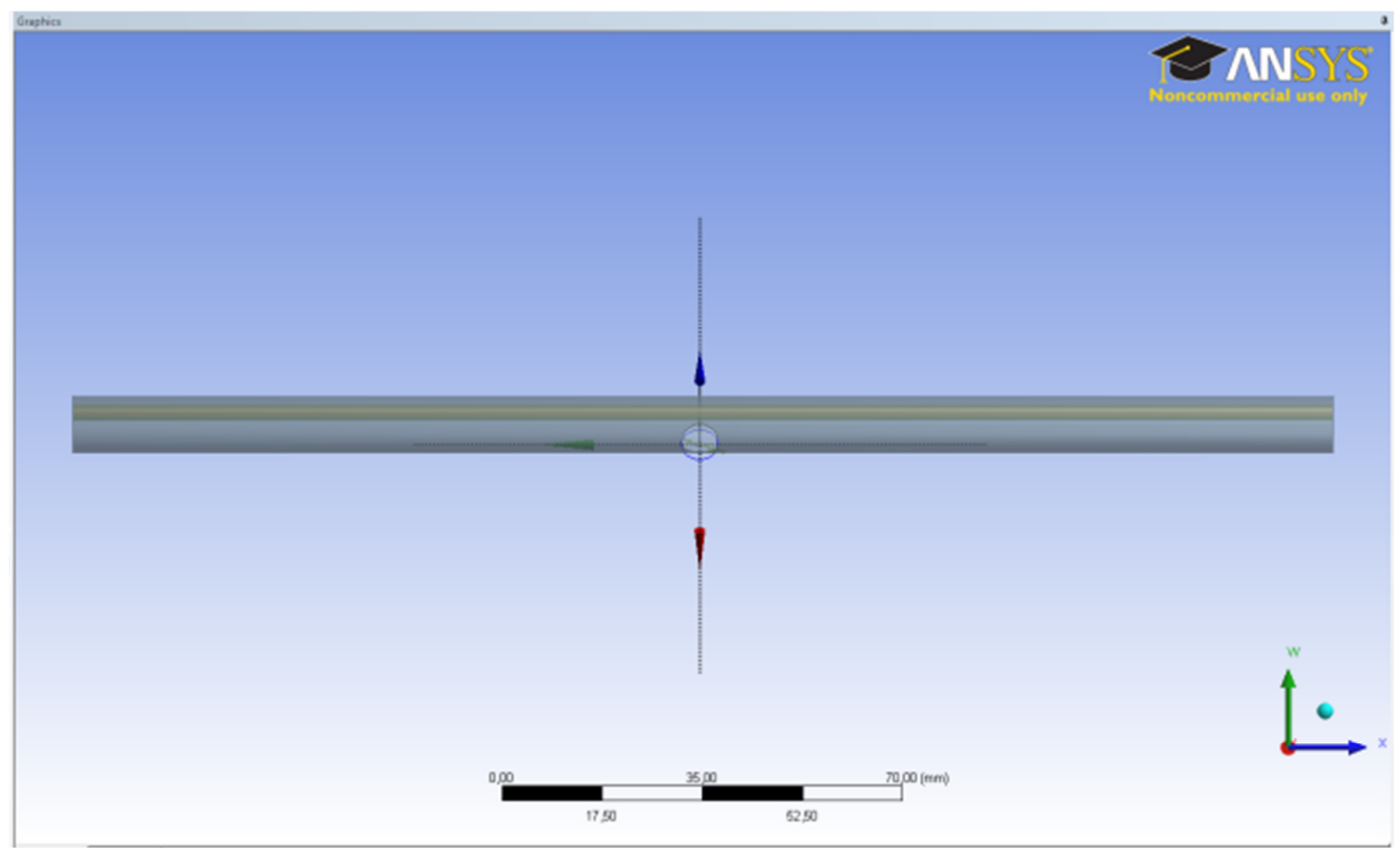

Figura 13: Geometria equivalente ao equipamento real, com saída única. 


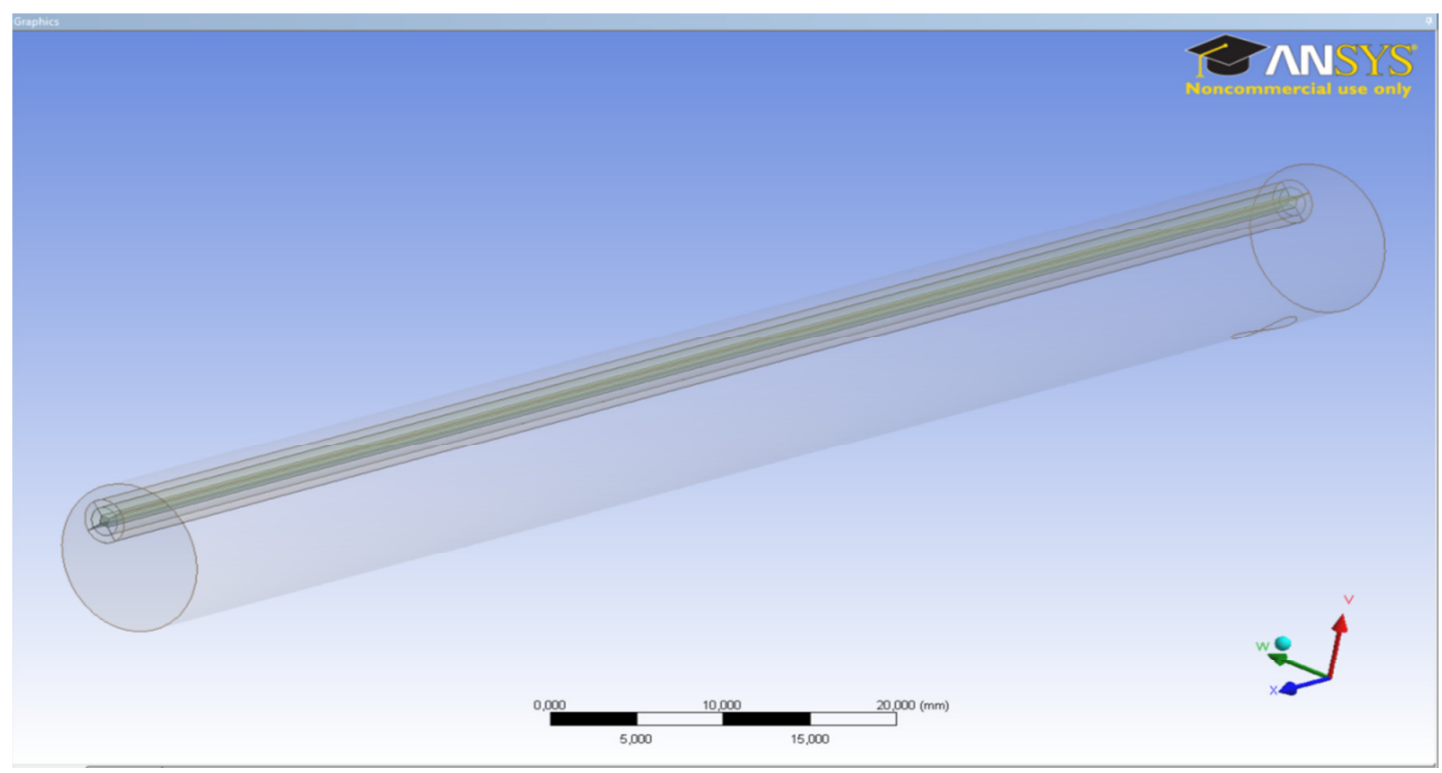

Figura 14: Geometria modificada, com saída dupla.

Observa-se nas figuras acima que para o caso da geometria equivalente ao equipamento real - não obstante a simetria longitudinal - optou-se por modelar a geometria completa. Tal decisão deve-se ao fato de a saída dos produtos da reação a partir do casco coincidir com o eixo de simetria, podendo tal simplificação afetar os resultados nessa região.

Para a geometria modificada, por outro lado, optou-se pela modelagem de meio comprimento da membrana. Considerando-se o número de células envolvido, da ordem de um milhão, essa simplificação resulta em economia relevante em termos computacionais. Ao mesmo tempo, é esperada manutenção da qualidade dos resultados pelo fato de o eixo central neste caso não coincidir com região de mudança de regime de escoamento.

\subsection{Malhas de volumes finitos}

\subsubsection{Comparação com malhas obtidas em literatura}

A partir da revisão de literatura no estado da arte em estudo via CFD de reatores de membrana, observa-se que a quase totalidade dos artigos publicados apresenta domínios computacionais simples ou simplificados. Entre os fatores de simplicidade ou simplificação estão a redução do problema a 2-D, o foco em reatores homogêneos, em fase gasosa, a não-inclusão de alguns dos efeitos do entorno no 
sistema e a característica de coincidência de eixos, no caso de conjunto composto de cilindros (Rahimi et al.; 2009. Sideridis et al.; 2008, Koukou et al., 1999; Park et al., 2003).

Diante dessa observação, nota-se o caráter de evolução ilustrado nas figuras das malhas geradas para o conjunto membrana e casco. Como exemplo, apresenta-se abaixo malha gerada por Park et al. (2003) em estudo da reação de deslocamento do vapor d'água (water-gas shift reaction, WGS), cuja malha é apresentada na Figura 15, a seguir:

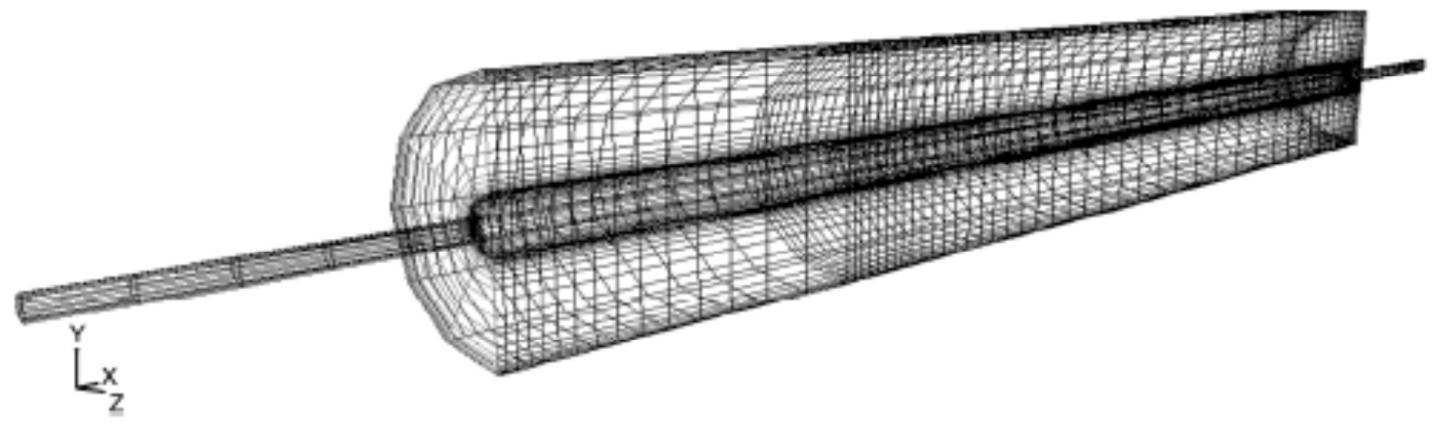

Figura 15: Malha gerada por Park (2003) para estudo de reação WGS em CMR.

Afirma-se aqui, portanto, que comparativamente a malhas utilizadas por outros últimos autores, desenvolveu-se aqui uma estrutura de malha anisotrópica, com nível de refinamento que propicia comparação de todas as imperfeições e ao mesmo tempo impõe escoamentos sem desvios decorrentes de erros de malhas, incluindo elementos hexagonais, tetraédricos e prismáticos onde necessários. Além das últimas versões do software comercial facilitarem esta construção, o resultado dessa malha final vem de um processo de estudo e elaboração que é descrito brevemente a seguir.

\subsubsection{Versões preliminares}

Conforme mencionando anteriormente, no capítulo sobre domínio computacional, foram realizados alguns estudos preliminares.

Nessas versões, foram obtidas malhas grosseiras e simplificadas, similares aos modelos encontrados em literatura. Determinou-se, no entanto, que os fenômenos 
de interesse para o trabalho não seriam detectáveis com tais malhas, devido ao seu alto grau de dependência numérica ao elemento em três dimensões.

As malhas dessa etapa preliminar ficaram sempre com um número de elementos tridimensionais cerca de dez vezes menor do que o das malhas finais adotadas para o estudo.

Como os casos preliminares foram simulados em computador escasso recursos favoráveis ao uso de software de CFD, o tempo de processamento foi muito longo e dificultou significativamente a possibilidade de se testar soluções para a questão da razão de aspecto intrínseca da geometria do reator.

\subsubsection{Versão final}

Completando a etapa de pré-processamento, a leitura dos dados geométricos e topológicos do domínio pela ferramenta selecionada dá início ao processo de geração da malha de volumes finitos.

Conforme se pode concluir a partir das dimensões apresentadas no capítulo 2.2, uma das características fundamentais da geometria da membrana estudada é sua alta razão de aspecto: o comprimento da membrana corresponde a mais de 75 vezes seu diâmetro externo e a exatamente 440 vezes sua espessura. Sob o aspecto do balanço entre qualidade de resultados e custo computacional, essa característica deve ser levada em conta para se obter uma malha que seja suficientemente refinada na direção radial, mas que, por outro lado, não represente refinamento excessivo na direção axial, causando apenas prolongamento do período até convergência.

Diante das considerações apresentadas, gerou-se malha anisotrópica, com observância à necessidade de refinamento nas seguintes regiões:

- Membrana porosa, na totalidade de sua espessura, onde se estabelecem elevados gradientes de concentração e velocidade; 
- Canal central da membrana, também em sua totalidade, devido ao pequeno diâmetro do canal e decorrente proximidade do fluido às paredes;

- Região do fluido no interior do casco próximo à membrana, dada a presença de interface;

- Região do fluido no interior do casco próximo às paredes do casco, com vistas a considerar adequadamente a presença de camada limite.

A malha computacional gerada foi composta de regiões estruturadas e nãoestruturadas, incluindo elementos hexagonais, tetraédricos e prismáticos.

O método de varredura (Sweep) foi adotado nas regiões passíveis de varredura (sweepable): canal da membrana e membrana, regiões em que toda a malha foi formada por elementos hexagonais, para os quais se obtém alta resolução com relativamente baixo número de células. Conforme documentação específica, um volume pode ter sua malha desenhada por esse método caso preencha os seguintes requisitos:

- Presença de, no máximo, um conjunto de faces continuamente conectadas no corpo.

- Ausência de vazios completamente contidos no corpo.

- Inexistência de par de faces no corpo que sejam opostas uma à outra na topologia do corpo e tenham arestas conectando cada um dos primeiros vértices da face com os segundos vértices das faces (em outras palavras, não pode haver uma face que seja origem, source, e destino, target, simultaneamente).

- Presença de um controle de tamanho utilizado em corpo com tamanho rígido de aresta, mais presença de faces origem e destino que contenham divisões rígidas que não sejam as mesmas para as respectivas arestas.

Esse método de geração de malha oferece a vantagem de resultar em menor número de nós e elementos do que os demais métodos, além de requerer tempo relativamente curto para ser processado. 
A fim de garantir a uniformidade da malha na região da membrana, tanto no canal como meio poroso, considerada relevante em decorrência das pequenas dimensões no sentido radial, a zona porosa da membrana e seu canal central foram divididos em subdomínios. Inicialmente, foi realizada uma blocagem da geometria. Para tanto, desenhou-se duto quadrado no centro da membrana como subdomínio auxiliar, somente para a geração de malhas. A partir do elemento central, dividiu-se na direção angular o restante do canal e a membrana em quatro unidades idênticas. Para cada uma dessas unidades foi definido um número específico de divisões das arestas, através da ferramenta de definição de tamanho (Sizing). Ao elemento central aplicou-se a ferramenta de malha $\mathrm{O}$ (Ogrid). As divisões definidas são apresentadas na Tabela 9:

Tabela 9: Subdomínios de malha e volume médio das células obtidas.

\begin{tabular}{l|l|l|l}
\hline Subdomínio & $\begin{array}{l}\text { Formato e número de } \\
\text { divisões radiais ou x/y }\end{array}$ & $\begin{array}{l}\text { Número de divisões } \\
\text { longitudinais }\end{array}$ & $\begin{array}{l}\text { Volume médio da } \\
\text { célula }\left(\mathbf{m m}^{3}\right)\end{array}$ \\
\hline $\begin{array}{l}\text { Duto de blocagem no } \\
\text { canal central da } \\
\text { membrana }\end{array}$ & $\begin{array}{l}\text { Duto quadrado } \\
10 \text { divisões }\end{array}$ & $\begin{array}{l}600 \text { divisões* }^{*} \\
1.200 \text { divisões }^{* *}\end{array}$ & $\begin{array}{l}6,60 \mathrm{E}-04^{*} \\
6,60 \mathrm{E}-04^{* *}\end{array}$ \\
\hline $\begin{array}{l}\text { Região entre duto de } \\
\text { blocagem e meio poroso } \\
\text { no canal central da } \\
\text { membrana }\end{array}$ & $\begin{array}{l}\text { Cilindro externo com } \\
\text { duto extraído do interior }\end{array}$ & $\begin{array}{l}600 \text { divisões* }^{*} \\
12 \text { divisões }\end{array}$ & $\begin{array}{l}6,23 \mathrm{E}-04^{*} \\
6,23 \mathrm{E}-04^{* *}\end{array}$ \\
\hline $\begin{array}{l}\text { Região porosa da } \\
\text { membrana }\end{array}$ & $\begin{array}{l}\text { Cilindro oco } \\
10 \text { divisões }\end{array}$ & $\begin{array}{l}600 \text { divisões }^{*} \\
1.200 \text { divisões }^{* *}\end{array}$ & $\begin{array}{l}1,73 \mathrm{E}-03^{*} \\
1,27 \mathrm{E}-03^{* *}\end{array}$ \\
\hline $\begin{array}{l}\text { Fluido entre casco e } \\
\text { membrana }\end{array}$ & $\begin{array}{l}\text { Malha tetraédrica com } 8 \\
\text { camadas de prismática }\end{array}$ & $\begin{array}{l}600 \text { divisões* }^{*} \\
1.200 \text { divisões }^{* *}\end{array}$ & $\begin{array}{l}3,35 \mathrm{E}-02^{*} \\
3,24 \mathrm{E}-02^{* *}\end{array}$ \\
\hline
\end{tabular}

Para a região do fluido entre a membrana e casco foi adotado método de conformação ao caminho (Patching Conforming), de malha não-estruturada, tetraédrica. Esse método mostrou-se conveniente para a região por ser rapidamente gerado adequando-se à assimetria do corpo e pelo fato de o escoamento no casco apresentar pequenos gradientes e, portanto, requerer relativamente baixo refinamento de malha. 
A ferramenta de refinamento (Inflation) foi utilizada na região do fluido no casco para definir refinamento nas interfaces na direção radial, com taxa de crescimento de 1,4. Com isso, pôde-se obter uma malha mais adequada às regiões de camada limite de transição turbulenta.

A malha gerada para a geometria real, apresentada na Figura 14, resultou em 3.354.119 células.

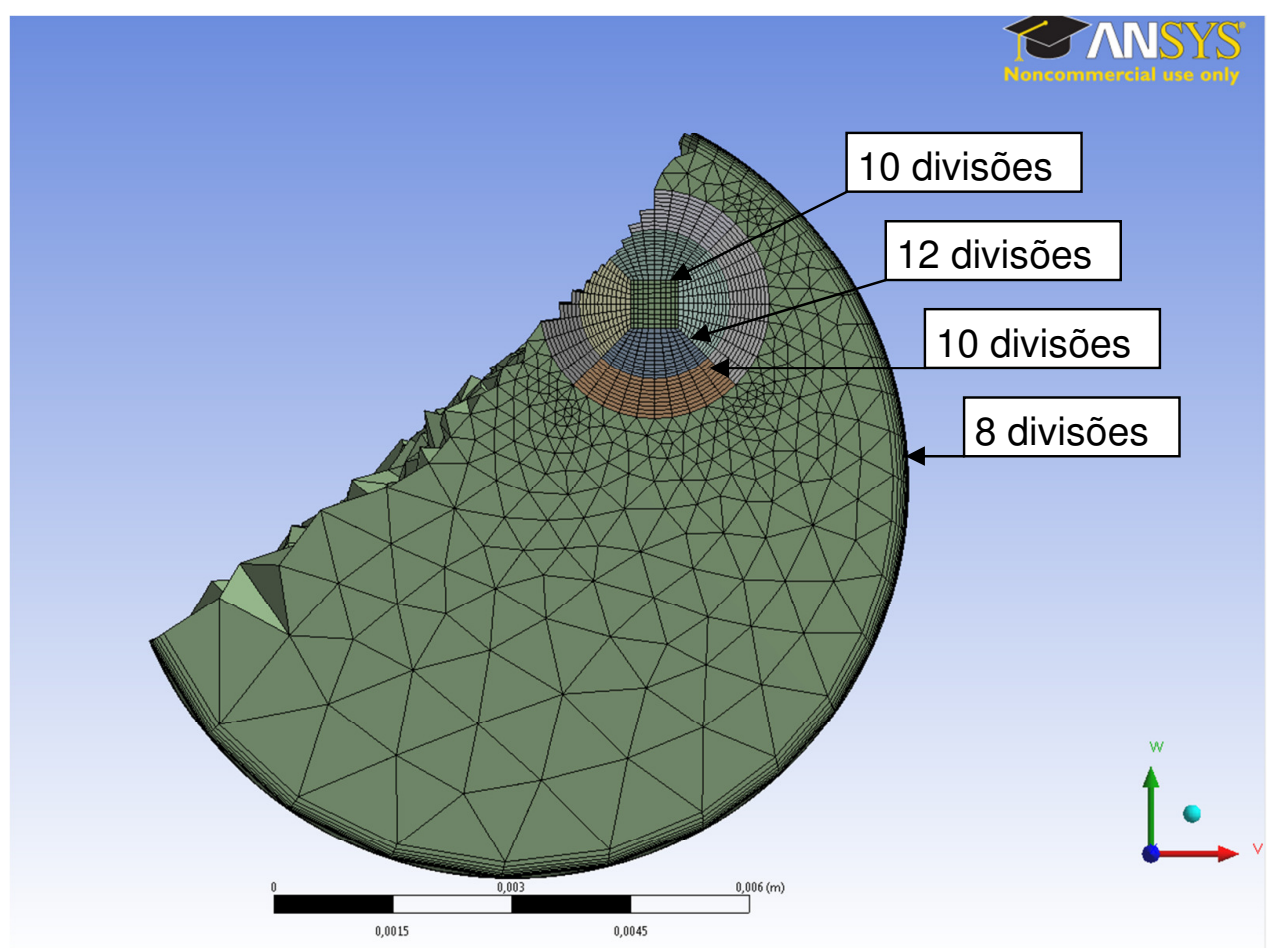

Figura 16: Malha gerada no ANSYS Meshing,com 3.354.119 células para geometria equivalente ao equipamento real, com saída única.

A malha gerada, apresentada na Figura 17, resultou em 1.477.391 células. 


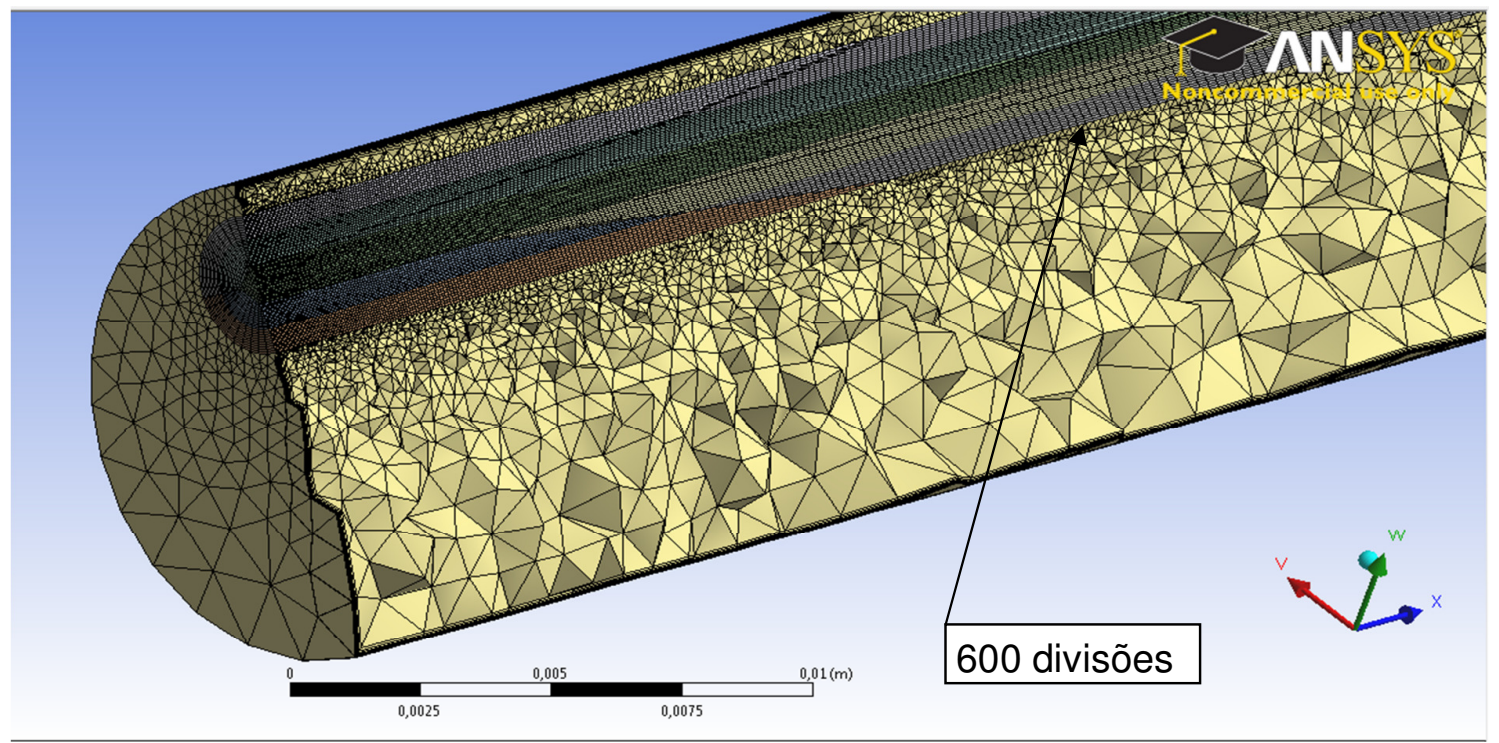

Figura 17: Malha gerada no ANSYS Meshing, com 1.477.391 células para geometria modificada, com saída dupla.

Através das figuras apresentadas, observa-se que foi obtida uma malha plenamente uniforme na região de máximos gradientes, correspondente à membrana, e que responde aos gradientes esperados localmente nas demais regiões.

Ainda no ambiente do gerador de malhas, ANSYS DesignModeler, é possível definir regiões nomeadas, Named Selections, para as quais serão definidas as condições de contorno do problema, em etapa posterior. Caso os nomes informados sejam similares a qualquer dos tipos disponíveis de condições de contorno, o software CFD automaticamente atribui tais condições às regiões nomeadas, durante a leitura da malha. Assim, no modelo do reator de membrana, foram nomeadas as seguintes seleções:

Tabela 10: Seleções nomeadas no caso para geometria real.

\begin{tabular}{l|l|l}
\hline Nome da seleção & $\begin{array}{l}\text { Identificação das faces } \\
\text { incluídas }\end{array}$ & $\mathbf{N}^{\circ}$ de faces incluídas \\
\hline $\begin{array}{l}\text { velocity_inlet } \\
\text { (velocidade de entrada) }\end{array}$ & $\begin{array}{l}\text { Face do canal da } \\
\text { membrana, visto de }+Z\end{array}$ & 5 faces \\
\hline $\begin{array}{l}\text { velocity_inlet } \\
\text { (velocidade de entrada) }\end{array}$ & $\begin{array}{l}\text { Face do canal da } \\
\text { membrana, visto de }-Z\end{array}$ & 5 faces \\
\hline
\end{tabular}




\begin{tabular}{l|l|l}
\hline $\begin{array}{l}\text { wall } \\
\text { (parede) }\end{array}$ & $\begin{array}{l}\text { Espessura da membrana, } \\
\text { extremidade }+Z\end{array}$ & 4 faces \\
\hline $\begin{array}{l}\text { wall } \\
\text { (parede) }\end{array}$ & $\begin{array}{l}\text { Fluido no casco, } \\
\text { extremidade }+Z\end{array}$ & 1 face \\
\hline $\begin{array}{l}\text { wall } \\
\text { parede) }\end{array}$ & $\begin{array}{l}\text { Espessura da membrana, } \\
\text { extremidade }-Z, \text { simetria }\end{array}$ & 4 faces \\
\hline $\begin{array}{l}\text { wall } \\
\text { (parede) }\end{array}$ & $\begin{array}{l}\text { Fluido no casco, } \\
\text { extremidade }-Z, \text { simetria }\end{array}$ & 1 face \\
\hline $\begin{array}{l}\text { wall } \\
\text { (parede) }\end{array}$ & $\begin{array}{l}\text { Fluido no casco, face } \\
\text { cilíndrica }\end{array}$ & 1 face \\
\hline $\begin{array}{l}\text { pressure_outlet } \\
\text { (pressão de saída) }\end{array}$ & Orifício de saída & 1 face \\
\hline
\end{tabular}


Tabela 11: Seleções nomeadas no caso para geometria modificada.

\begin{tabular}{l|l|l}
\hline Nome da seleção & $\begin{array}{l}\text { Identificação das faces } \\
\text { incluídas }\end{array}$ & $\mathbf{N}^{\circ}$ de faces incluídas \\
\hline $\begin{array}{l}\text { velocity_inlet } \\
\text { (velocidade de entrada) }\end{array}$ & $\begin{array}{l}\text { Face do canal da } \\
\text { membrana, visto de }+Z\end{array}$ & 5 faces \\
\hline $\begin{array}{l}\text { wall } \\
\text { (parede) }\end{array}$ & $\begin{array}{l}\text { Face do canal da } \\
\text { membrana, visto de }-Z\end{array}$ & 5 faces \\
\hline $\begin{array}{l}\text { wall } \\
\text { (parede) }\end{array}$ & $\begin{array}{l}\text { Espessura da membrana, } \\
\text { extremidade }+Z\end{array}$ & 4 faces \\
\hline $\begin{array}{l}\text { wall } \\
\text { (parede) }\end{array}$ & $\begin{array}{l}\text { Fluido no casco, } \\
\text { extremidade }+Z\end{array}$ & 1 face \\
\hline $\begin{array}{l}\text { wall } \\
\text { (parede) }\end{array}$ & $\begin{array}{l}\text { Espessura da membrana, } \\
\text { extremidade }-Z, \text { simetria }\end{array}$ & 4 faces \\
\hline $\begin{array}{l}\text { wall } \\
\text { (parede) }\end{array}$ & $\begin{array}{l}\text { Fluido no casco, } \\
\text { extremidade }-Z, \text { simetria }\end{array}$ & 1 face \\
\hline $\begin{array}{l}\text { wall } \\
\text { (parede) }\end{array}$ & $\begin{array}{l}\text { Fluido no casco, face } \\
\text { cilíndrica }\end{array}$ & 1 face \\
\hline $\begin{array}{l}\text { pressure_outlet } \\
\text { (pressão de saída) }\end{array}$ & \begin{tabular}{l} 
Orifício de saída \\
\hline
\end{tabular} & 1 face \\
\hline
\end{tabular}

\subsection{Escolha do modelo de turbulência}

A escolha do modelo de turbulência a ser utilizado depende de considerações quanto às características físicas pertinentes ao escoamento estudado, à prática estabelecida para determinada classe de problemas, o nível requerido de acurácia, os recursos computacionais disponíveis e o tempo total disponível para a simulação (ANSYS 12.0 User's Guide).

Um refinamento do modelo $k-\varepsilon$ padrão foi desenvolvido a partir de uma rigorosa técnica estatística (teoria do grupo de renormalização, ReNormalization Group Theory), resultando no modelo RNG $k-\varepsilon$, dotado das seguintes melhorias comparativamente ao modelo $k-\varepsilon$ padrão, que o tornam aplicável ao sistema estudado: 
Dentre os modelos de turbulência disponibilizados no código comercial adotado, aquele que apresenta o menor custo computacional é o Spalart-Allmaras, baseado em apenas uma equação de transporte. A aplicação desse modelo para o caso estudado foi descartada por duas razões (ANSYS 12.0 Theory Guide):

- Spalart-Allmaras não é confiável para predições de turbulência homogênea e isotrópica, como se espera observar nas diferentes regiões da membrana;

- O modelo não responde adequadamente a mudanças bruscas na escala de comprimento, como ocorre na passagem do canal da membrana para a zona porosa e, finalmente, para o interior do casco.

Considera-se aqui como forma simples os modelos de turbulência $k-\varepsilon$ baseados na solução de duas equações de transporte: uma para a energia cinética turbulenta $(k)$ e outra para sua taxa de dissipação $(\varepsilon)$. O modelo $k-\varepsilon$ padrão foi desenvolvido com base na hipótese de escoamento totalmente turbulento e despreza efeitos de viscosidade molecular (ANSYS 12.0 Theory Guide), sendo, portanto, inadequado para o reator estudado.

Um refinamento do modelo $k-\varepsilon$ padrão foi desenvolvido a partir de uma rigorosa técnica estatística (teoria do grupo de renormalização, ReNormalization Group Theory), resultando no modelo RNG $k-\varepsilon$, dotado das seguintes melhorias comparativamente ao modelo padrão, que o tornam aplicável ao sistema estudado:

- O modelo RNG apresenta um termo na sua equação $\varepsilon$, que melhora significativamente a acurácia para escoamentos submetidos a rápida deformação.

- Enquanto que o $k-\varepsilon$ padrão é um modelo para alto número de Reynolds, a teoria RNG fornece uma fórmula diferencial derivada analiticamente para viscosidade efetiva, levando em consideração efeitos de baixo número de Reynolds.

Devido ao fato de ser comumente aplicado para escoamentos reativos e como uma forma de implementação mais elaborada de modelagem CFD, o modelo $k-\omega$ chegou a ser considerado e aplicado no presente estudo, em suas versões padrão e SST 
(Shear Stress Transport, transporte da tensão de cisalhamento), porém somente proporcionou resultados bem sucedidos no caso de escoamento não-reativo. Após ter sido ativado o modelo de reação e transporte de espécies, o modelo resultou em divergência em $k$, como pode ser observado na Figura 18.

Em decorrência dos fatores apresentados na discussão acima, em particular as vantagens de modelos de duas equações e o insucesso da aplicação do $k-\omega$ no caso estudado de membrana, adotou-se definitivamente o modelo RNG $k-\varepsilon$ nas simulações realizadas no presente trabalho. Esse foi o modelo adotado por Rahimi et al. (2009), em estudos experimentais e de CFD sobre a obstrução por incrustações em membrana de microfiltração.

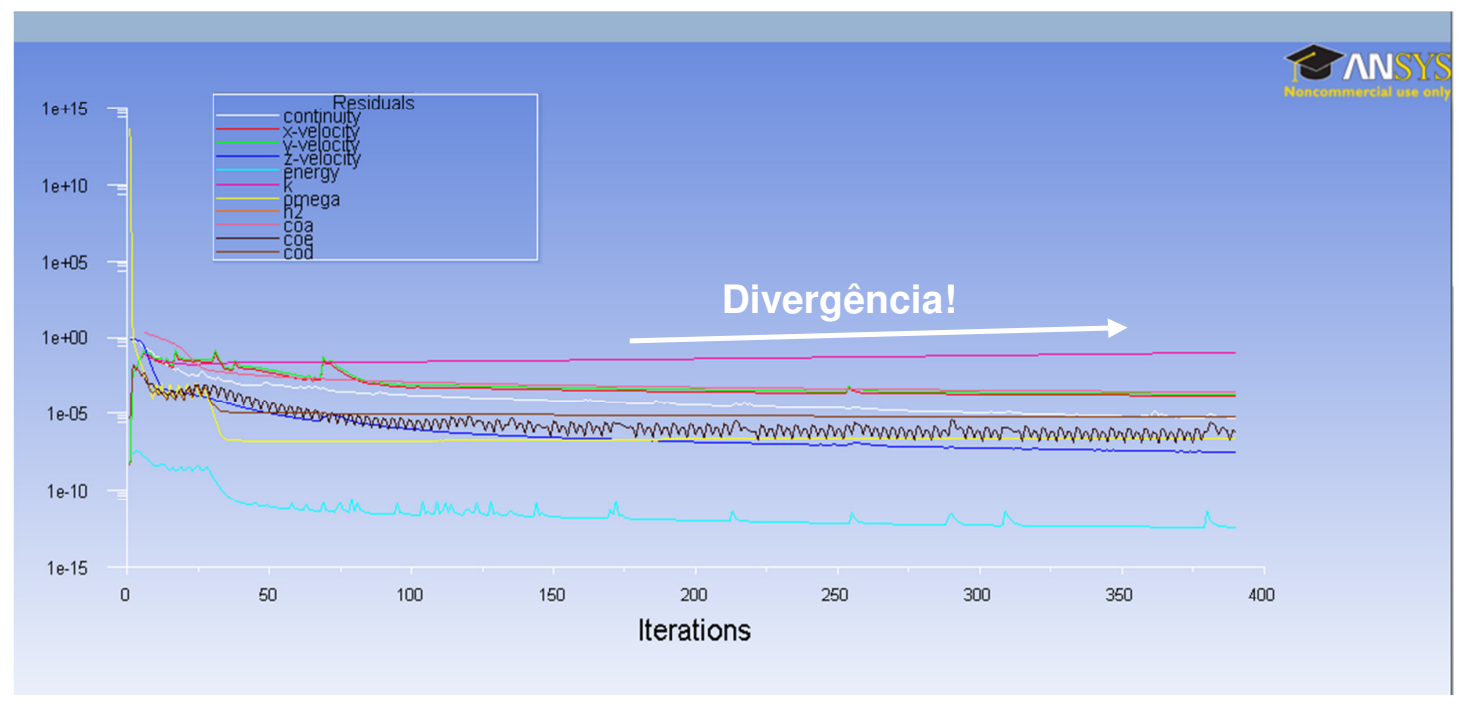

Figura 18: Resíduos em escala obtidos em simulação de reação e transporte de espécies no reator de membrana, com modelo $k-\omega$, descartado por divergir. 


\subsection{Propriedades físicas dos compostos}

Para a inclusão de modelo de reação e transporte de espécies, o software adotado apresenta interface específica, a qual conta com banco de dados de propriedades de diversos compostos, entre eles o hidrogênio, por exemplo. Para compostos não listados no banco de dados, o programa apresenta interface para definição de novos compostos. As propriedades adotadas para cada um dos compostos presentes no sistema estudado são apresentadas na Tabela 12, a seguir:

Tabela 12: Propriedades dos compostos presentes no sistema estudado.

\begin{tabular}{|c|c|c|c|c|c|}
\hline & $\begin{array}{l}\mathrm{n}- \\
\text { heptano }^{2,3,4}\end{array}$ & $\operatorname{COD}^{5,6}$ & $\operatorname{COE} 4^{, 6}$ & $\operatorname{coA} 4^{, 6}$ & $\mathrm{H}_{2}{ }^{7}$ \\
\hline Densidade $\left(\mathrm{kg} / \mathrm{m}^{3}\right)$ & 702 & 882 & 846 & 834 & 0,08189 \\
\hline $\begin{array}{l}\text { Cp (Calor } \\
\text { específico) } \\
(\mathrm{J} / \mathrm{kg} . \mathrm{K})\end{array}$ & 2.679 & 1.616 & 1.886 & 1.909 & 14.283 \\
\hline $\begin{array}{l}\text { Condutividade térmica } \\
(\mathrm{W} / \mathrm{m} . \mathrm{K})\end{array}$ & 0,140 & $--^{8}$ & ---8 & ---8 & 0,1672 \\
\hline Viscosidade (kg/m.s) & $7,4 \times 10^{-4}$ & ---8 & ---8 & ---8 & $8,411 \times 10^{-6}$ \\
\hline $\begin{array}{l}\text { Peso molecular } \\
\text { (kg/kgmol) }\end{array}$ & 100,2 & 108,18 & 110,1968 & 112,2126 & 2,01594 \\
\hline $\begin{array}{l}\text { Entalpia no estado } \\
\text { padrão (J/kgmol) }\end{array}$ & 188,5 & $2,4 \times 10^{7}$ & $1,23 \times 10^{8}$ & $1,6945 \times 10^{8}$ & 0 \\
\hline $\begin{array}{l}\text { Entropia no estado } \\
\text { padrão (J/kgmol.K) }\end{array}$ & 328 & $2,5 \times 10^{5}$ & $2,545 \times 10^{5}$ & $2,62 \times 10^{5}$ & $1,306 \times 10^{5}$ \\
\hline $\begin{array}{l}\text { Temperatura de } \\
\text { referência }(K)\end{array}$ & 298,15 & 298,15 & 298,15 & 298,15 & 298,15 \\
\hline
\end{tabular}

${ }^{2}$ Engineers Edge: http://www.engineersedge.com/fluid flow/fluid data.htm

${ }^{3}$ Engineering Toolbox: http://www.engineeringtoolbox.com/thermal-conductivity-liquids-d 1260.html

${ }^{4}$ Cheméo High Quality Chemical Properties: http://chemeo.com/cid/36-653-7, http://chemeo.com/cid/55-220-6

${ }^{5}$ Fischer Scientific:

https://ecat.fishersci.ca/\%28S\%28b54e30udu0q3zwimenohur55\%29\%29/ViewMSDS.aspx?cat=AC406115000

6 NIST National Institute of Standards and Technology: http://webbook.nist.gov/cgi/cbook.cgi?ID=C111784\&Mask=2, http://webbook.nist.gov/cgi/cbook.cgi?ID=C931884\&Units=SI\&Mask=7

${ }^{7}$ Banco de dados do ANSYS FLUENT.

${ }^{8}$ Dado que a condutividade térmica a quantidade dos reagentes e produtos relativamente à quantidade de solvente é pequena e o modelo adotado é isotérmico, a condutividade térmica e a viscosidade de reagentes e produtos são admitidas iguais às do solvente. 


\subsection{Parâmetros da mistura reacional}

A definição da mistura reacional, denominada mistura-padrão (mixture-template) no código comercial de CFD utilizado neste trabalho é realizada através de interface específica para indicação dos componentes presentes no sistema. A inclusão de componentes deve ser realizada de forma que o componente presente em maior concentração seja o último a ser incluído. Isso se deve ao fato de o programa adotar como solvente o último composto informado. Em observância a esse preceito, as espécies presentes na mistura reacional foram indicadas na seguinte ordem: $\mathrm{H}_{2}$, COD, COE, COA, n-heptano.

Quanto às propriedades físicas da mistura, foram utilizados os valores apresentados na Tabela 13:

Tabela 13: Parâmetros adotados na definição da mistura reacional no código CFD

\begin{tabular}{c|c}
\hline Densidade & $\begin{array}{c}\text { Lei de mistura por peso ponderado } \\
\text { (volume-weighted mixing law) }\end{array}$ \\
\hline Condutividade térmica & $\begin{array}{c}1,40 \mathrm{e}-01 \mathrm{~W} / \mathrm{m} \mathrm{K} \\
\text { (igual à do solvente, } \mathrm{n} \text {-heptano) }\end{array}$ \\
\hline Viscosidade (dinâmica) & $\begin{array}{c}7,4 \mathrm{e}-04 \mathrm{~kg} / \mathrm{m} \mathrm{s} \\
\text { (igual à do solvente, } \mathrm{n} \text {-heptano) }\end{array}$ \\
\hline Difusividade mássica - método & $\begin{array}{c}\text { Aproximação por constante em meio diluído } \\
\text { (constant dilute approximation) }\end{array}$ \\
\hline Difusividade mássica - valor & $\begin{array}{c}4,12 \mathrm{e}-09 \mathrm{~m} \mathrm{~m}^{2} \mathrm{~s} \\
\text { (auto-difusividade do solvente, n-heptano) }\end{array}$ \\
\hline
\end{tabular}

Com relação à difusividade mássica, a documentação do software utilizado recomenda a adoção do método de aproximação por constante em meio diluído, caracterizado pela presença de fluido "transportador" dos demais componentes, estes presentes em concentrações relativamente baixas.

O valor adotado foi o da auto-difusividade de n-heptano, obtido de Fishman (1955). 


\subsection{Definição das reações no código comercial de CFD}

Conforme mencionado no item anterior, adotou-se modelo simplificado, sem considerar cobertura de superfície, apenas para se obter informações qualitativas sobre o comportamento geral do reator diante de alterações no escoamento.

Dessa forma, a reação foi definida utilizando-se diretamente a interface para entrada de reação de Arrhenius. Os parâmetros adotados, obtidos de Schmidt (2007), são apresentados na Tabela 14:

Tabela 14: Dados empregados na definição das reações no ANSYS FLUENT

\begin{tabular}{|c|c|c|}
\hline & Reação 1 & Reação 2 \\
\hline Nome & cod-coe & coe-coa \\
\hline Tipo & $\begin{array}{l}\text { Reação de superfície } \\
\text { (Wall Surface) }\end{array}$ & $\begin{array}{l}\text { Reação de superfície } \\
\text { (Wall Surface) }\end{array}$ \\
\hline Reagentes & $\begin{array}{l}\mathrm{H}_{2} \\
\mathrm{COD}\end{array}$ & $\begin{array}{l}\mathrm{H}_{2} \\
\mathrm{COE}\end{array}$ \\
\hline Produtos & COE & $\mathrm{COA}$ \\
\hline $\begin{array}{l}\text { Coeficientes } \\
\text { estequiométricos }\end{array}$ & $\begin{array}{l}\mathrm{H}_{2}: 1 \\
\text { COD: } 1 \\
\text { COE: } 1\end{array}$ & $\begin{array}{l}\mathrm{H}_{2}: 1 \\
\text { COE: } 1 \\
\text { COA: } 1\end{array}$ \\
\hline $\begin{array}{l}\text { Modificação da } \\
\text { equação de } \\
\text { Arrhenius }\end{array}$ & $\begin{array}{l}\text { Fator pré-exponencial: } \\
\qquad 1,94 \mathrm{e}+09 \mathrm{~mol} \cdot \mathrm{mg}_{\mathrm{Pd}}{ }^{-1} \cdot \mathrm{s}^{-1} \\
\text { Energia de ativação: } 7,4 \mathrm{e}+07 \mathrm{~J} / \mathrm{kgmol} \\
\text { Expoente de temperatura: } 1\end{array}$ & $\begin{array}{l}\text { Fator pré-exponencial: } \\
\qquad 1,85 \mathrm{e}+11 \mathrm{~mol} \cdot \mathrm{mg}_{\mathrm{Pd}}{ }^{-1} \cdot \mathrm{s}^{-1} \\
\text { Energia de ativação: } 9,8 \mathrm{e}+07 \mathrm{~J} / \mathrm{kgmol} \\
\text { Expoente de temperatura: } 1\end{array}$ \\
\hline
\end{tabular}

\subsection{Condições de zonas de células}

Em termos de escoamento e reações, podem-se identificar três diferentes regiões com características uniformes:

- Canal central da membrana

- Zona porosa da membrana

- Fluido entre membrana e casco 
Para cada uma delas, definem-se no software CFD as chamadas condições de zonas de células (cell zone conditions). As zonas de células consistem de fluidos e sólidos, com meios porosos sendo definidos como zona fluida. As condições adotadas para cada uma das regiões são apresentadas a seguir:

\subsubsection{Canal central da membrana}

\subsubsection{Reação e transporte de espécies}

No canal central da membrana, foi definida a ausência de reação, compatível com o dado conhecido de que a reação só se dá na presença de catalisador e, portanto, somente em contato com nanopartículas de Pd impregnadas na membrana.

\subsubsection{Valores fixos}

Como decorrência do fato de não ocorrer reação nessa zona de células, a concentração é fixa para todas as espécies nessa região. Esse conhecimento prévio pode ser informado na interface do programa, economizando tempo de computação. As concentrações fixadas - informadas como fração mássica - correspondem ao valor inicial da corrente de entrada de fluido, apresentadas na Tabela 15:

Tabela 15: Concentração inicial das espécies.

\begin{tabular}{lccccc} 
& n-heptano & COD & COE & COA & $\mathbf{H}_{\mathbf{2}}$ \\
\hline $\begin{array}{l}\text { Volume inicial } \\
(\mathrm{mL})\end{array}$ & 104,5 & 5,5 & 0 & 0 & 2,36 \\
\hline $\begin{array}{l}\text { Densidade } \\
\left(\mathbf{k g} / \mathbf{m}^{3}\right)\end{array}$ & 702 & 882 & 846 & 834 & 0,08189 \\
\hline $\begin{array}{l}\text { Pressão inicial } \\
\text { (bar) }\end{array}$ & --- & --- & -- & --- & 10 \\
\hline $\begin{array}{l}\text { Solubilidade } \\
\text { (vol/vol) }\end{array}$ & --- & --- & -- & 0,0214 \\
\hline $\begin{array}{l}\text { Massa inicial (g) } \\
\text { Fração mássica }\end{array}$ & 73,36 & 4,85 & 0 & 0 & $1,93 \times 10^{-4}$ \\
inicial & $9,380 \times 10^{-1}$ & $6,203 \times 10^{-2}$ & 0 & 0 & $2,465 \times 10^{-6}$ \\
\hline
\end{tabular}


Os dados apresentados na Tabela 15 têm por referência a Tabela 12, de propriedades dos compostos, e a Tabela 4 , de dados experimentais.

\subsubsection{Zona porosa da membrana}

Nessa região do sistema, duas definições fazem-se necessárias: parâmetros da porosidade, opção pela ativação ou inativação do cálculo de turbulência, e ativação da ocorrência de reação e transporte de espécies.

\subsubsection{Parâmetros de porosidade}

O modelo de meios porosos do ANSYS FLUENT consiste da aplicação de uma perda de carga no escoamento, determinada através de parâmetros informados para tal. Nesse modelo, transporte de calor pode ser avaliado, porém com a restrição de que se parte do pressuposto de equilíbrio térmico entre meio poroso e escoamento. A modelagem se dá através da imposição de uma resistência ao escoamento empiricamente determinada, correspondendo ao acréscimo de um termo-fonte de momento nas equações que governam o modelo, apresentadas a seguir.

Meios porosos são modelados no software pela adição de um termo-fonte às equações padrão de escoamento. O termo-fonte é composto de duas partes, apresentadas na equação (37):

$$
\overbrace{\begin{array}{l}
\text { Termo de perda } \\
\text { viscosa }
\end{array}}^{S_{i}=-\left(\sum_{j=1}^{3} D_{i j} \mu v_{j}+\sum_{j=1}^{3} C_{i j} \frac{1}{2} \rho|v| v_{j}\right)} \overbrace{\begin{array}{c}
\text { Termo de perda } \\
\text { inercial }
\end{array}}^{-}
$$

Onde $S_{i}$ é o termo-fonte para a i-ésima equação de momento $(x, y$, ou $z),|v|$ é a magnitude da velocidade e $D$ e $C$ são matrizes. Essa perda de momento contribui para o gradiente de pressões na célula porosa, gerando uma perda de carga proporcional à velocidade do fluido na célula. 
Para o caso simples de meios porosos homogêneos, a equação (37) resulta na expressão simples apresentada na equação (38):

$$
\begin{aligned}
& S_{i}=-\left(\frac{\mu}{\alpha} v_{i}+C_{2} \frac{1}{2} \rho|v| v_{i}\right)
\end{aligned}
$$

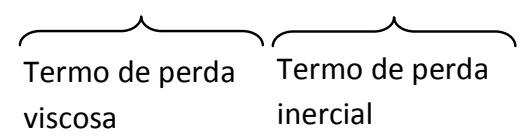

onde $\alpha$ é a permeabilidade e $C_{2}$ é o fator de resistência inercial.

Para definição do meio poroso, basta especificar $D$ e $C$ como matrizes diagonais $1 / \alpha$ e $C_{2}$, respectivamente, nas diagonais (e zero para todos os outros elementos).

Em escoamentos laminares, a perda de carga é tipicamente proporcional à velocidade e o fator de resistência inercial $C_{2}$ pode ser considerado zero, o que reduz o modelo à Lei de Darcy. A resistência $C_{2}$ corresponde a um coeficiente de perda por unidade de comprimento ao longo da direção de escoamento.

O código utilizado também permite que o termo-fonte seja modelado como lei de potência a partir da magnitude de velocidade, conforme equação (39), resultando em perda de carga isotrópica:

$$
S_{i}=-C_{0}|v|^{C_{1}}=-C_{0}|v|^{\left(C_{1}-1\right)} v_{i}
$$

Onde $C_{0}$ e $C_{1}$ são coeficientes empíricos definidos pelo usuário.

No presente trabalho, a porosidade foi modelada utilizando-se a equação (38). Os parâmetros de resistência inercial e resistência viscosa foram determinados por aproximação da membrana a leito fixo, definido pela equação de Ergun (40):

$$
\frac{|\Delta p|}{L}=\frac{150 \mu}{D_{p}{ }^{2}} \frac{(1-\varepsilon)^{2}}{\varepsilon^{3}} v_{\infty}+\frac{1.75 \rho}{D_{p}} \frac{(1-\varepsilon)}{\varepsilon^{3}} v_{\infty}^{2}
$$

Onde 
$\Delta p:$ perda de carga

$L$ : comprimento do leito (espessura da membrana, neste caso)

$\mu$ : viscosidade

$D_{p}$ : diâmetro médio das partículas

$\varepsilon$ : porosidade

$v_{\infty}$ : velocidade bulk

Comparando-se a equação de Ergun (40) à equação (38), tem-se para o inverso da resistência viscosa a equação (41):

$$
\alpha=\frac{D_{p}{ }^{2}}{150} \frac{\varepsilon^{3}}{(1-\varepsilon)^{2}}
$$

E para a resistência inercial a equação (42):

$$
C_{2}=\frac{3.5}{D_{p}} \frac{(1-\varepsilon)}{\varepsilon^{3}}
$$

A porosidade, $\varepsilon$, da membrana estudada tem valor conhecido, obtido de Schmidt (2007), igual a $30 \%$.

Para determinação do tamanho de grão das partículas de alumínio, foi utilizado o software open source de estereologia ImageJ, do National Institute of Health, USA, conforme utilizado por Harimkar e Dahotre (2006), a partir de imagem de microscopia eletrônica de varredura (SEM, scanning electron microscopy), obtida de Schmidt (2007), ilustrada na Figura 19 e Figura 20. 


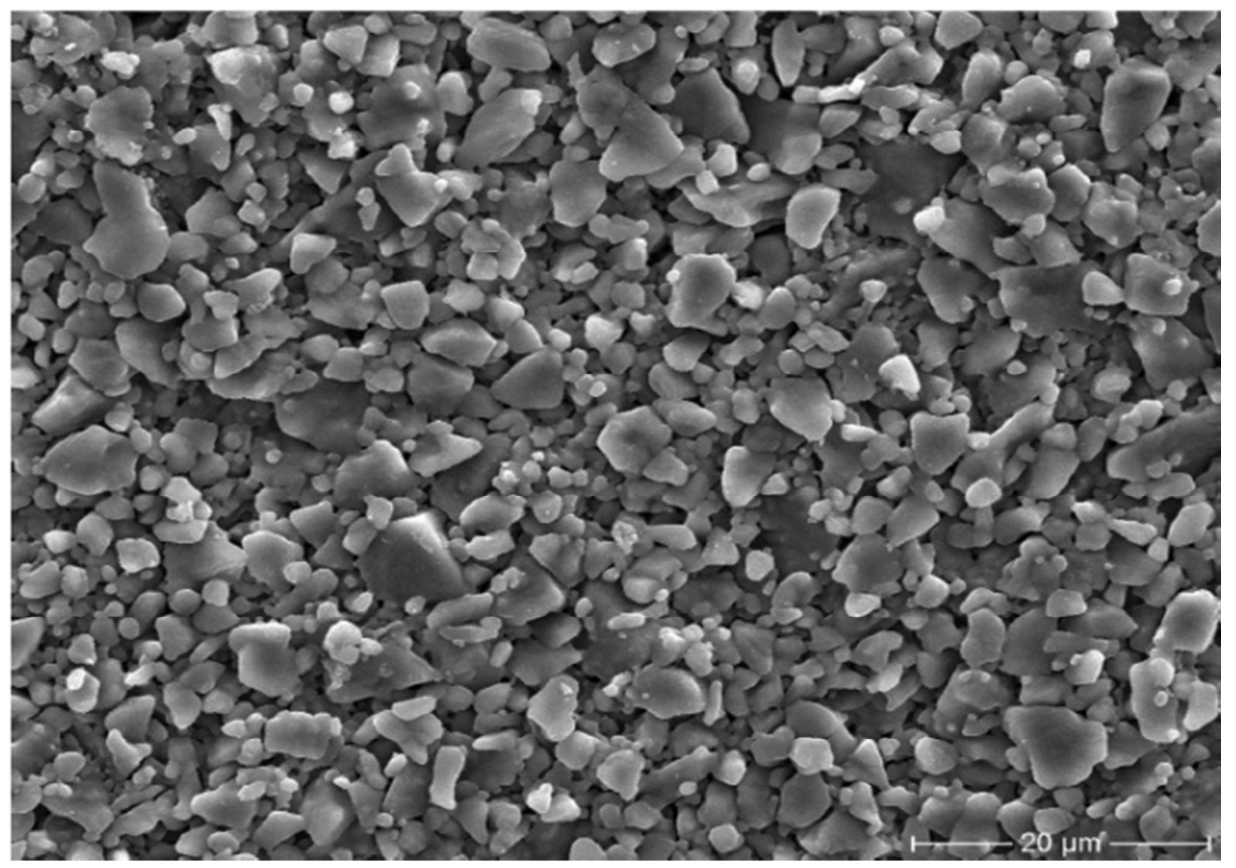

Figura 19: Imagem de SEM do interior da membrana.

Ao ser importada pelo software, a imagem primeiramente recebeu tratamento para resultar no contraste e delineação adequada de fronteiras para leitura e identificação dos grãos pelo programa. A imagem obtida é exibida na Figura 20.

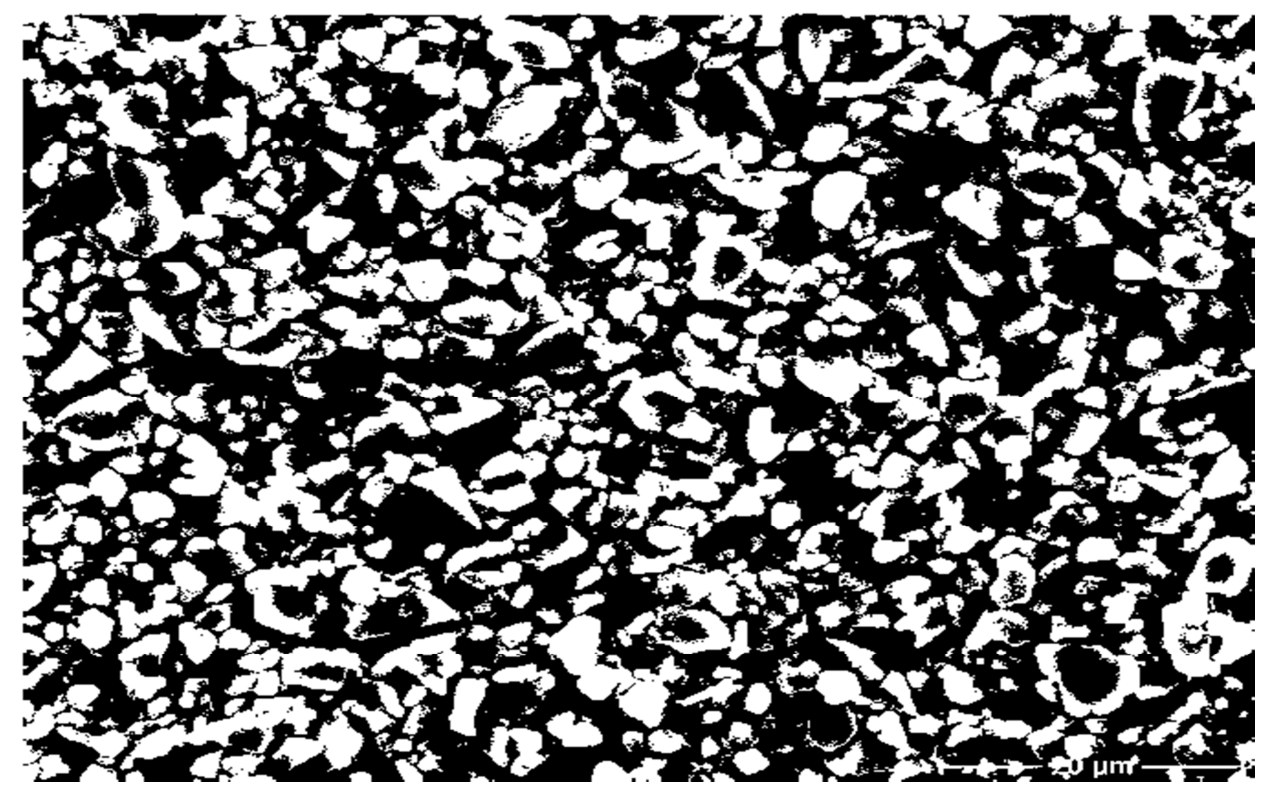

Figura 20: Imagem SEM do interior da membrana, após ajuste de bordas. 
A determinação é realizada pela divisão da área total da imagem pela contagem do número total de grãos identificados, Figura 21.

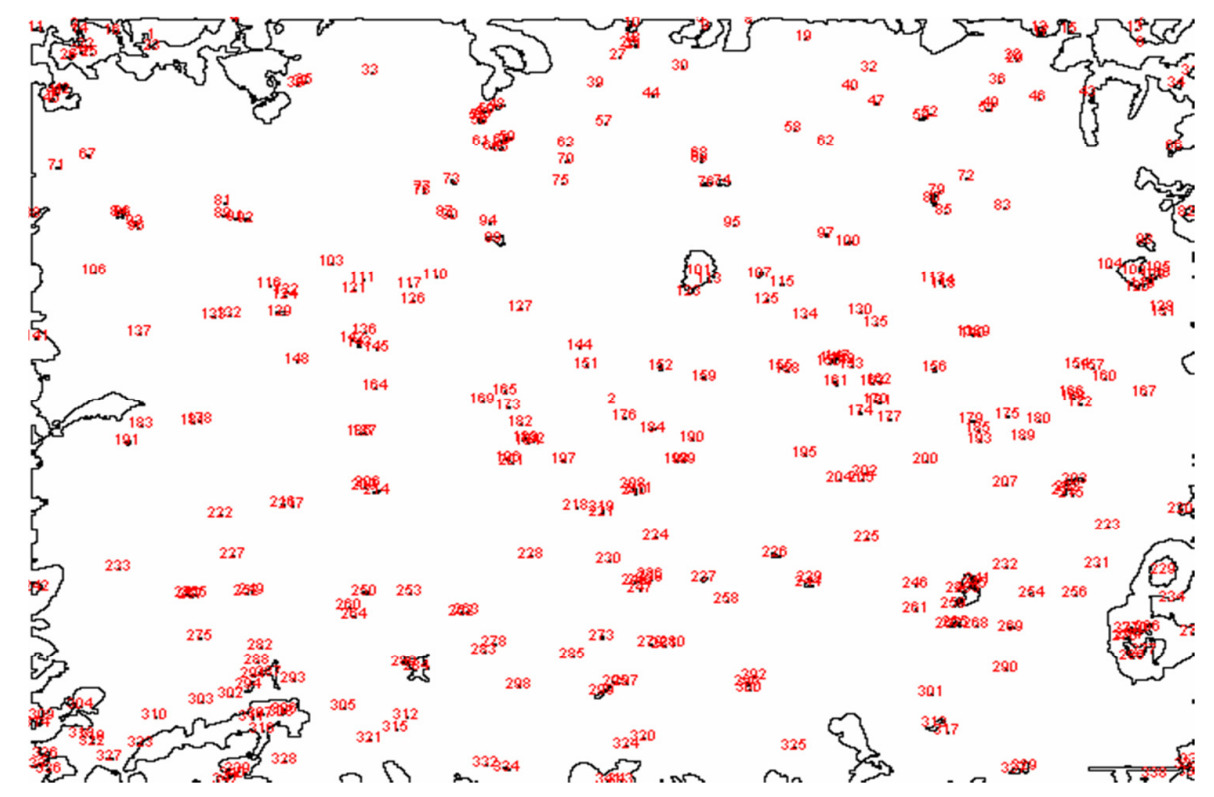

Figura 21: Contagem do número de grãos da membrana.

O tamanho de grão determinado foi o seguinte:

- Área total da imagem: $7.739,400 \mathrm{~mm}^{2}$

- Número de grãos obtido na contagem: 343

- Diâmetro médio estimado dos grãos: 5,36 $\mu \mathrm{m}$

Com esse valor de tamanho de grão e a porosidade, já conhecida, foram determinados valores de resistência porosa, apresentados na Tabela 16:

Tabela 16: Parâmetros de resistência porosa utilizados no modelo

\begin{tabular}{c|c}
\hline Resistência porosa viscosa & $9,47532 \mathrm{e}+13$ \\
$(1 / \alpha)$ & \\
\hline Resistência porosa inercial & $1,69292 \mathrm{e}+07$ \\
$\left(C_{2}\right)$ & \\
\hline
\end{tabular}




\subsubsection{Ativação ou inativação do cálculo de turbulência}

O código comercial de CFD utilizado no presente trabalho permite a definição de zonas de células específicas em que se queira desativar o modelo de turbulência. No presente trabalho, a ferramenta foi utilizada para se avaliar a relevância do modelo de escoamento nos resultados obtidos para simulação do reator de membrana.

\subsubsection{Reação e transporte de espécies}

O único parâmetro de reação informado como condição de zona de células é a razão superfície/volume $(1 / \mathrm{m})$, calculada como o quociente entre a superfície específica da membrana e a densidade da membrana de alumina. Ambos os valores foram obtidos de Schmidt (2007), Tabela 17:

Tabela 17: Parâmetros para definição de reação em zona de células no meio poroso.

\begin{tabular}{c|c|c}
\hline Grandeza & Valor & Fonte \\
\hline Superfície específica da membrana & $9 \mathrm{~m}^{2} / \mathrm{g}$ & Schmidt (2007) \\
\hline Densidade da membrana & $3,92 \mathrm{~g} / \mathrm{m}^{3}$ & Schmidt (2007) \\
\hline Razão superfície/volume & $2,30 \mathrm{~m}^{2} / \mathrm{m}^{3}$ & Calculada \\
\hline
\end{tabular}

5.9.3. Fluido entre membrana e casco

\subsubsection{Reação e transporte de espécies}

$\mathrm{Na}$ região entre o fluido e o casco não ocorre reação, de forma que é conveniente desabilitar o cálculo de reações nessa zona de células.

\subsection{Condições operacionais}

$\mathrm{Na}$ interface de condições operacionais, foi informado o valor de 10 bar para a pressão operacional, conforme obtida na Tabela 4, de dados experimentais. 


\subsection{Condições de contorno}

Conforme mencionado anteriormente no item 5.4, Malhas de volumes finitos, as condições de contorno foram definidas a partir das Seleções Nomeadas definidas no ANSYS Meshing:

- Velocidade de entrada (velocity_inlet)

- Parede (wall)

- Pressão de saída (pressure_outlet)

A justificava para escolha de tais condições de contorno bem como os parâmetros informados para definição das mesmas são apresentados a seguir.

\subsubsection{Velocidade de entrada}

Para as condições operacionais dessa região, as condições de contorno aplicáveis seriam as seguintes:

- Velocidade de entrada (velocity_inlet)

- Pressão de entrada

- Vazão mássica de entrada

Dentre as alternativas apresentadas, aquela que apresenta melhor contribuição para a facilidade de convergência é a velocidade de entrada. Por essa razão, a vazão mássica de entrada é somente recomendada no caso de escoamentos compressíveis.

Os parâmetros informados para definição da condição de contorno velocidade de entrada foram magnitude de velocidade, especificação da turbulência, temperatura e fração mássica inicial. 


\subsubsection{Magnitude de velocidade}

A magnitude de velocidade adotada foi calculada a partir da vazão média dos experimentos, Tabela 4, e diâmetro interno da membrana, conforme apresentado na Tabela 18, a seguir:

Tabela 18: Cálculo da velocidade de entrada

\begin{tabular}{c|cc} 
Vazão volumétrica & 160 & $\mathrm{~mL} / \mathrm{min}$ \\
\hline Vazão volumétrica & $2,67 \mathrm{E}-06$ & $\mathrm{~m} / \mathrm{s}$ \\
\hline $\mathbf{D}_{\text {interno }}$ & 1,9 & $\mathrm{~mm}$ \\
\hline Superfície transversal & $2,84 \mathrm{E}-06$ & $\mathrm{~m}^{2}$ \\
\hline Velocidade & $\mathbf{0 , 9 4}$ & $\mathbf{m} / \mathbf{s}$
\end{tabular}

\subsubsection{Turbulência}

Em algumas situações, faz-se conveniente especificar um valor uniforme para a quantidade de turbulência na fronteira em que ocorre a entrada do escoamento. $O$ manual do usuário do software adotado recomenda tal medida para escoamentos completamente desenvolvidos em dutos se o perfil preciso de quantidades de turbulência for desconhecido, como no caso estudado.

Dada a característica de escoamento interno plenamente desenvolvido, foi adotado método Intensidade de Turbulência e Diâmetro Hidráulico, conforme recomendo na documentação específica. 
A Intensidade de Turbulência no centro de escoamento plenamente desenvolvido em duto pode ser estimada a partir da seguinte fórmula, obtida de correlação empírica para escoamento em tubos (ANSYS 12.0 User's Guide):

$$
I \equiv \frac{u^{\prime}}{u_{\text {avg }}}=0,16\left(\operatorname{Re}_{D H}\right)^{-1 / 8}
$$

Tabela 19: Cálculo da Intensidade de Turbulência

\begin{tabular}{|c|c|c|}
\hline Vazão volumétrica & 2,66667E-06 & $\mathrm{m}^{3} / \mathrm{s}$ \\
\hline Diâmetro hidráulico & 0,0019 & $\mathrm{~m}$ \\
\hline Viscosidade dinâmica & 7,40E-04 & $\mathrm{kg} / \mathrm{m} \mathrm{s}$ \\
\hline Densidade & 702 & $\mathrm{~kg} / \mathrm{m}^{3}$ \\
\hline Viscosidade cinemática & 1,05E-06 & $\mathrm{m}^{2} / \mathrm{s}$ \\
\hline Área da superfície transversal & 2,83529E-06 & $\mathrm{m}^{2}$ \\
\hline Número de Reynolds (Re) & $1,70 \mathrm{E}+03$ & \\
\hline Intensidade de Turbulência (I) & $6 \%$ & \\
\hline
\end{tabular}

O diâmetro hidráulico corresponde ao próprio diâmetro interno da membrana, 1,9e$03 \mathrm{~m}$.

\subsubsection{Temperatura}

Conforme informação de dados experimentais, Tabela 4 , foi adotado o valor de $50^{\circ} \mathrm{C}$ para temperatura do reator.

\subsubsection{Concentração inicial}

Como concentrações iniciais foram apresentados os valores indicados na Tabela 15, apresentada no item 5.9.1.2 para fixação de valores no canal central. 


\subsubsection{Parede}

A condição de contorno do tipo parede (wall) não requer nenhum parâmetro adicional.

\subsubsection{Pressão de saída}

Como alternativa à definição da pressão de saída, o ANSYS FLUENT apresenta a possibilidade de se definir uma vazão de saída (outflow). No entanto, essa condição é desfavorável à convergência e somente utilizada no caso de desconhecimento das condições de pressão.

\subsubsection{Magnitude da pressão de saída}

Definida como Gauge $=0(\mathrm{~Pa})$

\subsubsection{Turbulência}

$\mathrm{Na}$ definição de turbulência de saída foram adotados os mesmos valores da condição de entrada, apresentados anteriormente. 


\subsection{Métodos de solução}

\subsubsection{Acoplamento pressão-velocidade}

O método originalmente escolhido para acoplamento pressão-velocidade havia sido - PISO (Pressure-Implicit with Spliting of Operators, pressão implícita com separação de operadores). A escolha fundamentou-se no fato de o método, com correção de assimetria, ser recomendado para malhas com presença de distorção. No entanto, não foram encontrados fatores de sub-relaxação adequados para a convergência pelo método, pelo que se retomou o método-padrão, SIMPLE.

O método SIMPLE é recomendado para cálculos no estado estacionário e resultou em convergência adequada para diferentes parâmetros de simulação.

\subsubsection{Discretização espacial}

\subsubsection{Gradiente}

O método dos mínimos quadrados, Least Squares, apresentado como padrão no software, foi adotado para as simulações, com base no fato de ser mais eficiente para malhas irregulares não-estruturadas, resultando em qualidade comparável à de métodos baseados em nós, em menor tempo de computação.

\subsubsection{Pressão}

Embora o método PRESTO! tenha sido inicialmente adotado, por ser recomendado para escoamentos envolvendo meio poroso, adotou-se novamente o método padrão Standard, em decorrência de problemas de convergência. Haveria a possibilidade de se trabalhar fatores de sub-relaxação, ajustando-os até a obtenção de valores adequados. Porém, optou-se pelo método padrão, que ofereceu uma resposta adequada ser a necessidade de ajustes. 
5.12.2.3. Momento, energia cinética turbulenta, taxa de dissipação de turbulência, espécies e energia

Em conformidade com o nível de precisão aplicável ao presente trabalho, de observação qualitativa do comportamento geral do reator, o esquema Upwind de Primeira Ordem (First Order Upwind) foi adotado para todas essas variáveis.

\subsection{Critério de convergência}

O resíduo em escala definido para convergência de cada variável observada é apresentado na a seguir:

Tabela 20: Critério de convergência adotado

\begin{tabular}{l|l|l|l|l|l|l|l|l|l|l}
\hline Continuity & $\begin{array}{l}\mathbf{x}- \\
\text { velocity }\end{array}$ & $\begin{array}{l}\mathbf{y}- \\
\text { velocity }\end{array}$ & $\begin{array}{l}\mathbf{z}- \\
\text { velocity }\end{array}$ & energy & $\mathbf{k}$ & Omega & $\mathbf{H}_{2}$ & COD & COE & COA \\
\hline $1,00 \mathrm{E}-08$ & $1,00 \mathrm{E}-05$ & $1,00 \mathrm{E}-05$ & $1,00 \mathrm{E}-05$ & $1,00 \mathrm{E}-05$ & $1,00 \mathrm{E}-05$ & $1,00 \mathrm{E}-05$ & $1,00 \mathrm{E}-03$ & $1,00 \mathrm{E}-03$ & $1,00 \mathrm{E}-03$ & $1,00 \mathrm{E}-03$ \\
\hline
\end{tabular}




\section{Resultados e discussão}

\subsection{Caso M1 - Estudo de sensibilidade do modelo: somente escoamento}

$\mathrm{Na}$ primeira simulação para estudo de sensibilidade do modelo, obteve-se curva suave e estável de resíduos em escala, tendo a convergência sido atingida após cerca de 6.500 iterações (Figura 22).

Os resultados apresentados na Figura 23 indicam o caminho seguido pelo fluido no interior do reator. Observa-se que, nas condições adotadas, toda a extensão da membrana participa do escoamento, indicando eficiência do projeto do reator, em termos de minimização de zonas mortas, o que se confirma na Figura 24. A Figura 25 é indicativa de alta resistência da membrana ao escoamento.

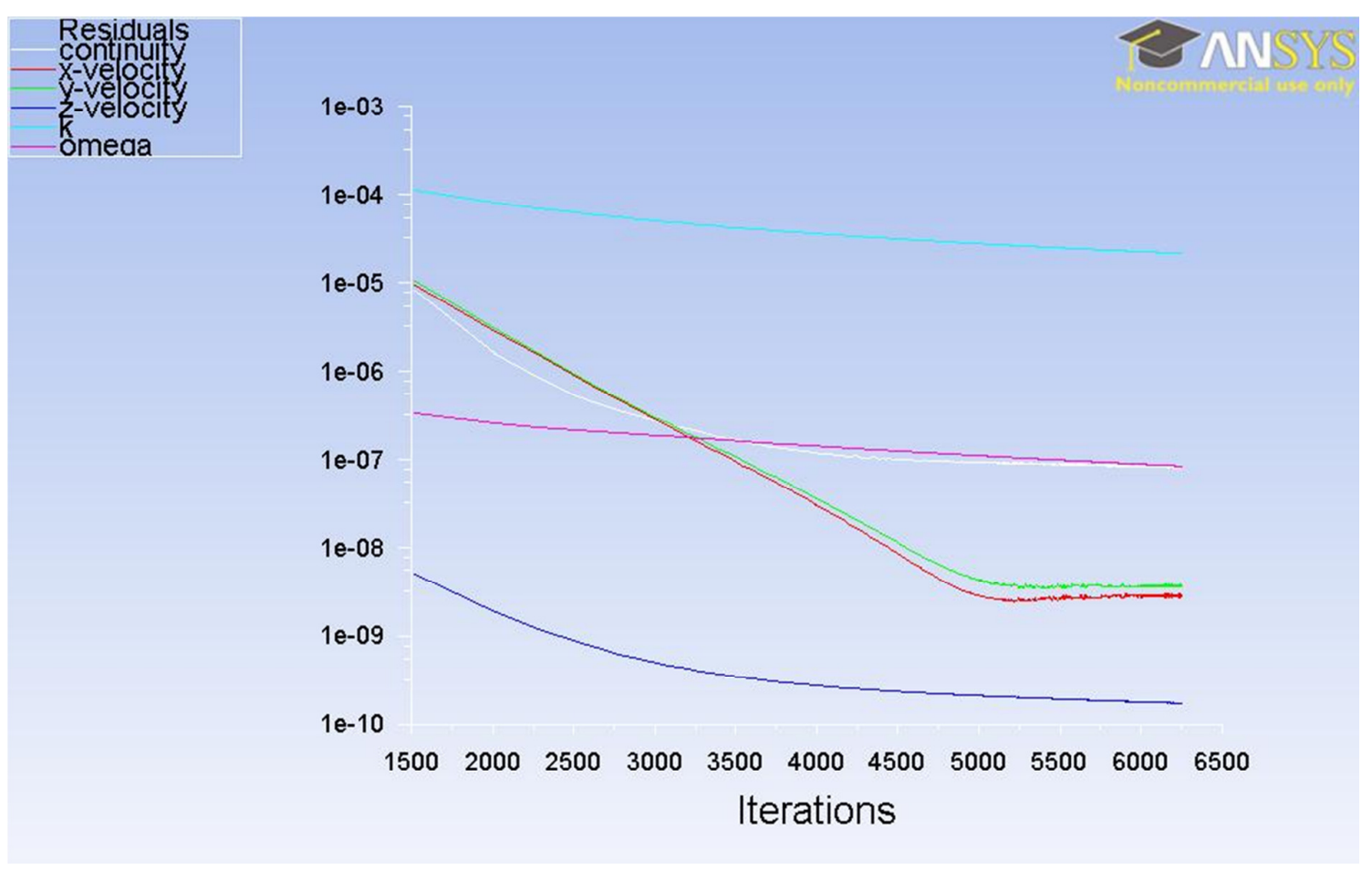

Figura 22: Resíduos em escala, Caso M1. 


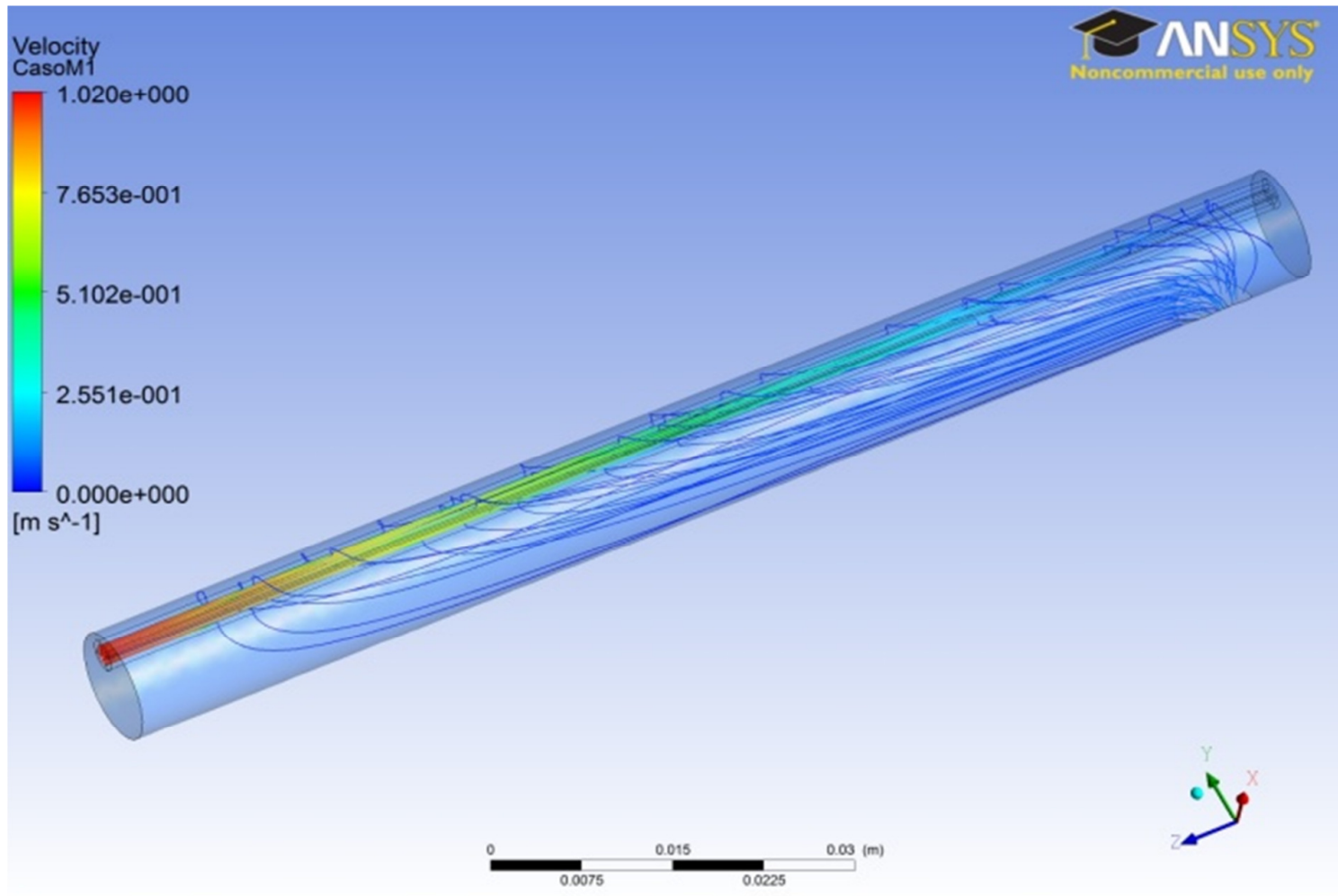

Figura 23: Linhas de corrente, Caso M1.

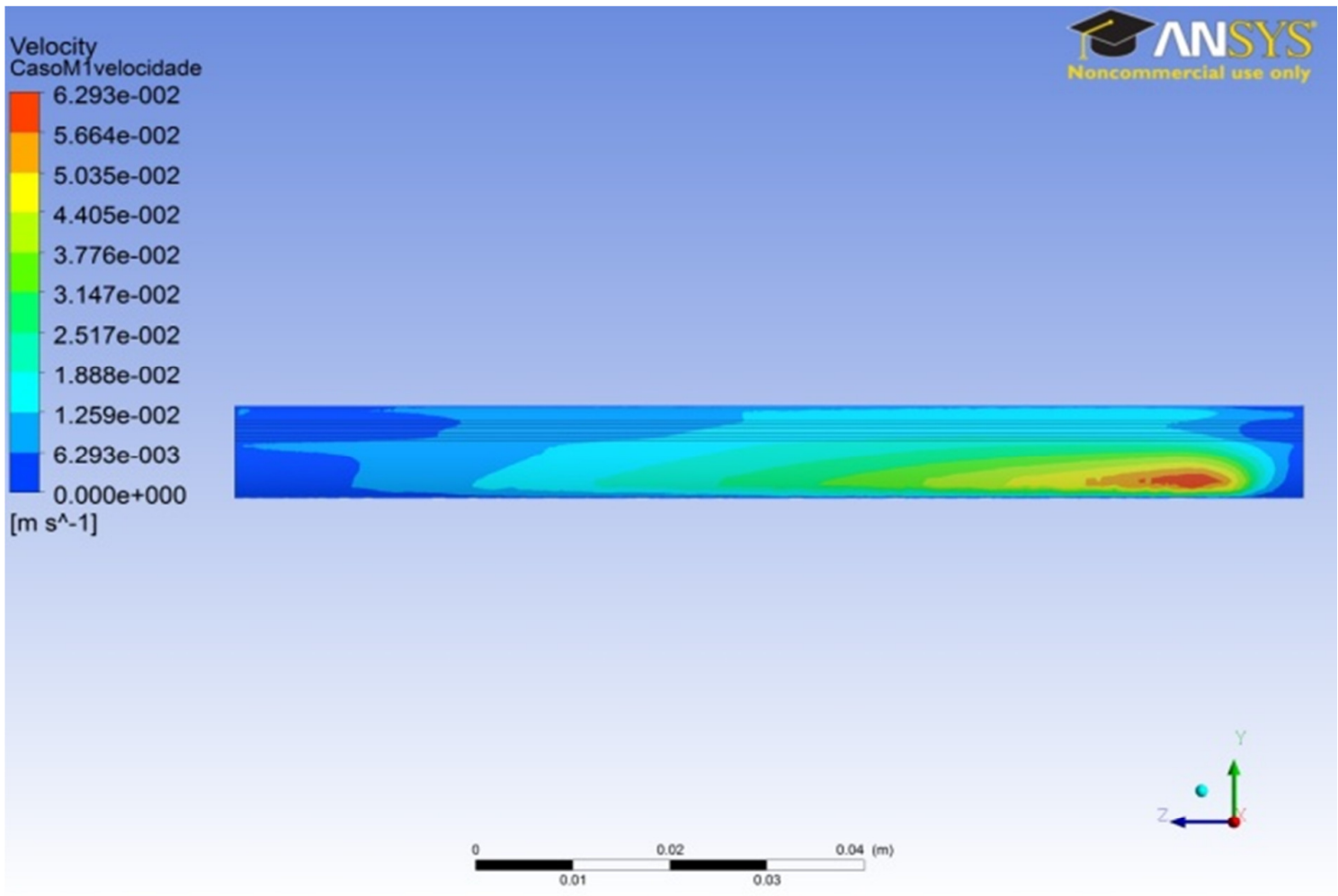

Figura 24: Perfil de velocidades no plano central, Caso M1. 


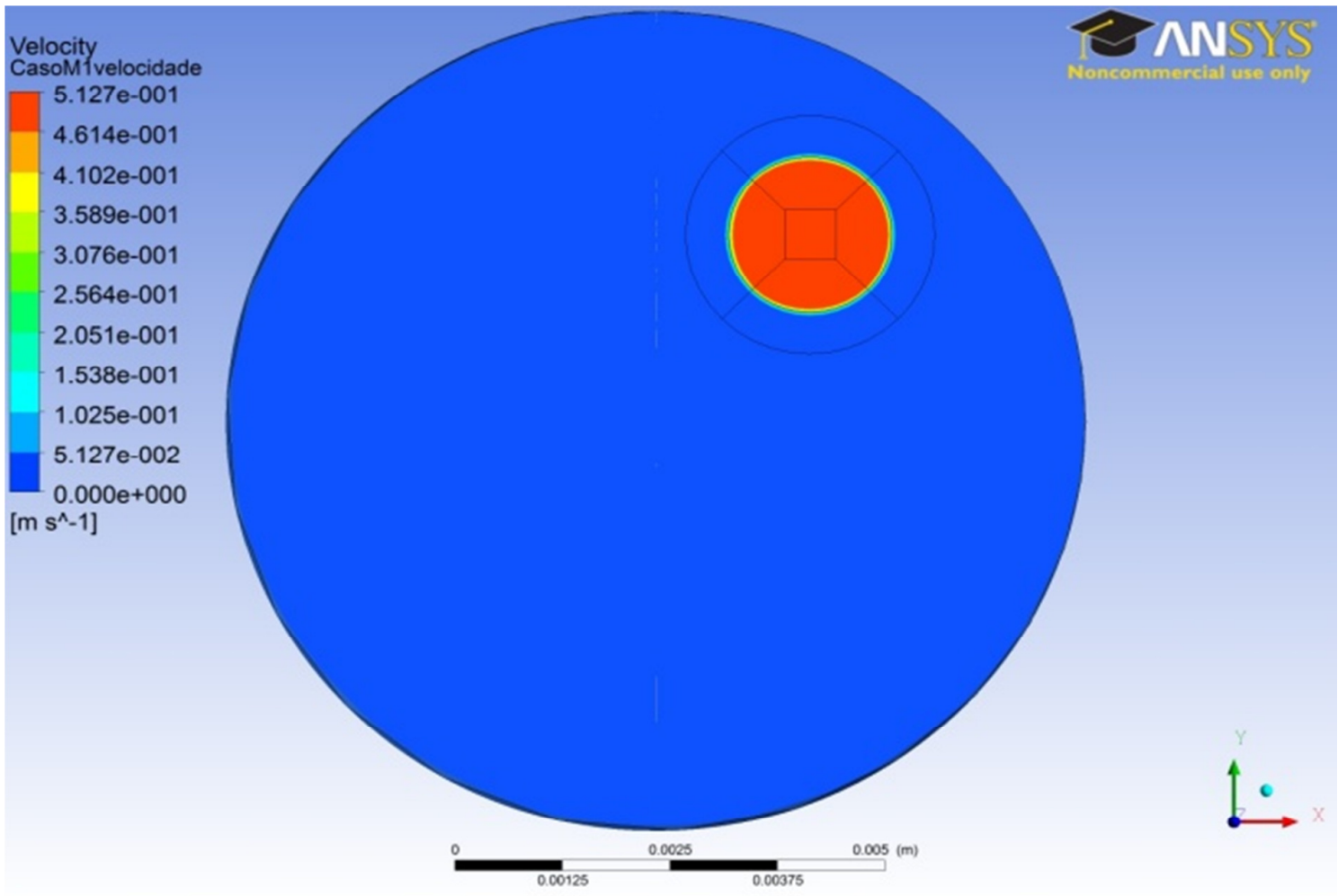

Figura 25: Perfil de velocidades no plano central, Caso M1. 


\subsection{Caso M2 - Estudo de sensibilidade do modelo: inclusão de reação}

Comparando-se a Figura 26 à Figura 22, nota-se que a inclusão da reação ao sistema gera uma perturbação no perfil de convergência da equação de continuidade. Não obstante, no caso incluindo reação, a convergência foi atingida em cerca de 2.100 iterações. Quanto à observação das concentrações locais, da Figura 27 até Figura 31 observa-se a pequena escala de conversão dos reagentes, praticamente indetectável, decorrente do fato de a simulação estar representando apenas um ciclo dentre os diversos realizados durante seguidas horas de reação em bancada.

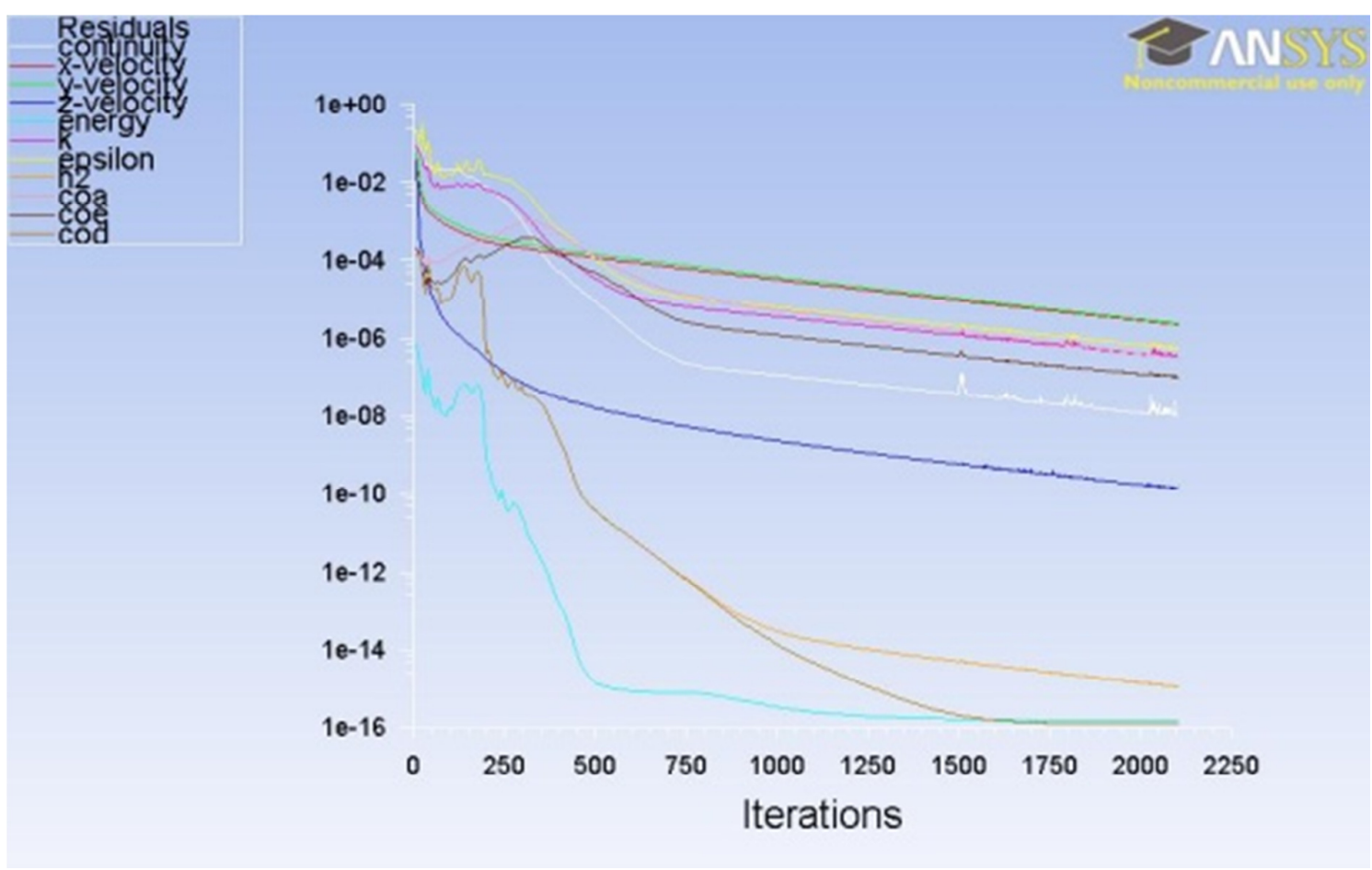

Figura 26: Resíduos em escala, Caso M2. 


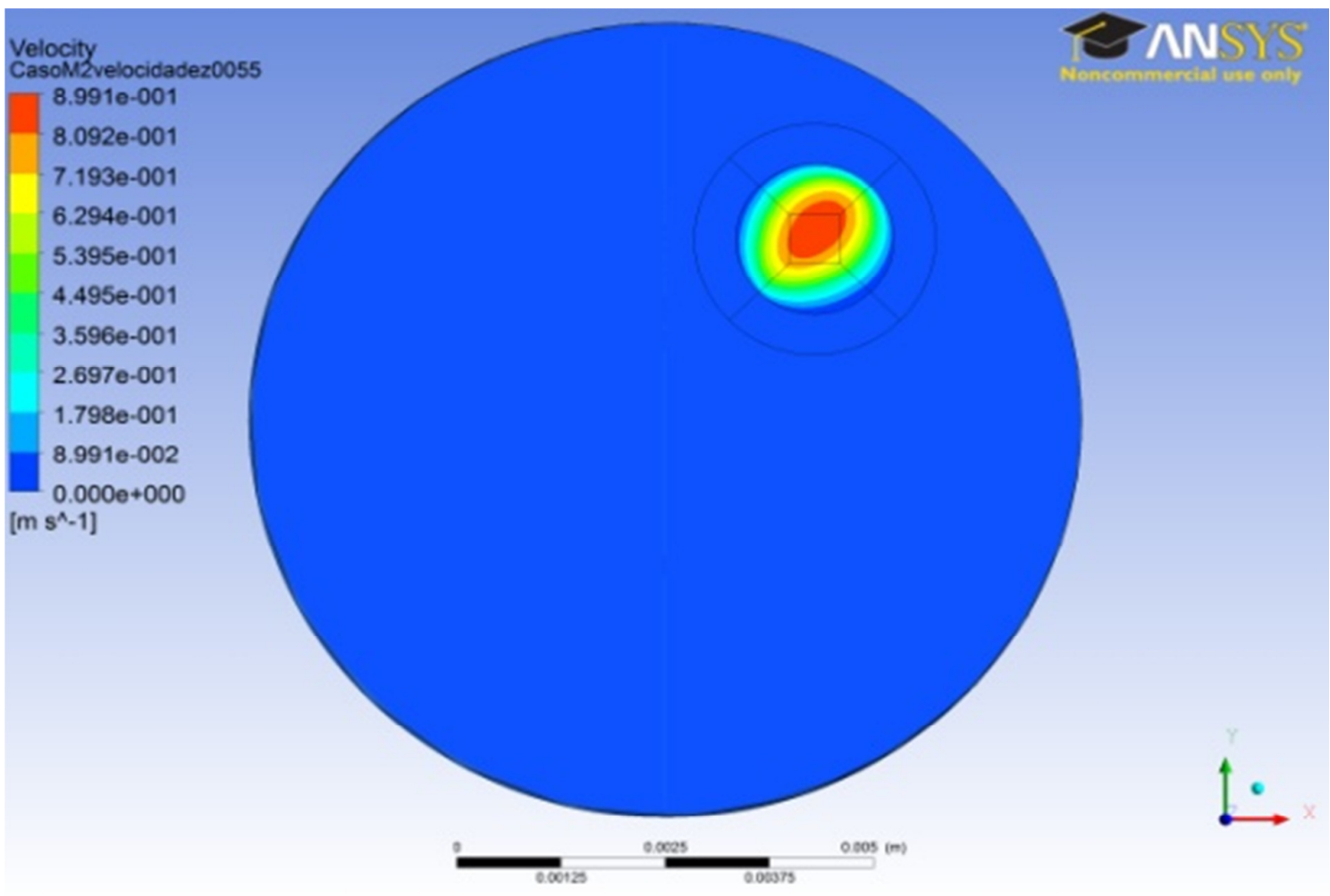

Figura 27: Velocidade em plano central, Caso M2.

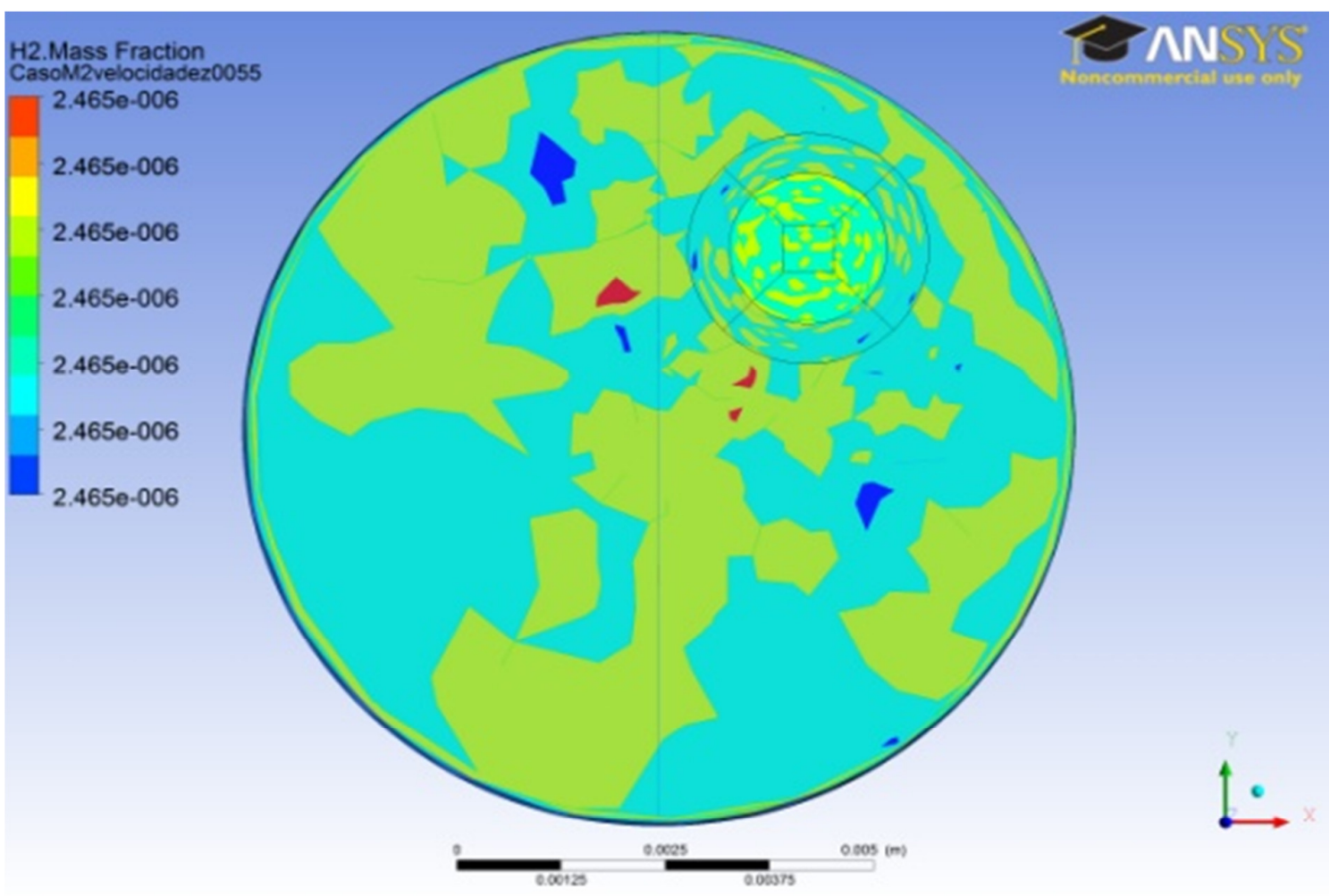

Figura 28: Fração mássica de $\mathrm{H}_{2}$, Caso M2. 


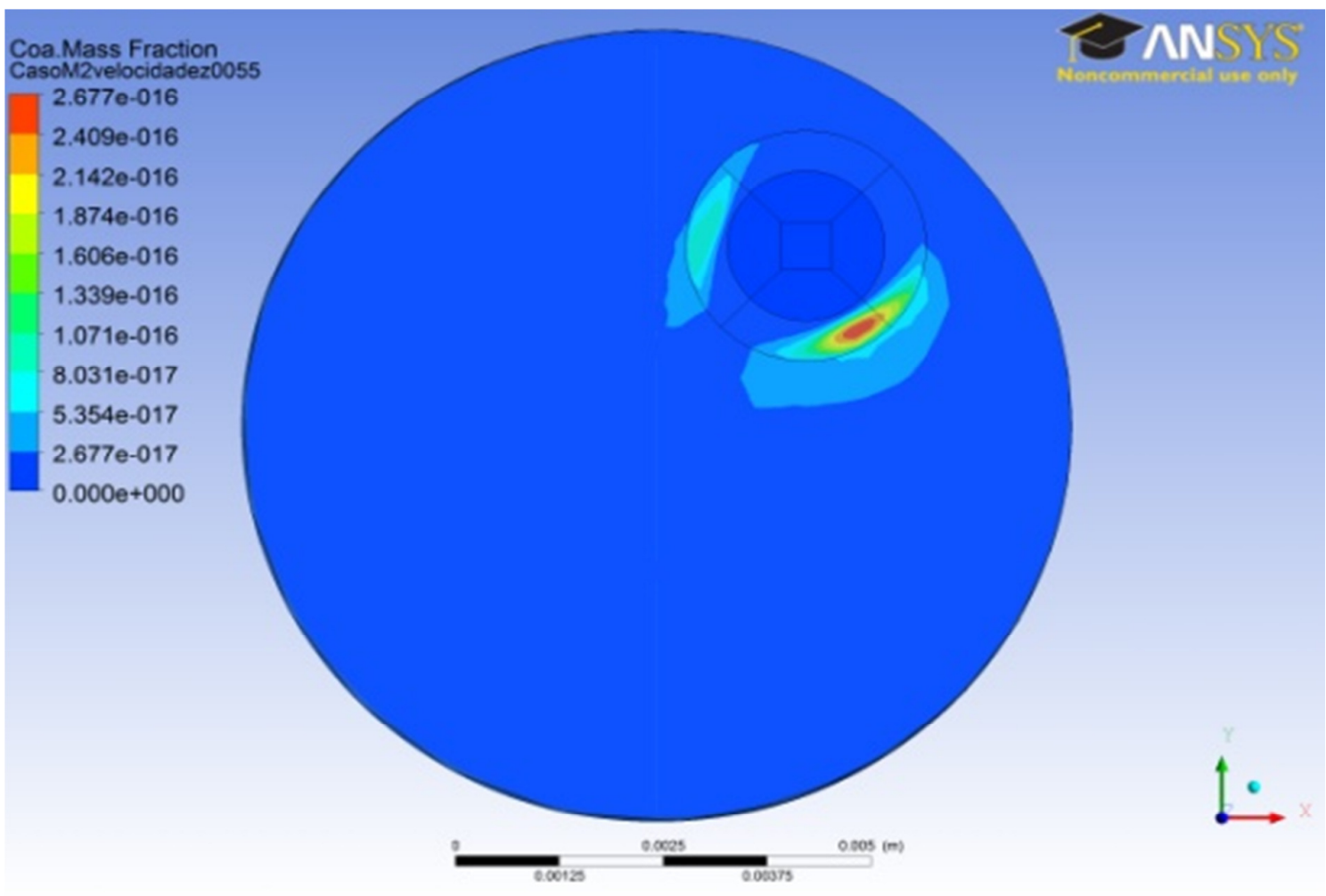

Figura 29: Fração mássica de COA, Caso M2.

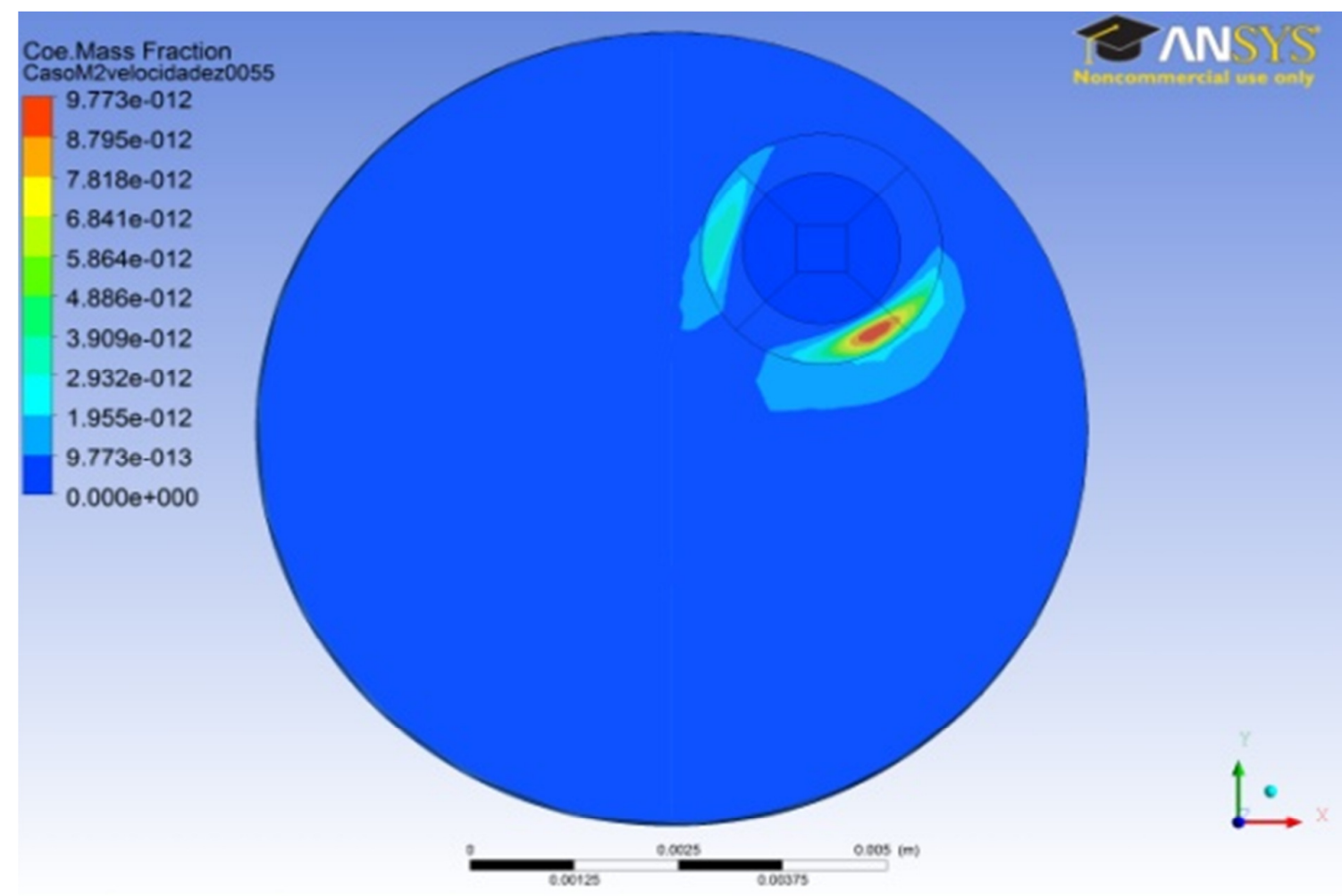

Figura 30: Fração mássica de COE, Caso M2. 


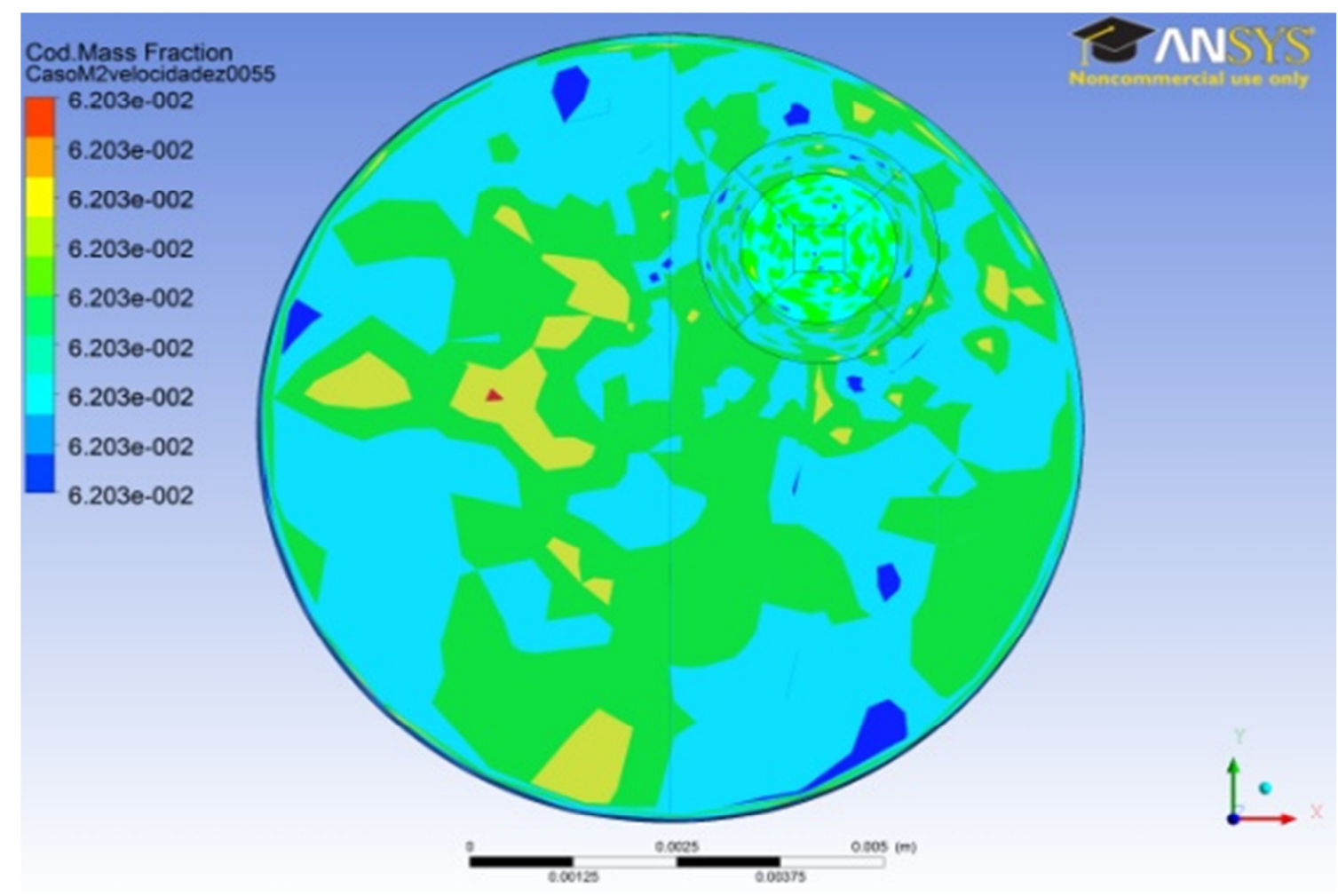

Figura 31: Fração mássica de COD, Caso M2.

\subsection{Caso M3 - Estudo de sensibilidade do modelo: variação da velocidade}

Com a redução substancial da velocidade, da ordem de um milhão de vezes, realizase uma compensação à simplificação de não incluir o reciclo e se passa a detectar nitidamente a ocorrência de reação, conforme ilustrado da Figura 33 à Figura 40. Conforme esperado, há formação preferencial de COE em relação a COA.

Observa-se, ainda na Figura 32 que a redução extrema da escala de velocidade introduz grande perturbação à convergência.

O conjunto da Figura 37 à Figura 40 apresenta o perfil longitudinal de concentrações no reator e evidencia um grande impacto do escoamento nas conversões. 

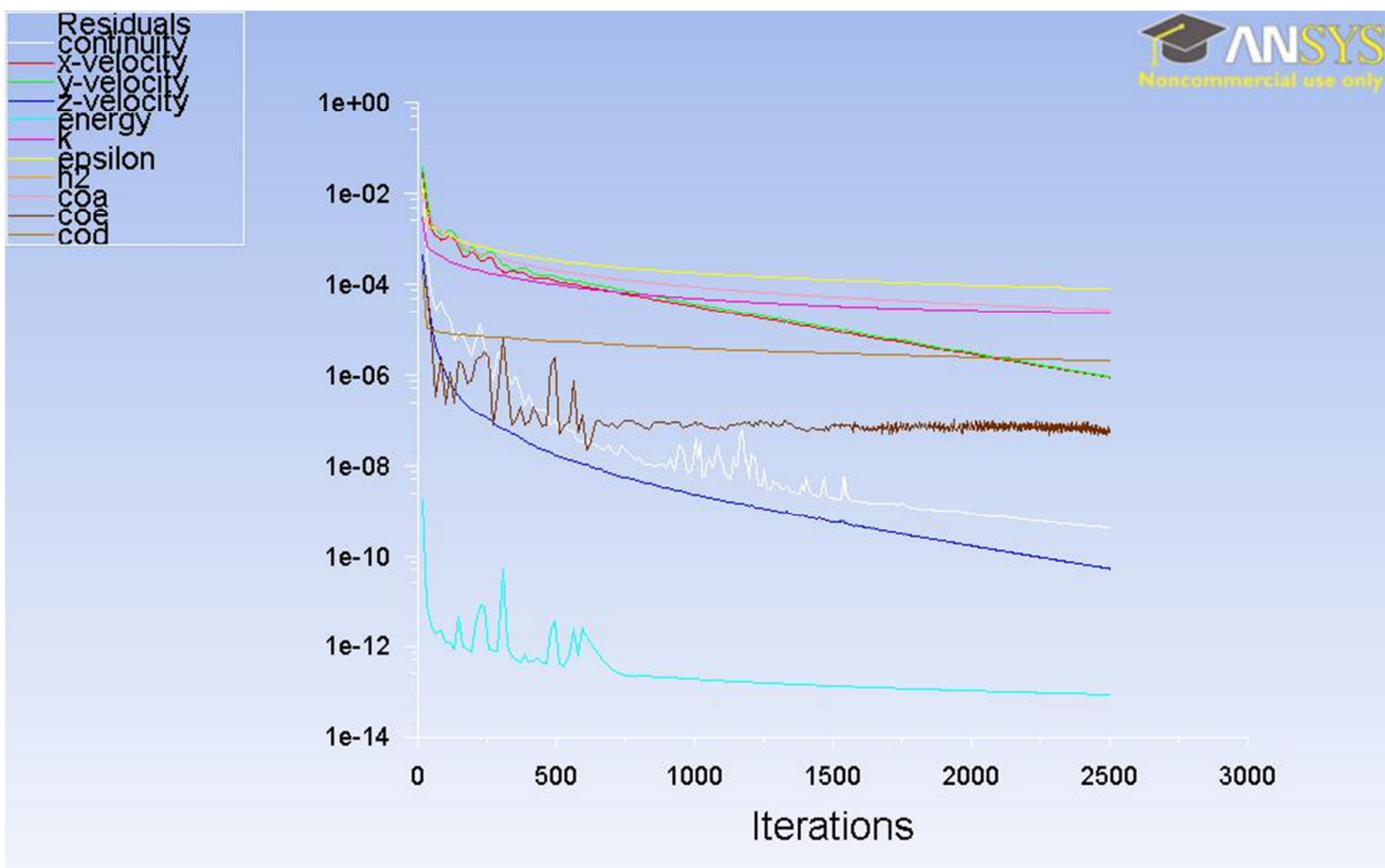

Figura 32: Resíduos em escala, Caso M3.

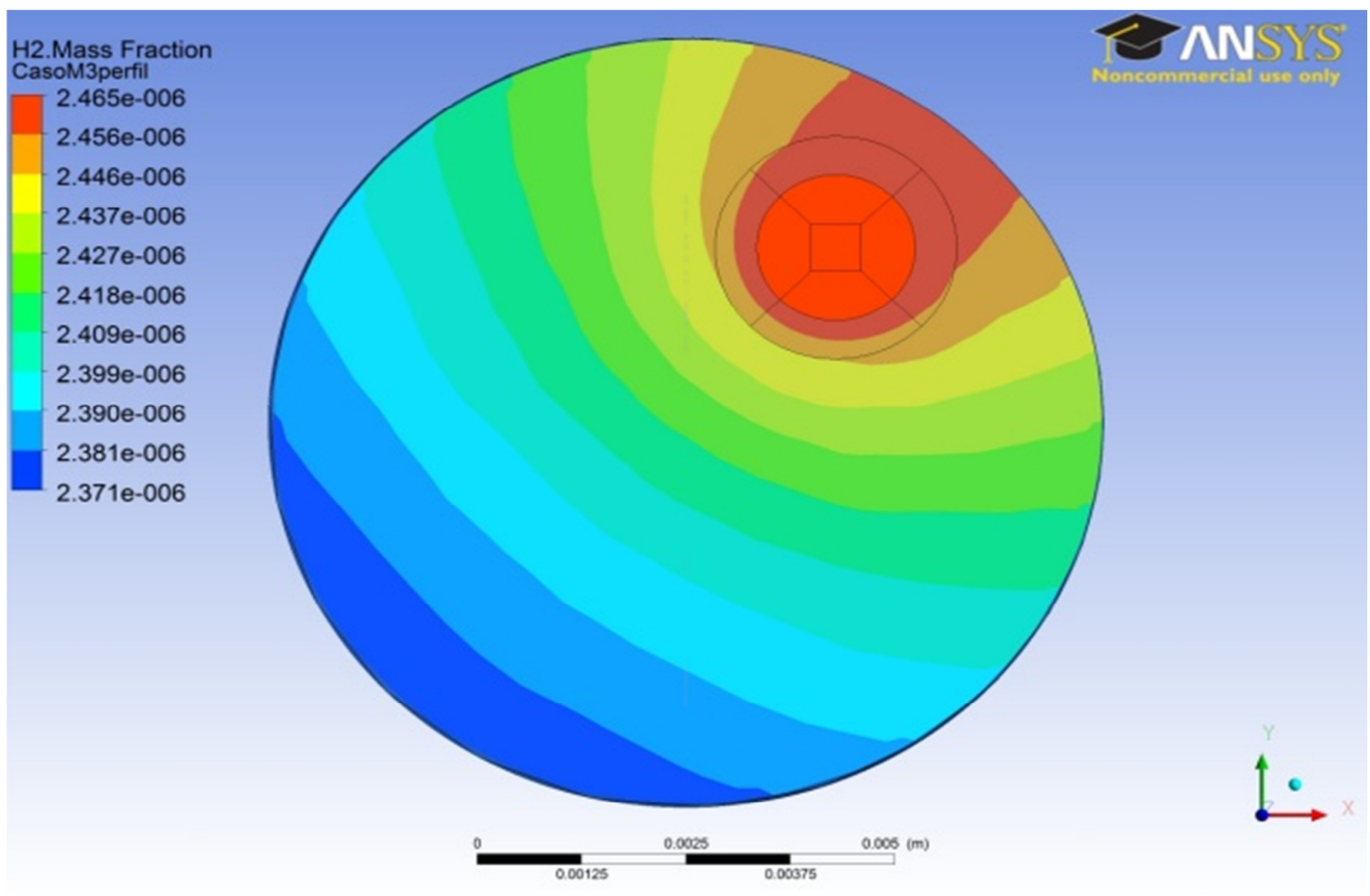

Figura 33: Fração mássica de $\mathrm{H}_{2}$, Caso M3. 


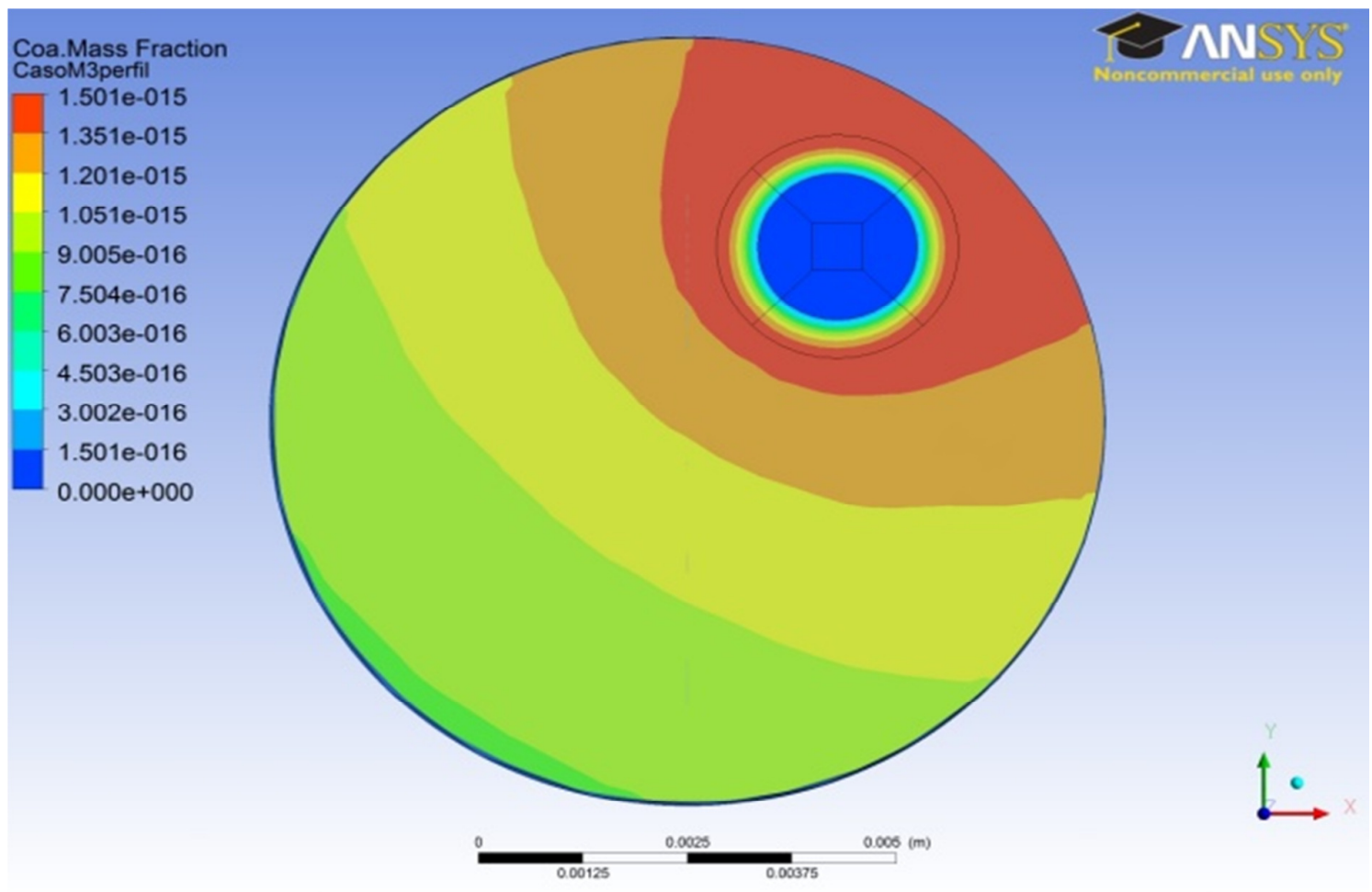

Figura 34: Fração mássica de COA, Caso M3.

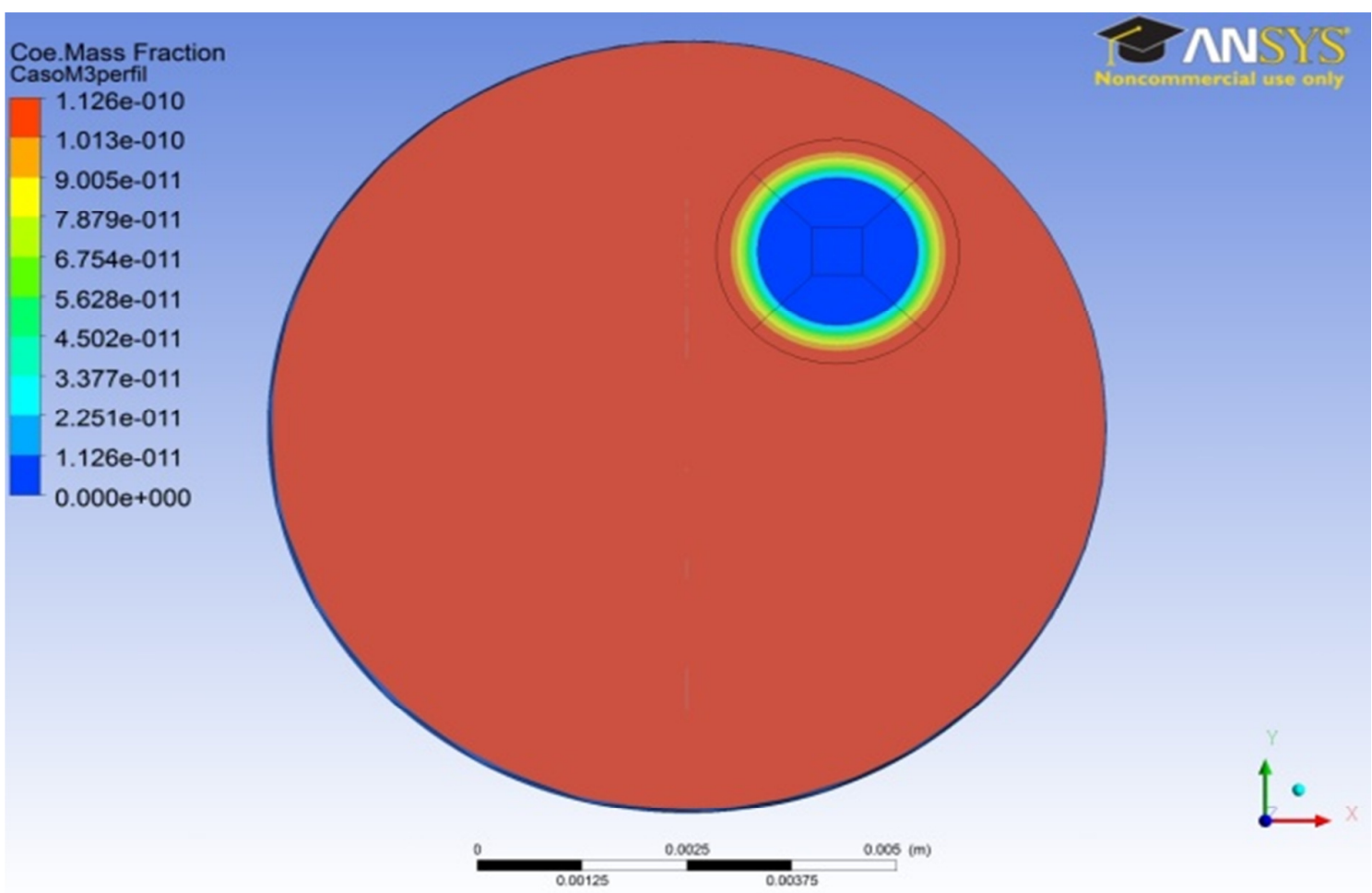

Figura 35: Fração mássica de COE, Caso M3. 


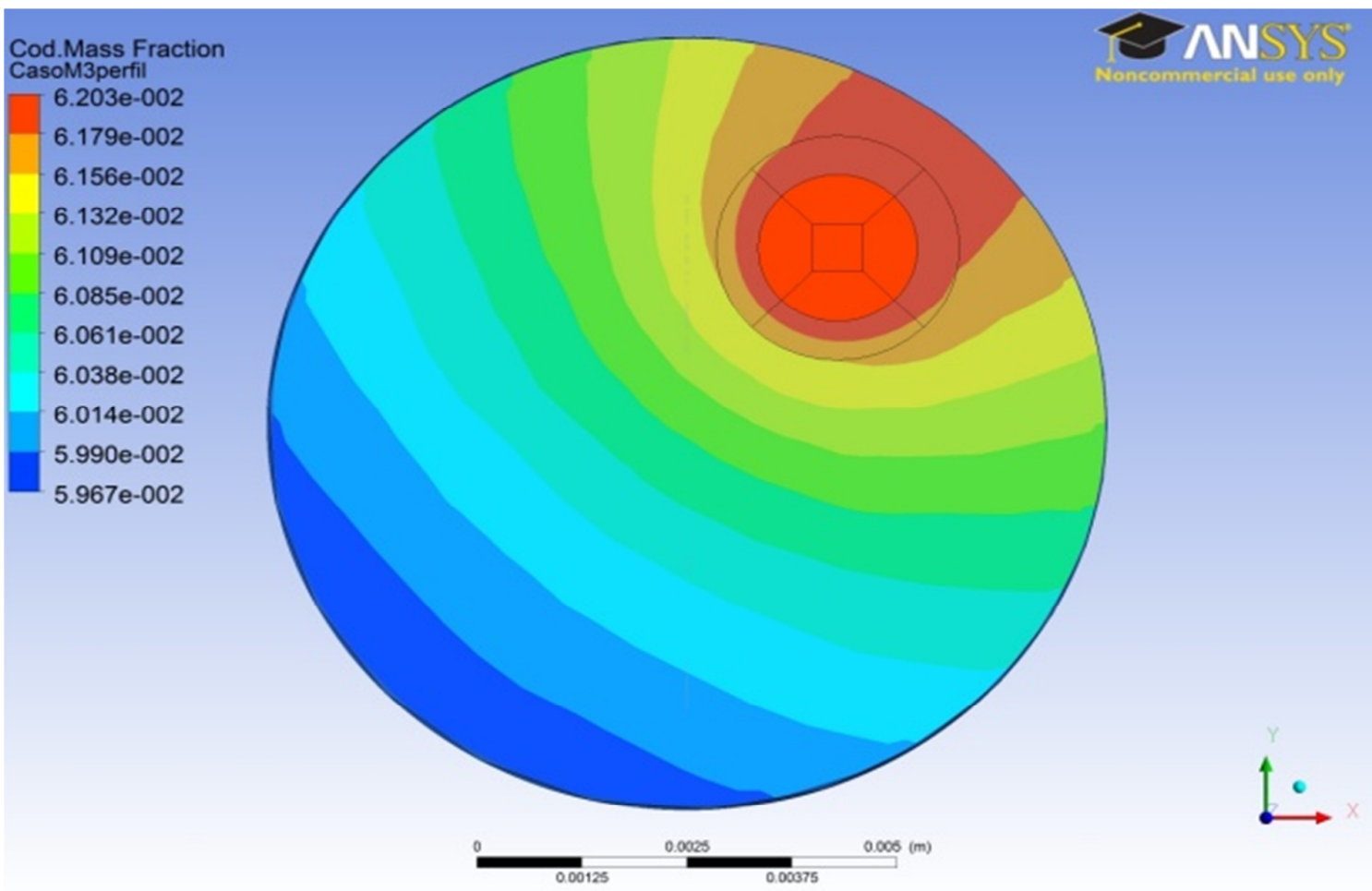

Figura 36: Fração mássica de COD, Caso M3.

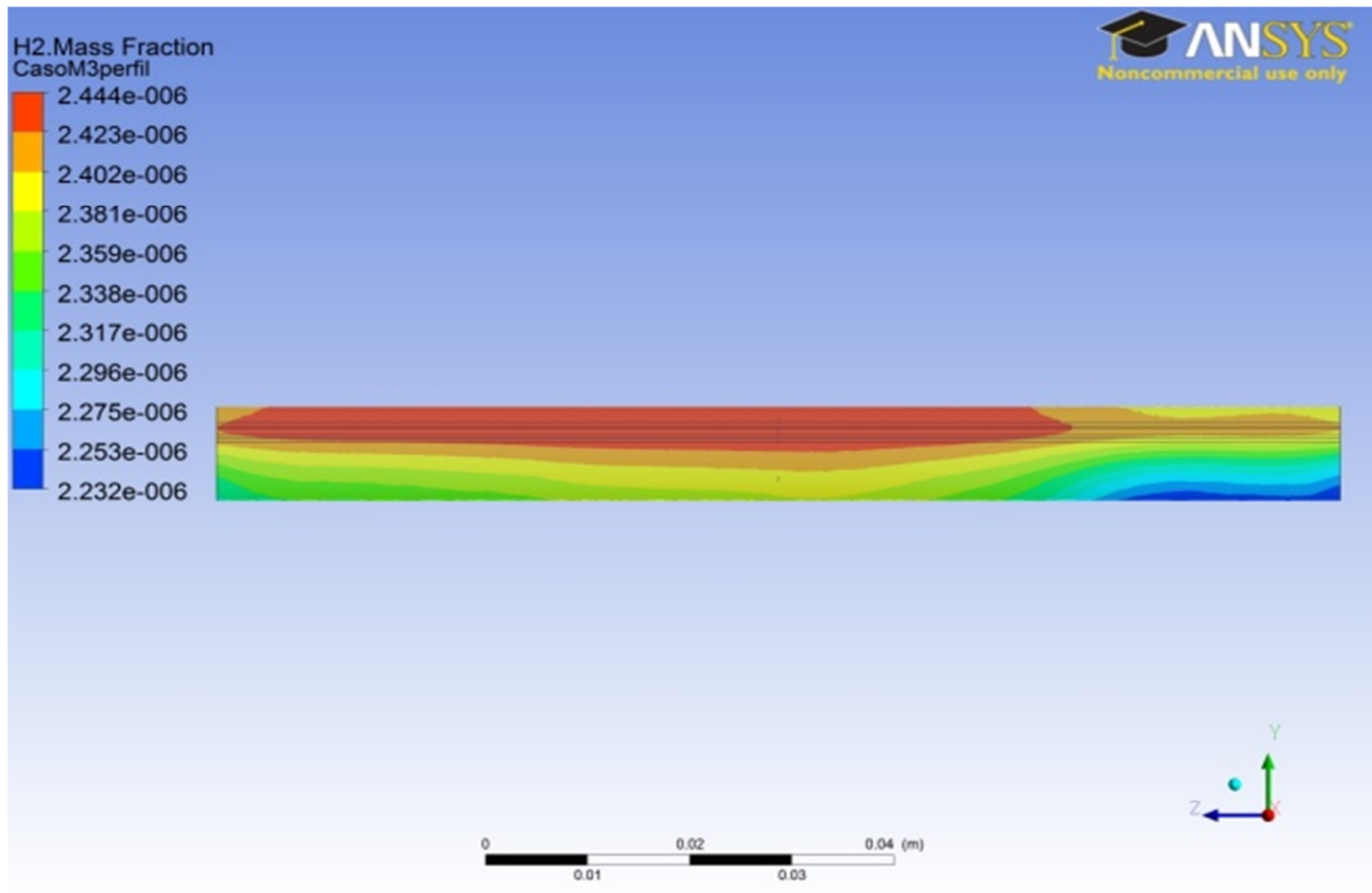

Figura 37: Fração mássica de $\mathrm{H}_{2}$, Caso M3. 


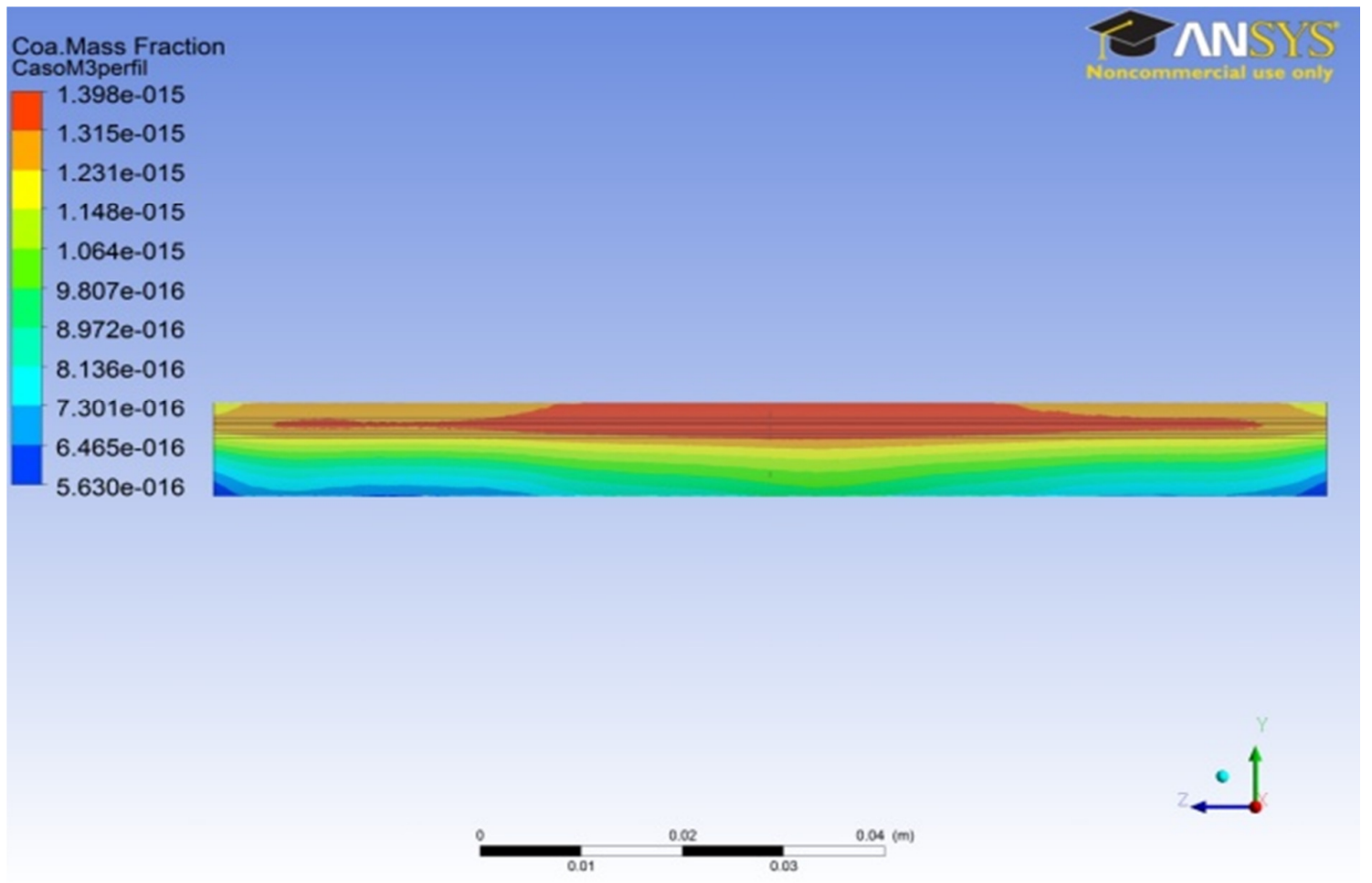

Figura 38: Fração mássica de COA, Caso M3.

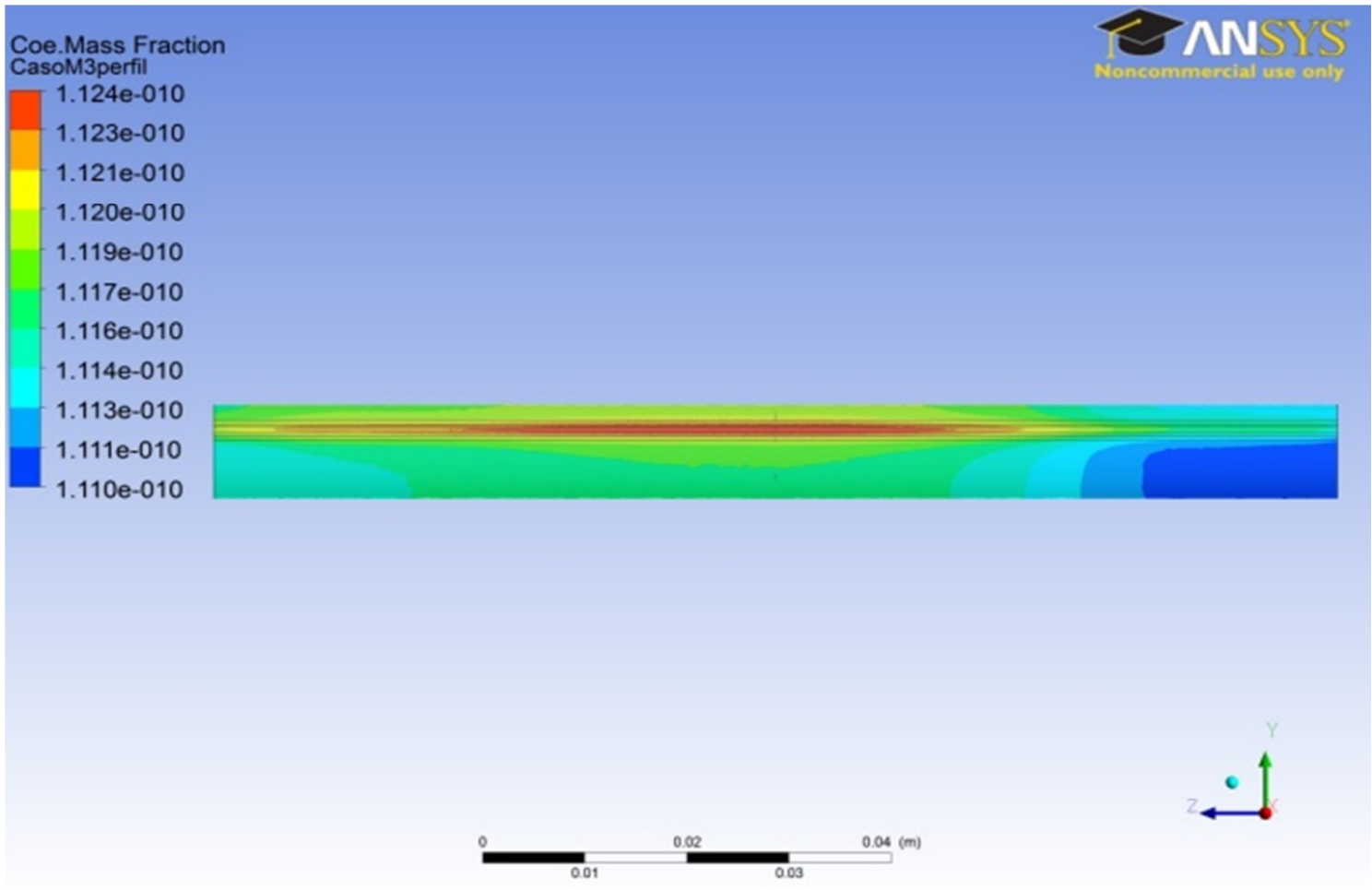

Figura 39: Fração mássica de COE, Caso M3. 


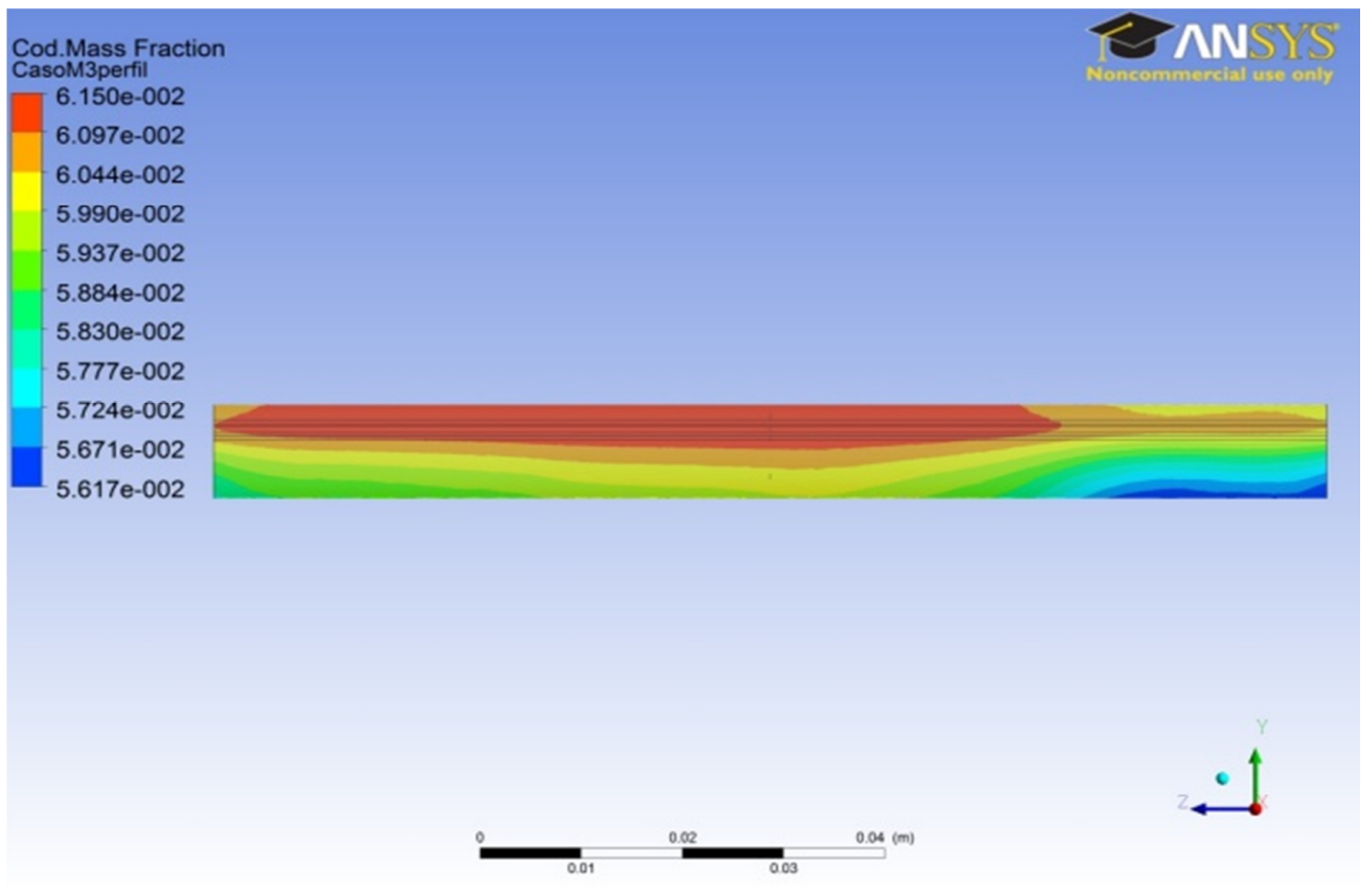

Figura 40: Concentração de COD, Caso M3. 


\subsection{Caso M4 - Estudo de sensibilidade do modelo: estudo da saída do escoamento}

A inclusão da geometria completa da membrana nas simulações é ilustrada na Figura 41, que ilustra também a boa distribuição das correntes de fluido por toda a extensão da membrana.

A Figura 42 apresenta um corte longitudinal do perfil de velocidades.

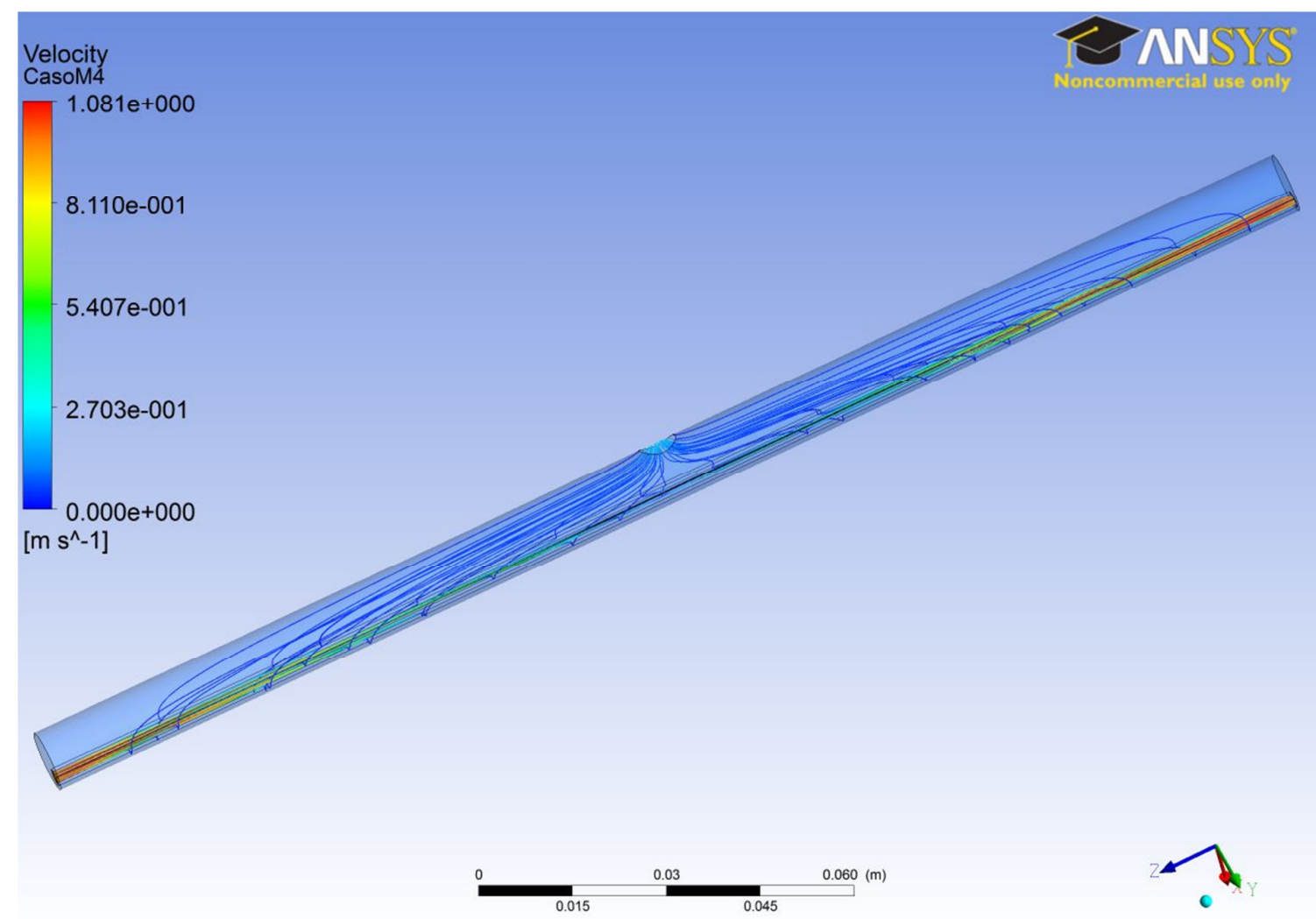

Figura 41: Linhas de corrente, Caso M4. 


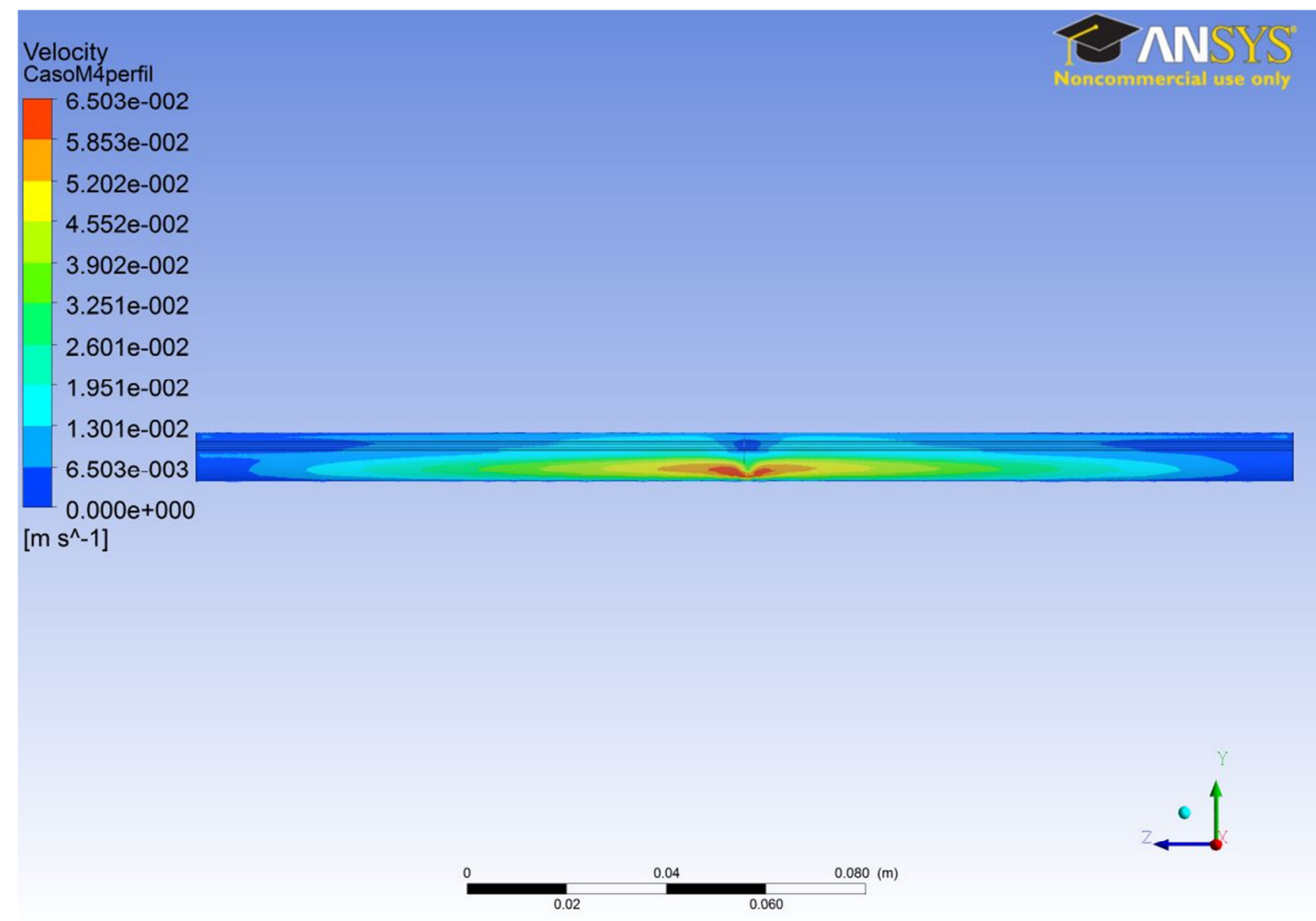

Figura 42: Velocidade em plano central, Caso M4.

A duplicação do número de células perturba e dificulta consideravelmente a convergência, como pode ser observado na Figura 43.

Com o retorno à velocidade real, tem-se que as concentrações voltam a ser muito baixas para serem detectadas numa única passagem através da membrana, como ilustrado da Figura 41 à Figura 47. 

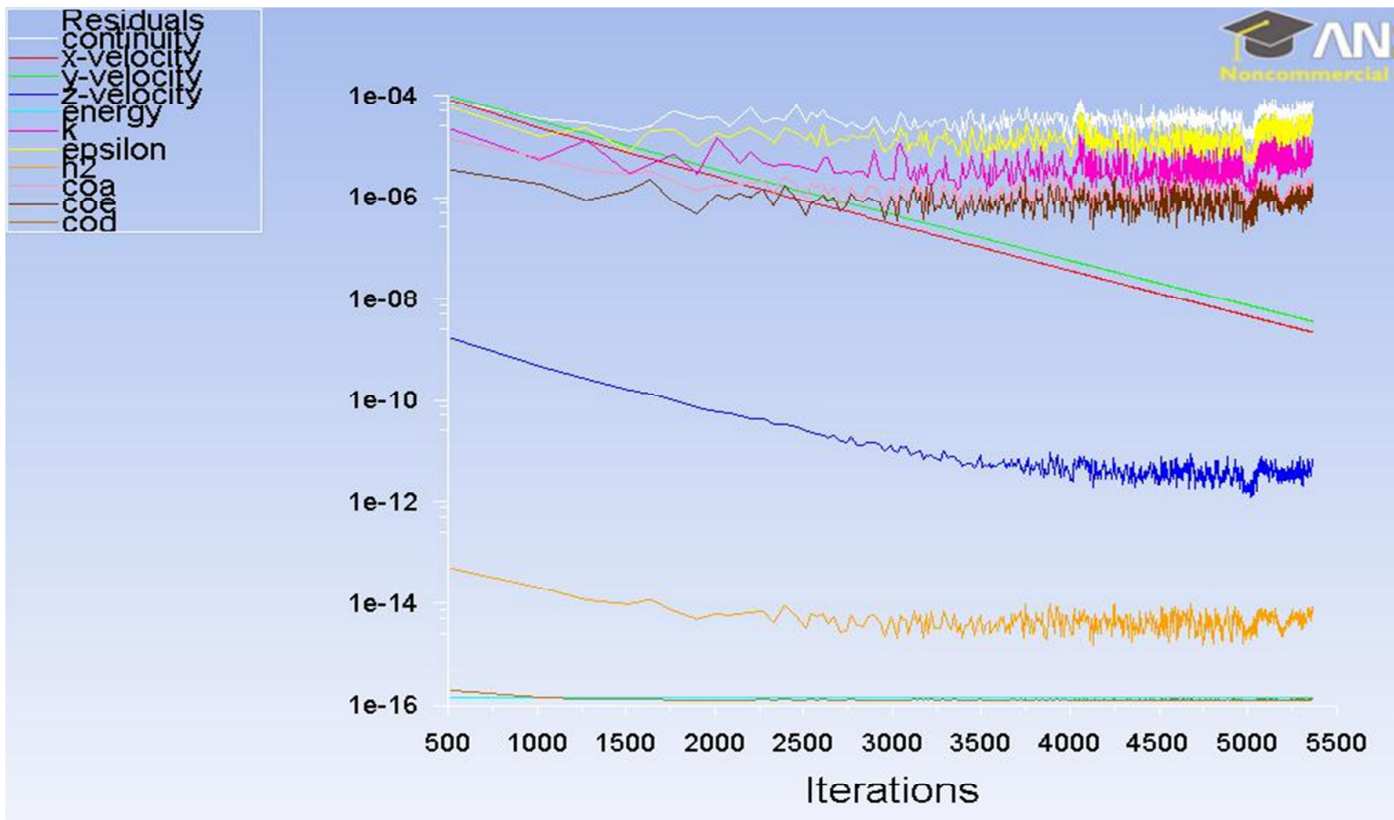

Figura 43: Resíduos em escala, Caso M4.

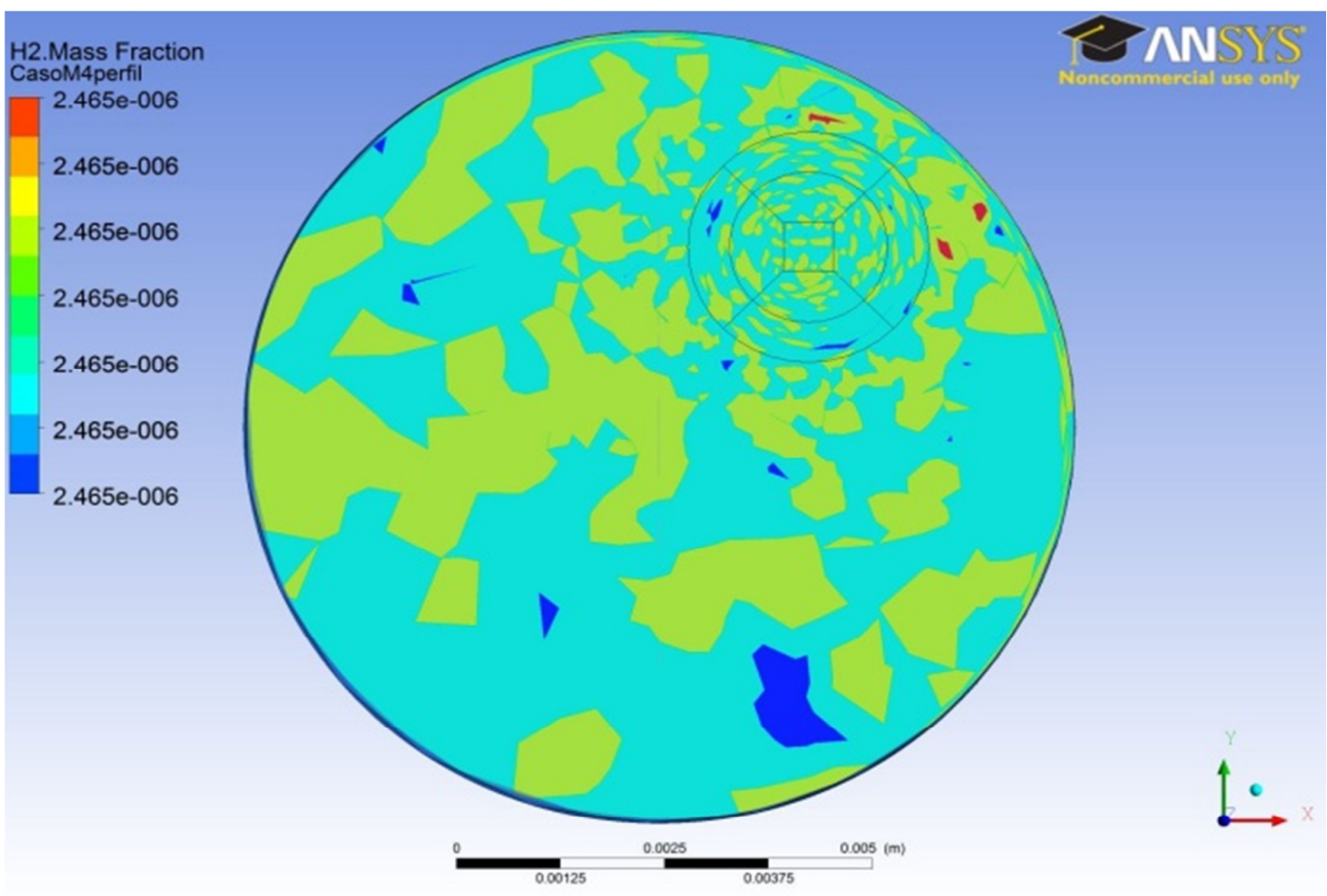

Figura 44: Fração mássica de $\mathrm{H}_{2}$, Caso M4. 


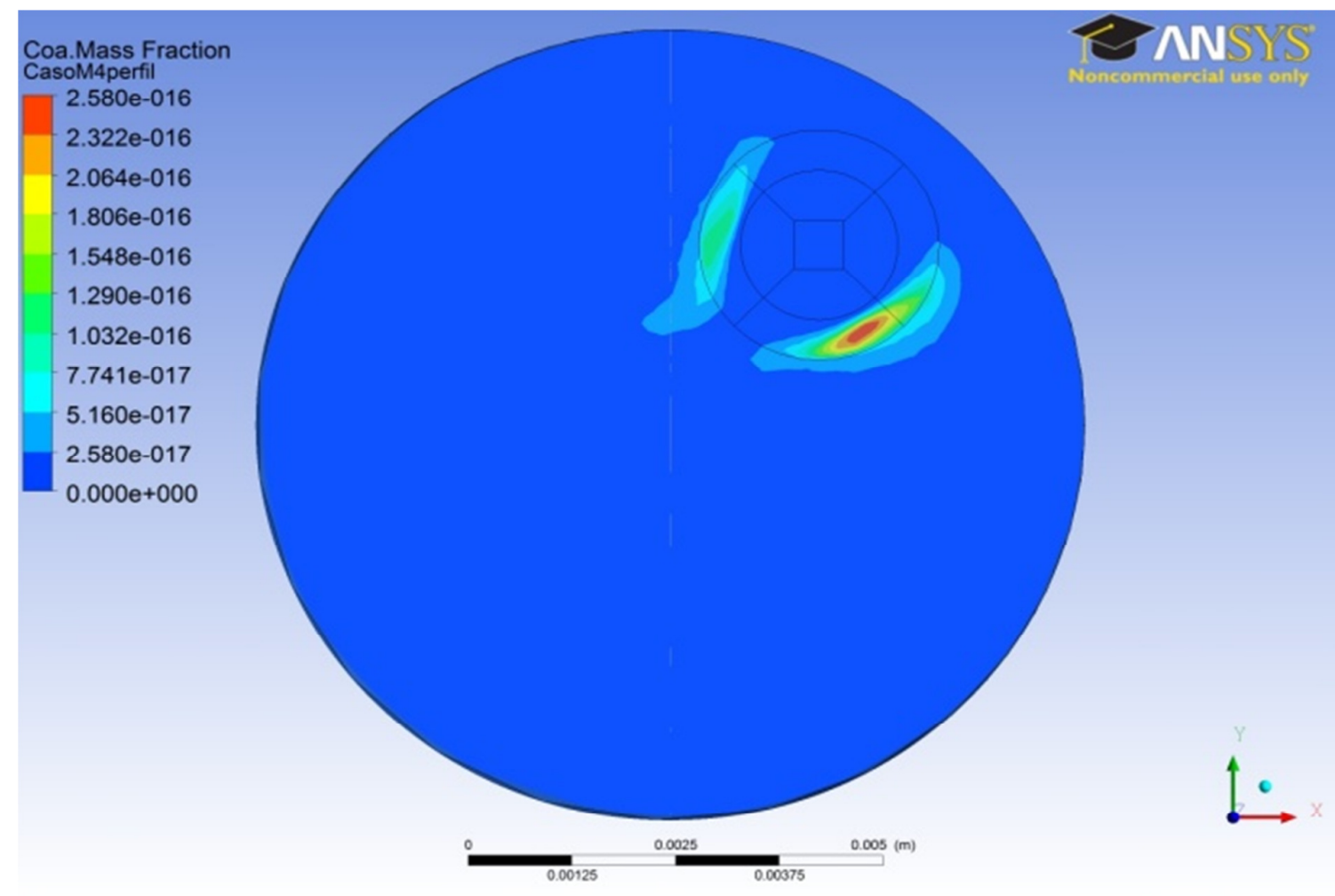

Figura 45: Fração mássica de COA, Caso M4.

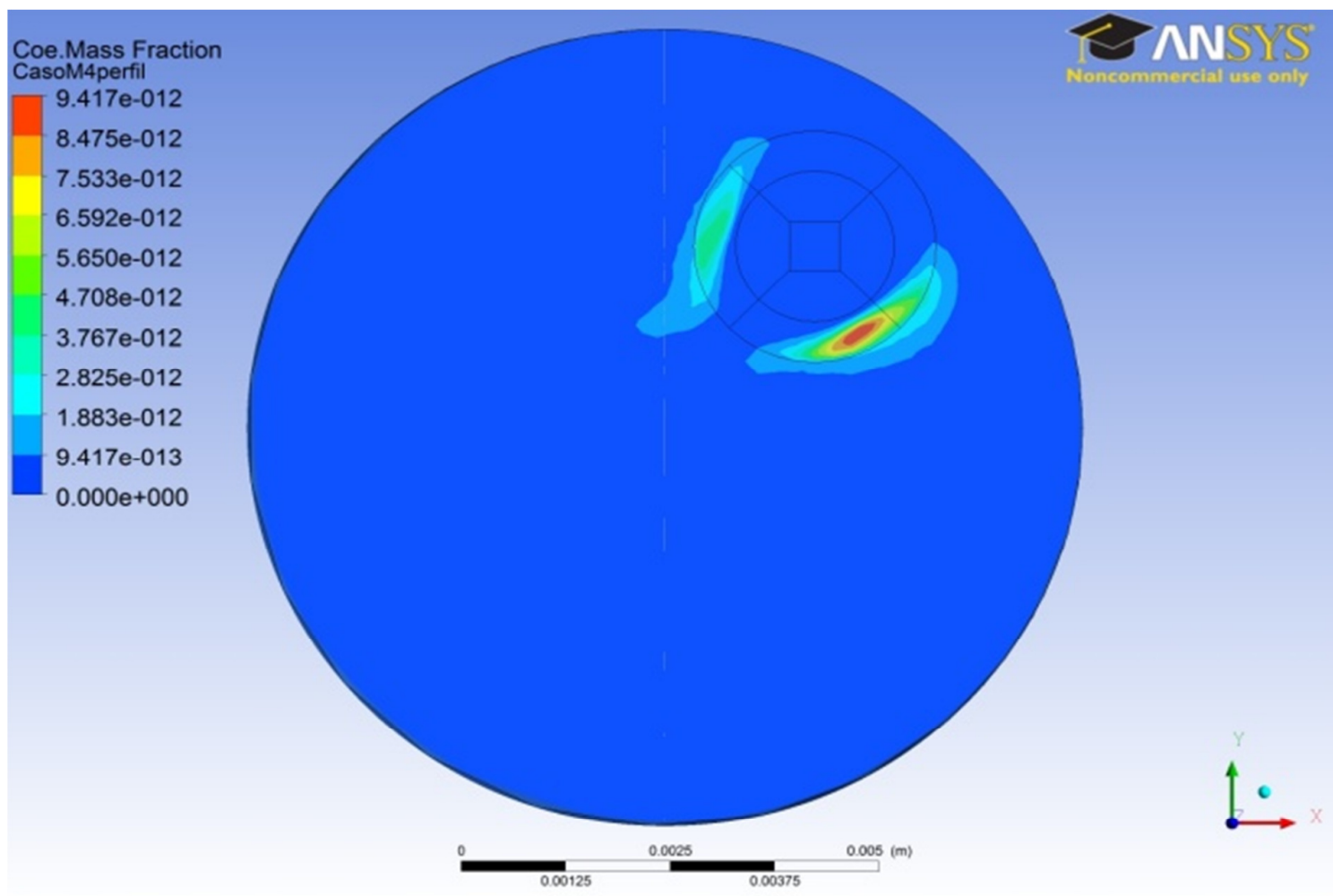

Figura 46: Fração mássica de COE, Caso M4. 


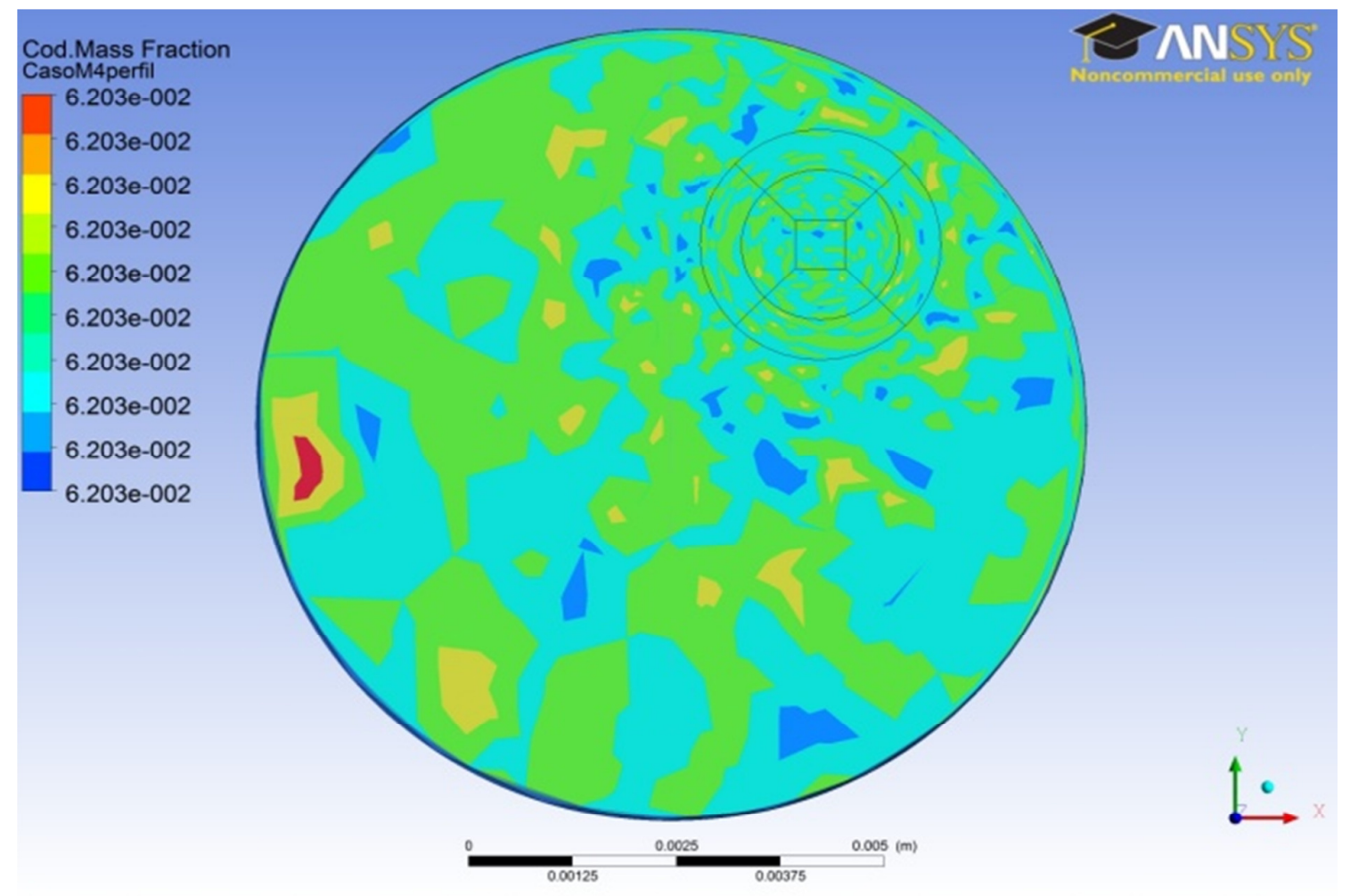

Figura 47: Fração mássica de COD, Caso M4. 


\subsection{Caso M5 - Estudo de sensibilidade do modelo: ativação de turbulência no meio poroso}

A ativação do modelo de turbulência no meio poroso resultou na formação de um perfil de escoamento com formação ainda mais reduzida de caminhos preferenciais. A consideração de turbulência no meio poroso resulta ainda na formação de região , como se observa na Figura 48 e Figura 49.

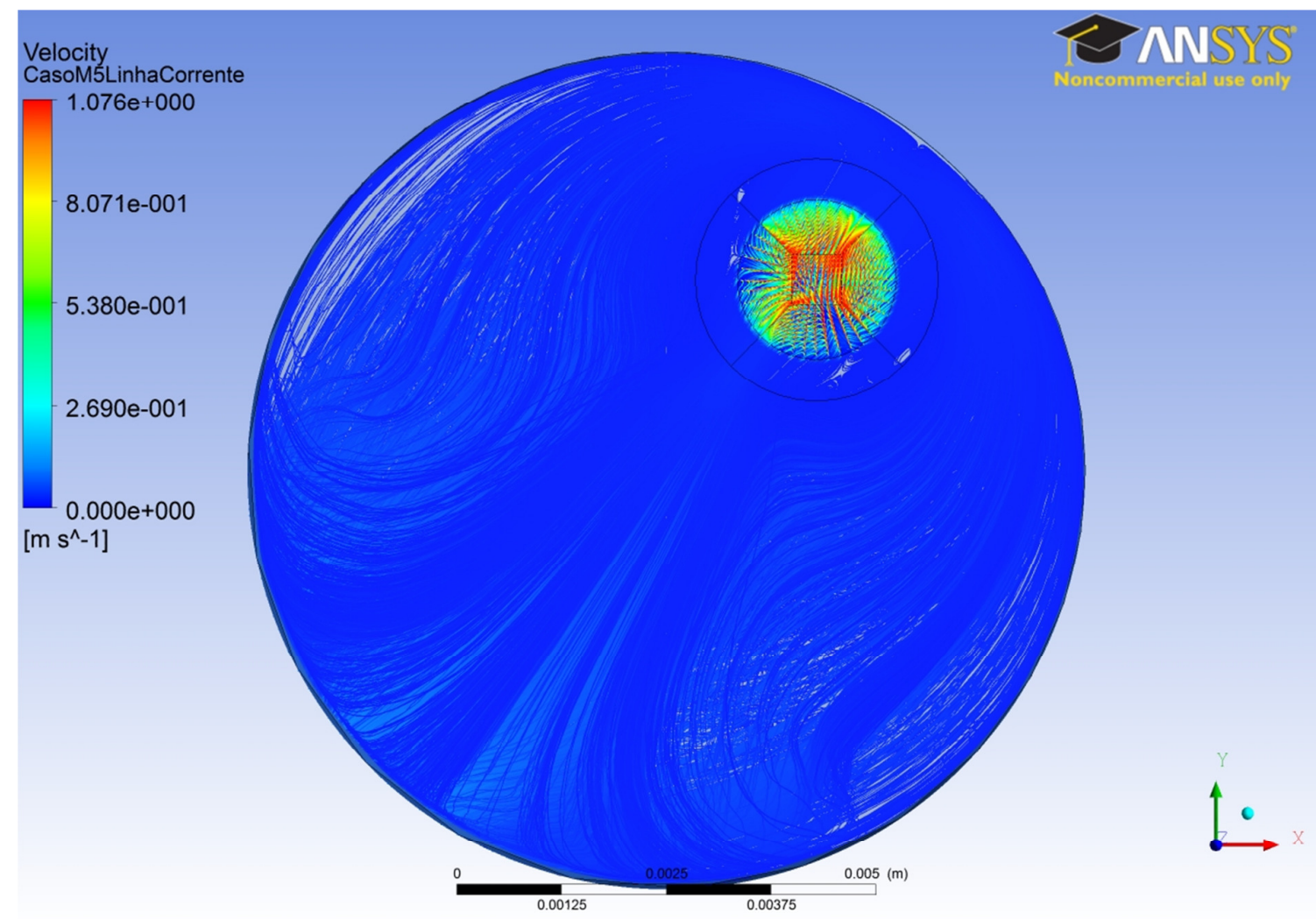

Figura 48: Linhas de corrente, Caso M5 - corte central. 


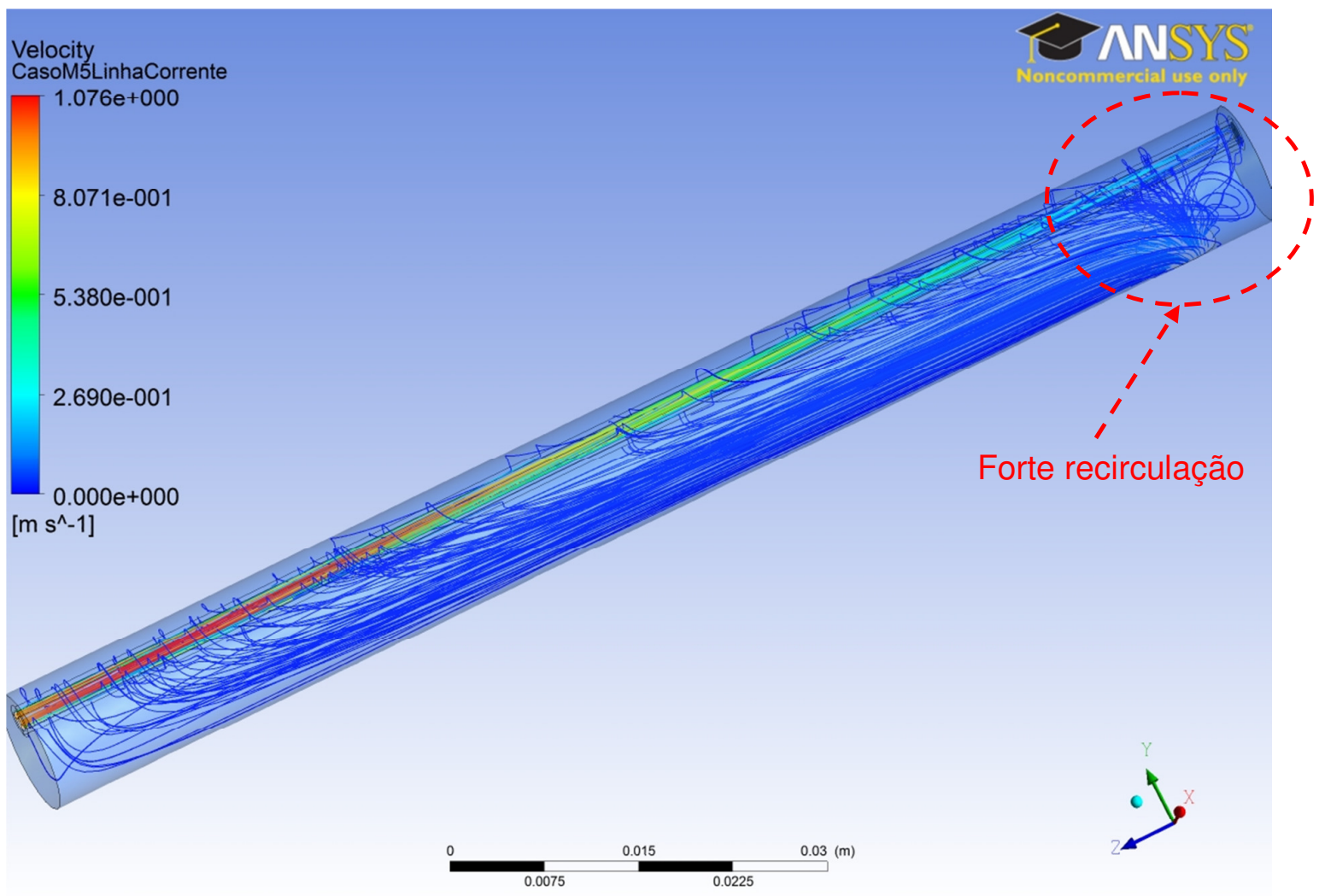

Figura 49: Linhas de corrente, Caso M5. 


\subsection{Caso S2 - Simulação de defeito estrutural sem perda de uniformidade azimutal: velocidade reduzida}

A ocorrência de defeito localizado ao longo de todo o comprimento da membrana exerce pouco efeito sobre o escoamento, como apresentado na Figura 50.

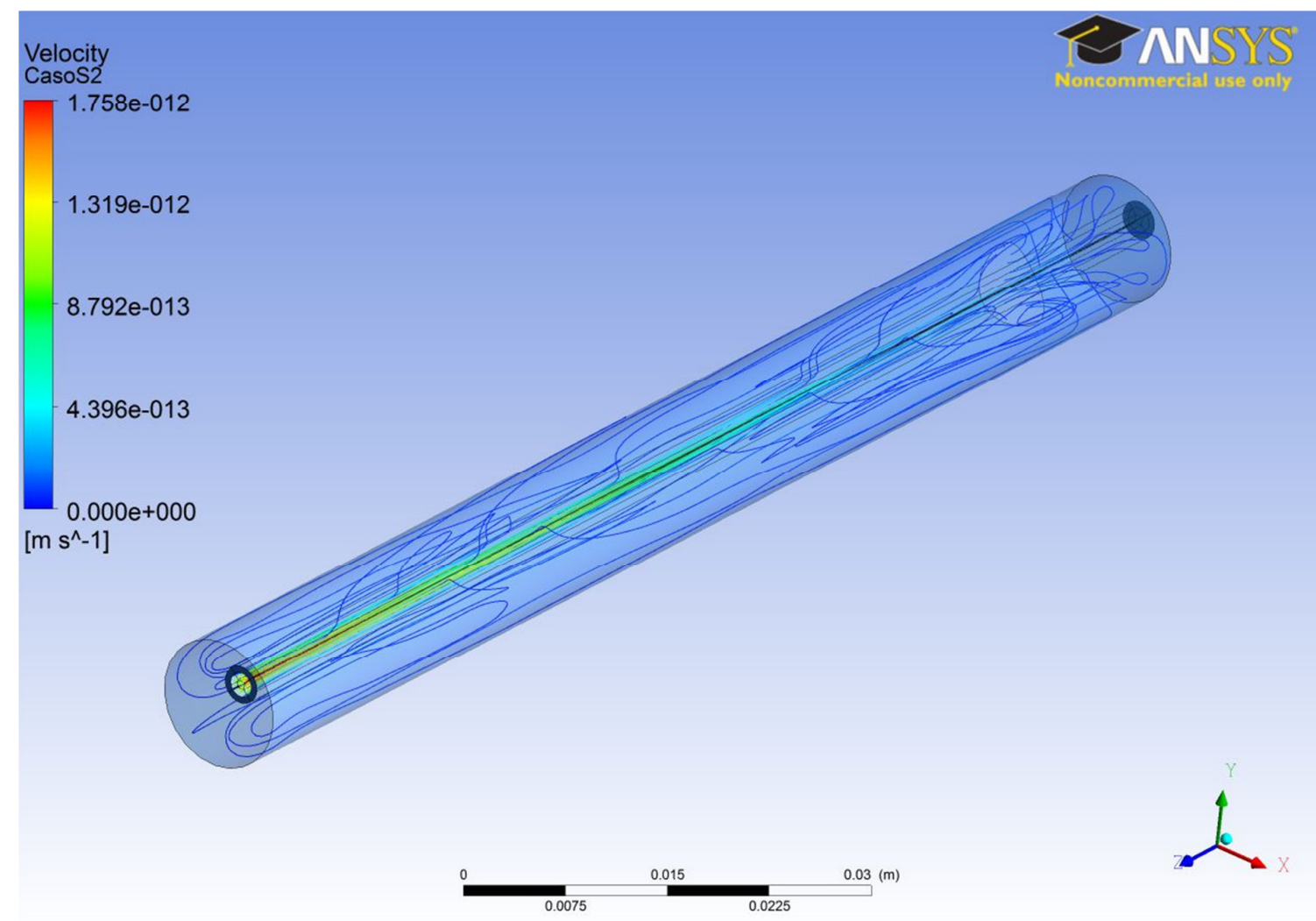

Figura 50: Linhas de corrente, Caso S2.

6.7. Caso S3 - Simulação de defeito estrutural sem perda de uniformidade azimutal: velocidade real

Para a velocidade real, o efeito de irregularidade na membrana é ainda menos detectável, comparando-se com o caso S2, como se observa na Figura 51. 


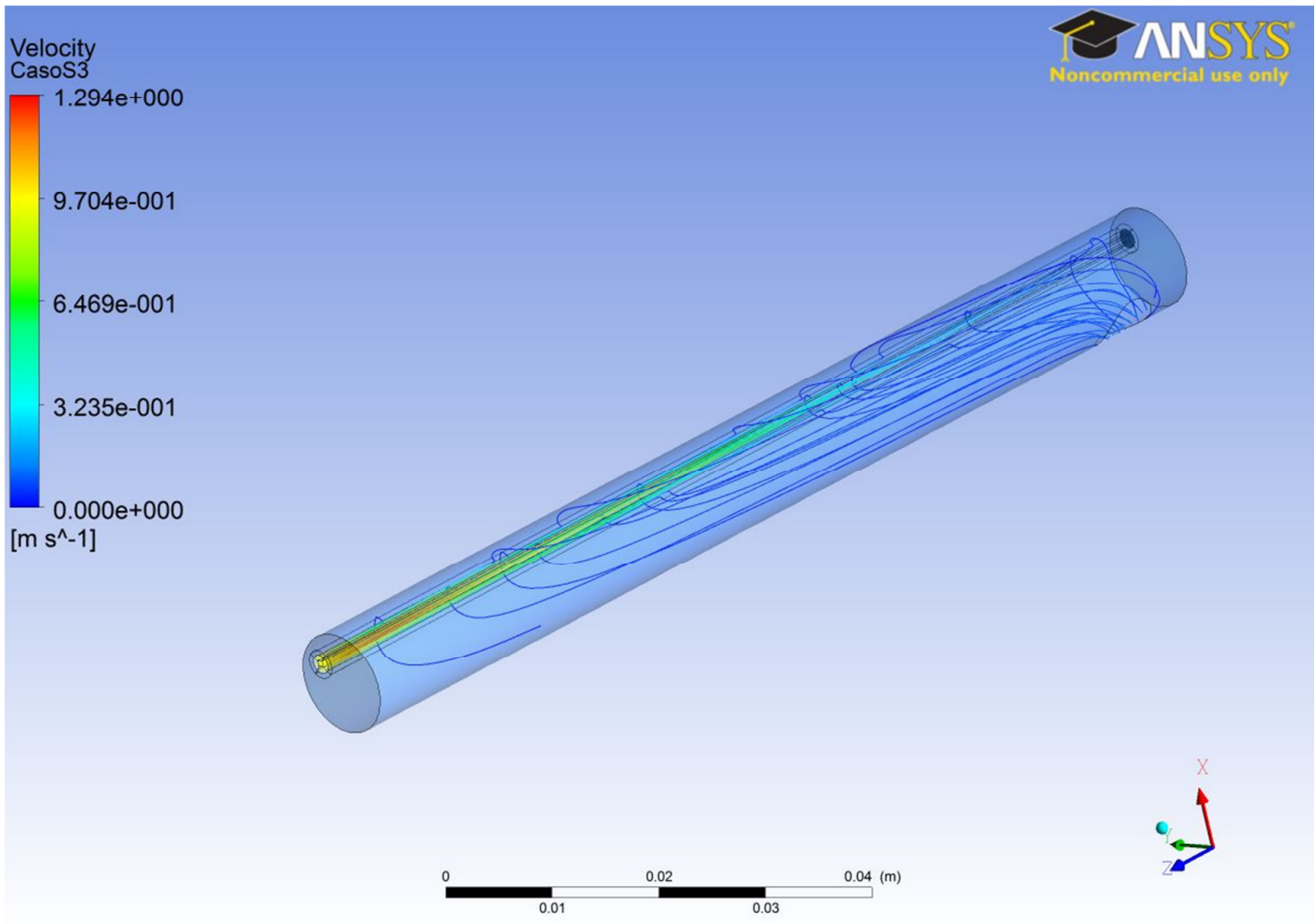

Figura 51: Linhas de corrente, Caso S3. 


\subsection{Caso S4 - Simulação de defeito estrutural com perda de uniformidade azimutal: velocidade real}

Diferentemente do observado nos dois casos anteriores, a definição de defeitos abrangendo toda a membrana e, em particular, a ocorrência de resistência diferenciada numa mesma linha longitudinal resulta na formação evidente de caminhos preferenciais e de zonas mortas, conforme observado na Figura 52.

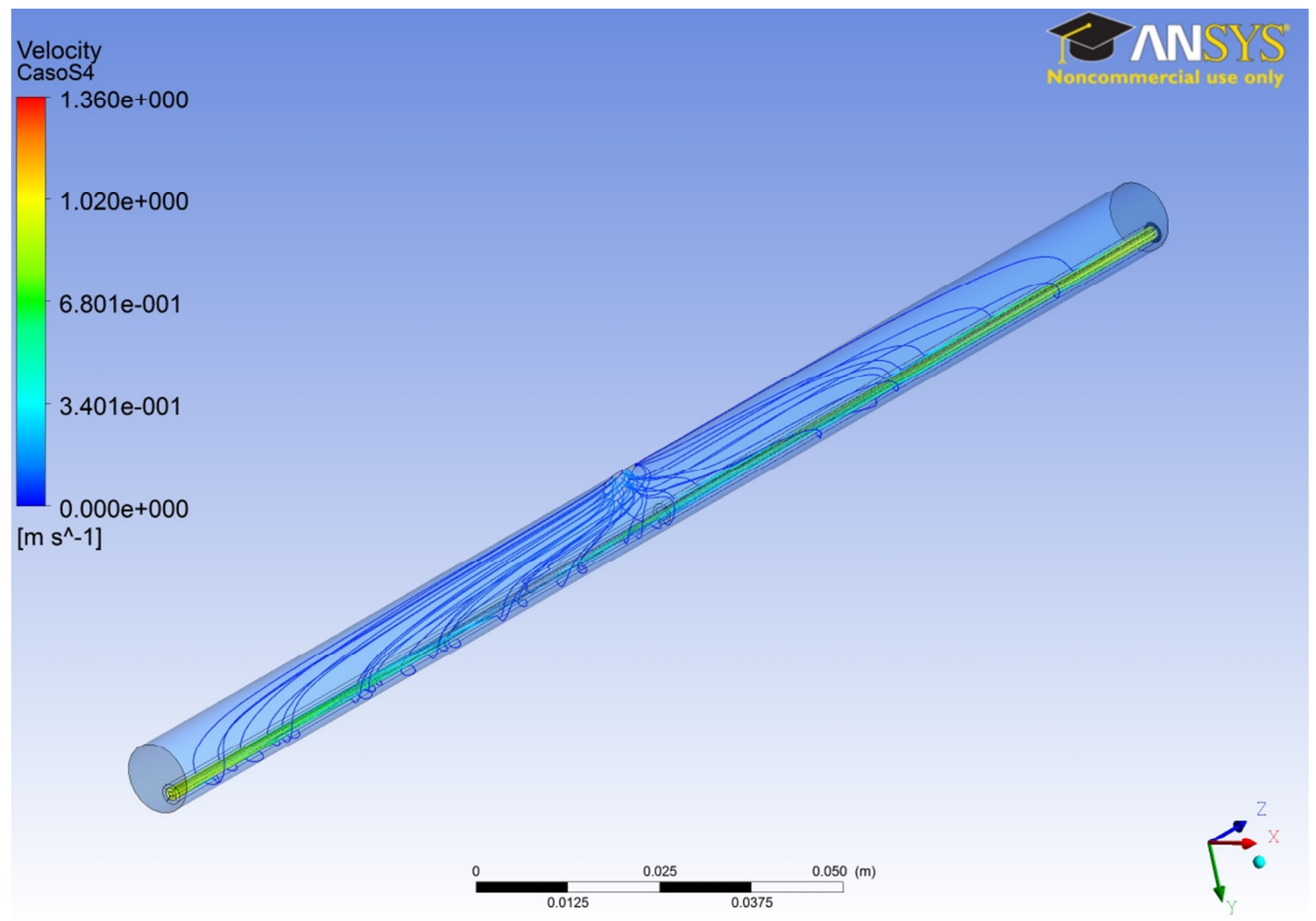

Figura 52: Linhas de corrente, Caso S4. 


\subsection{Verificação de consistência do modelo}

A dificuldade em se projetar e executar experimentos adequados à validação de modelos em micro escala é conhecida, especialmente quando se pretende observar efeitos de escoamento de pequena escala. Ghidossi (2006) menciona, inclusive, essa limitação como mais um fator motivador para a ampliação de estudos numéricos na área de modelagem de membranas, parcialmente cobrindo a lacuna ainda existente quanto a determinações experimentais.

Num estudo abrangente sobre técnicas de dinâmica dos fluidos computacional aplicadas à modelagem do escoamento em canais de membranas, Wiley e Fletcher (2003) apresentam propostas de soluções semi-analíticas que, aplicadas em conjunto permitem uma determinação da validade e utilidade dos modelos desenvolvidos.

Em resumo, isso significa que o presente objeto de tema de simulação CFD não é suscetível a comparação com medidas experimentais. Entretanto, tem-se que recorrer ao conceito de verificação da modelagem, mesmo que dentro de limites de precisão, no sentido de que esta implementação está conceitualmente correta dentro de exames de erros da simulação.

Tal procedimento foi realizado naturalmente no decorrer do presente trabalho, como resultado de diferentes e exaustivas construções de diferentes tipos de malhas, simuladas com graus de refinamento distintos, além da verificação de coerência de resultados de escoamento e de composição de substâncias. 


\section{Conclusões e sugestões para trabalhos futuros}

\subsection{Conclusões}

No presente trabalho, foram realizadas simulações de escoamento de líquido em reator de membrana do tipo contator ativo, a partir de modelo desenvolvido pela abordagem de dinâmica dos fluidos computacional em ANSYS FLUENT, com meio poroso aproximado por leito fixo, com parâmetros determinados pela equação de Ergun.

Pôde-se constatar que o sistema estudado apresenta uma série de desafios à abordagem teórica e, em particular, ao uso do CFD, dentre as quais se menciona: dificuldades relacionadas à definição de um modelo adequado para meio poroso, alta razão de aspecto da geometria, presença de recirculação e necessidade de observação de valores de pequenas escalas.

Por meio das simulações, conclui-se que pequenas alterações estruturais no equipamento podem resultar em grandes mudanças no regime de escoamento, afetando, por conseguinte, as taxas de reação e o desempenho final do reator.

Especificamente quanto à aplicação ao meio estudado, menciona-se que o modelo de turbulência RNG $k-\varepsilon$ mostrou adequado, em contraposição ao modelo $k$ - $\omega$, que resultou em divergência nas iterações.

O estudou demonstrou o potencial de aplicação de CFD para determinação local de concentração de componentes.

Pode-se ainda concluir que, em comparação a modelos simplificados, como 2-D, modelos completos 3-D podem fornecer informações relevantes sobre o sistema estudado, em particular sob condições não-ideais de escoamento, como a presença de defeitos estruturais nas membranas.

Outro aspecto de valor do presente trabalho, não do ponto de vista de métodos, e sim do ponto de vista de aplicação ao problema, é que teve como subproduto a 
necessidade de se obter e reunir todas as informações relevantes tais como cinética, propriedades químicas e físicas, medições de granulometria e diâmetros médios, que estão organizados para esta bancada experimental para futuras simulações.

\subsection{Sugestões de continuidade do trabalho}

Como primeiro passo para o avanço nas análises do comportamento do reator em termos de seu desempenho, avaliado principalmente sob o enfoque da seletividade, faz-se necessário desenvolver estratégia que permita o acompanhamento da evolução de concentração dos reagentes no reator.

Dessa forma, uma primeira abordagem a ser tratada incluiria o desenvolvimento de modelo transiente, levando em conta a operação de recirculação.

Desenvolvimento adicional do modelo é trazido também pelo detalhamento das equações que representam o meio reacional completo, levando em com todas as suas fases.

Recomenda-se também desenvolver uma comparação do modelo adotado no presente trabalho para representação das resistências viscosa e inercial da membrana com determinações experimentais. 


\section{Referências bibliográficas}

ANSYS FLUENT 6.3 Documentation, 2006.

ANSYS Release 11.0 Documentation for ANSYS Workbench.

ANSYS FLUENT 12.0 Theory Guide, 2009.

ANSYS FLUENT 12.0 User's Guide, 2009.

BERNSTEIN, S. AGARWALLA, C. R. F. LUND: Membrane reactors for catalytic series and series-parallel reactions. Journal of Membrane Science, Volume 77, Issues 2-3, 4 March 1993, pp. 155-164.

BOtTINO, A., CAPANNELLI, G., COMITE, A.: Catalytic membrane reactors for the oxidehydrogenation of propane: experimental and modelling study. Journal of Membrane Science 197 pp. 75-88, 2002.

BOtTino, A., CAPANNELLI, G., COMITE, A., DEL BORGHI, A., DI FELICE, R.: Catalytic ceramic membrane in a three-phase reator for the competitive hydrogenation-isomerisation of methylenecyclohexane. Separation and Purification Technology, Vol. 34, pp. 239-245, 2004.

BRINKMANN, T., PERERA, S. P. , THOMAS, W. J.: An experimental and theoretical investigation of a catalytic membrane reactor for the oxidative dehydrogenation of methanol. Chemical Engineering Science 56 pp. 2047-2061, 2001.

CENTI, G.; PERATHONER, S.: Catalysis and sustainable (green) chemistry. Catalysis Today 77 pp. 287-297, 2003.

CINI, P., BLAHA, S. R., HAROLD, M. P.: Preparation and characterization of modified tubular ceramic membranes for use as catalyst supports. Journal of Membrane Science, 55 pp. 199-225, 1991.

CRISCUOLI, A.; BASILE, A.; DRIOLI E.; LOIACONO, O.: An economic feasibility study for water gas shift membrane reator. Journal of Membrane Science $181 \mathrm{pp}$. 21-27 (2001). 
DALMON, J.A: Handbook of heterogeneous catalysis. New York: Wiley/VCH ch. 9.3, pp. 1387-1398 (1997).

DAUB, K. et al.: Studies on the Use of Catalytic Membranes for Reduction of Nitrate in Drinking Water. Chemical Engineering Science 54 pp. 1577-1582 (1999).

DIAKOV, V., VARMA, A.: Reactant distribution by inert membrane enhances packedbed reactor stability. Chemical Engineering Science 57 pp. 1099 - 1105, 2002.

DITTMEYER, R.; HÖLLEIN, V.; DAUB K.: Membrane reators for hydrogenation and dehydrogenation processes based on supported palladium. Journal of Molecular Catalysis A: Chemical 173 pp. 135-184, 2001.

DITTMEYER, R.; SVAJDA, K.; REIF, M.: A review of catalytic membrane layers for gas/liquid reactions. Topics in Catalysis, Vol. 29, Ns. 1-2, maio de 2004.

DIXON, A. G.: Analysis of intermediate product yield in distributed-feed nonisothermal tubular membrane reactors. Catalysis Today 67 pp. 189-203, 2001.

DIXON, A. G.: Recent Research in Catalytic Inorganic Membrane Reators. Int. J. Chemical Reator Engineering. Vol. 1, Review R6, 2003.

DIXON, A. G., NIJEMEISLAND, M., STITT, E. H.: Packed tubular reactor modeling and catalyst design using computational fluid dynamics. Advances in Chemical Engineering Computational Fluid Dynamics. Volume 31, 2006, pp. 307-389.

EIGENBERGER, G.: Catalytic fixed bed reators, Handbook of Heterogeneous Catalysis, G. Ertl., H. Knozinger, e J. Weitkamp (Eds.), Weinheim, Germany, VCH. Vol. 3, 1997.

ELTRON RESEARCH INC.: Advanced Hydrogen Transport Membranes for Vision 21 Fossil Fuel Plants. Boulder, 2005.

FISHMAN, E.: Self-diffusion in liquid n-pentane and n-heptane. J. Phys. Chem., 59 (5), pp. 469-472, 1955.

FOGLER, H. S.: Elements of Chemical Reaction Engineering, 4th Ed. Pearson Education, 2006. 
FRITSCH, D., BENGTSON, G.: Development of catalytically reactive porous membranes for the selective hydrogenation of sunflower oil. Catalysis Today, Volume 118, Issues 1-2, 30 October 2006, pp. 121-127.

GHIDOSSI, R., VEYRET, D., MOULIN, P.: Computational fluid dynamics applied to membranes: State of the art and opportunities. Chemical Engineering and Processing 45 (2006) pp. 437-454.

GRÖSCHEL, L.: Charakterisierung von PolyacrylsäurePalladiumverbundsystemen und ihre Anwendung im Membranreaktor. Tese de Doutorado. Química Industrial / Engenharia de Reações Multifásicas - Universidade Técnica de Berlim, 2004.

GRYAZNOV, V.: Membrane catalysis. Catalysis Today 51 (1999) pp. 391-395.

GRYAZNOV, V.M., ERMILOVA, M.M., OREKHOVA, N.V.: Membrane-catalyst systems for selectivity improvement in dehydrogenation and hydrogenation reactions. Catalysis Today 67 (2001) pp. 185-188.

HAN, L.-F., XU, Z.-L., CAOB, Y., WEIB, Y.-M., XUB, H.-T.: Preparation, characterization and permeation property of $\mathrm{Al} 2 \mathrm{O} 3, \mathrm{Al} 2 \mathrm{O} 3-\mathrm{SiO} 2$ and $\mathrm{Al} 2 \mathrm{O} 3-\mathrm{kaolin}$ hollow fiber membranes. Journal of Membrane Science Volume 372, Issues 1-2, 15 April 2011, pp. 154-164.

HARA, S., SAKAKI, K., ITOH, N.: Decline in hydrogen permeation due to concentration polarization and co hindrance in a palladium membrane reactor. Ind. Eng. Chem. Res. 1999, 38, pp. 4913-4918.

HARIMKAR, S. P., DAHOTRE, N. B.: Crystallographic and morphological textures in laser surface modified alumina ceramic. Journal of Applied Physics 100, 024901 2006.

HOU, K., Hughes, R., Ramos, R., Menéndez, M., Santamaría, J.: Simulation of a membrane reator for oxidative dehydrogenation of propane, incorporating radial concentration and temperature profiles, Chem. Eng. Sci., 56, pp. 57-67, 2001. 
ITOH, N.; XU, W.; HARAYA, K.: Radial mixing diffusion of hydrogen in a packed-bed type of palladium membrane reator. Ind. Eng. Chem. Res., 33, pp. 197-202, 1994.

KNÖZINGER, H.; KOCHLOEFL, K.: Heterogeneous Catalysis and Solid Catalysts. Handbook of heterogeneous catalysis. Wiley-VCH Verlag GmbH e Co. KGaA, Weinheim, 2005.

KOUKOU, M. J., CHALOULOU, G., PAPAYANNAKOS, N., MARKATOS, N. C.: Mathematical modelling of the performance of non-isothermal membrane reators. Int. J. Heat Mass Transfer, Vol. 40, No. 10, pp. 2407-2417, 1997.

KOUKOU, M. K., PAPAYANNAKOS, N., MARKATOS, N. C., BRACHT, M., VAN VEEN, H. M., ROSKAM, A.. Performance of ceramic membranes at elevated pressure and temperature: effect of non-ideal flow conditions in a pilot scale membrane separator. Journal of Membrane Science, Volume 155, Issue 2, 12 April 1999, pp. 241-259.

KOUKOU, M.K., N. PAPAYANNAKOS, N., MARKATOS, N. C.: On the importance of non-ideal flow effects in the operation of industrial-scale adiabatic membrane reactors. Chemical Engineering Journal 83 (2001) pp. 95-105.

LAMBERT, C. K.; GONZALEZ, R. D.: Activity and selectivity of a $\mathrm{Pd} / \gamma-\mathrm{Al}_{2} \mathrm{O}_{3}$ catalytic membrane in the partial hydrogenation reactions of acetylene and 1,3-butadiene. Catalysis Letters, Vol. 57, pp. 1-7, 1999.

LANGE, C. et al.: Selective Hydrogenation Reactions with a Microporous Membrane Catalyst, Prepared by Sol-Gel Dip Coating. Journal of Catalysis, Vol. 175, pp. 280293, 1998.

LANGHENDRIES, G., BARON, G.V., NEYS, P.E., JACOBS, P.A.: "Liquid Phase Hydrocarbon Oxidation using Supported Transition Metal Catalysts: Influence of the Solid Support”, Chem. Eng. Sci., 54, pp. 3563-3568 (1999).

LANGHENDRIES, G. et al.: Selective hydrocarbon oxidation using a liquid-phase catalytic membrane reactor. Catalysis Today 56 (2000) pp. 131-135. 
LAPKIN, A. A., TENNISON, S. R., THOMAS, W. J.: A porous carbon membrane reactor for the homogeneous catalytic hydration of propene. Chemical Engineering Science 57 (2002) pp. 2357-2369.

LAUNDER, B. E., SPALDING, D. B.: The numerical computation of turbulent flows. Computer Methods in Applied Mechanics and Engineering 3 (1974) pp. 269-289.

LI, K.: Ceramic membranes for separation and reaction. Wiley VCH Verlag, 2007.

LISBOA, E. F. A.: Uma abordagem multi-escala para o cálculo da permeabilidade longitudinal de meios porosos fibrosos randômicos. Dissertação de mestrado. Engenharia Mecânica - Universidade Federal do Rio de Janeiro, COPPE, 2000.

LU, Y., DIXON, A.G., MOSER, W.R. e MA, Y.H.: "Analysis and Optimization of Cross-Flow Reactors with Staged Feed Policies - Isothermal Operation with ParallelSeries, Irreversible Reaction Systems", Chem. Eng. Sci., 52, 1349 (1997b); 52, 2443 (1997).

LU, Y., DIXON, A.G., MOSER, W.R. e MA, Y.H.: "Analysis and Optimization of Cross-flow Reactors with Distributed Reactant Feed and Product Removal", Catal. Today, 35, 443 (1997a).

MIACHON, S., DALMON, J.-A.: Catalysis in membrane reactors: what about the catalyst? Topics in Catalysis Vol. 29, Nos. 1-2, April 2004.

NEKHAMKINA, O., RUBINSTEIN, B. Y., SHEINTUCH, M.: Spatiotemporal Patterns in Thermokinetic Models of Cross-Flow Reactors. AIChE Journal, August 2000 Vol. 46, No. 8.

PARK, J. S. et al.: Analysis of the Catalytic Membrane Reator by CFD Method. HWAHAK KONGHAK, Vol. 41, No. 6, pp. 700-709, December, 2003.

PATANKAR, S. V.: Numerical heat transfer and fluid flow. Taylor and Francis, 1980. 
PEDERNERA, M., ALFONSO, M. J., MENENDEZ, M., SANTAMAR, J.: Simulation of a catalytic membrane reactor for the oxidative dehydrogenation of butane. Chemical Engineering Science 57 (2002) pp. 2531 - 2544.

PELLERIN, E. et al:: Turbulent transport in membrane modules by CFD simulation in two dimensions. Journal of Membrane Science Volume 100, Issue 2, 14 April 1995, pp. 139-153.

PLATINUM METALS REVIEW: Palladium Membrane Reactors. Platinum Metals Review, 32, 1988.

PLATINUM METALS REVIEW: Palladium Membrane Reactors. Platinum Metals Review, 35, 1991.

PURNAMA, $H$. et al.: $\alpha$-methylstyrene hydrogenation in a flow-through membrane reactor. AiChE Journal, August 2006, Vol. 52, N8.

RAHIMI, M. et al.: CFD and experimental studies of fouling of a microfiltration membrane. Chemical Engineering and Processing: Process Intensification. Article in Press, 2009.

REIF, M.; DITTMEYER, R.: Porous, catalytically active ceramic membranes for gasliquid reactions: a comparison between catalytic diffuser and forced through flow concept. Catal. Today, Vol. 82, pp. 3-14, 2003.

SARACCO, G. et al.: High-temperature membrane reators: potentials and problems. Chem. Eng. Sci. 54, pp. 1997-2017, 1999.

SCHMIDT, A., SCHOMÄCKER, R.: Kinetics of 1,5-Cyclooctadiene Hydrogenation on $\mathrm{Pd} / \alpha-\mathrm{Al}_{2} \mathrm{O}_{3}$. Ind. Eng. Chem. Res. 46 (2007a) pp. 1677-1681.

SCHMIDT, A., SCHOMÄCKER, R.: Partial hydrogenation of sunflower oil in a membrane reactor. Journal of Molecular Catalysis A: Chemical 271 (2007b) pp. 192-199.

SCHMIDT, A.; HAIDAR, R.; SCHOMÄCKER, R.: Selectivity of partial hydrogenation reactions performed in a pore-through-flow catalytic membrane reator. Catal. Today, 104 (2005) pp. 305-312. 
SCHMIDT, A.: A pore-flow-through membrane reator for selective hydrogenation reactions. Tese de doutorado. Química Industrial / Engenharia de Reações Multifásicas - Universidade Técnica de Berlim, 2007.

SCHOMÄCKER, R. et al.: Membranen als Katalysatorträger. Chemie Ingenieur Technik, 2005, 77, № 5, pp. 549-558.

SEIDEL-MORGENSTERN, A. (editor): Membrane reactors: distributing reactants to improve selectivity and yield. Wiley-VCH Verlag, 2010.

SIDERIDIS, A., KOUTSONIKOLASY, D., MISSIRLISZ, D., TOPIS, S., KALDISYY, S., SKODRASZZ, G., SAKELLAROPOULOS, G.: Computational Fluid Dynamics Study on the Decomposition of Ammonia in a Selective Porous Membrane. Chemical Product and Process Modeling Volume 3, Issue 12008 Article 42.

SOUSA, J. M., CRUZ, P., MAGALHÃES, F. D., MENDES, A.: Modeling catalytic membrane reactors using an adaptive wavelet-based collocation method. Journal of Membrane Science 208 (2002) pp. 57-68.

STRUKUL, G. et al.: Use of palladium based catalysts in the hydrogenation of nitrates in drinking water: from powders to membranes. Catalysis Today 55 (2000) pp. 139-149.

TESSER, R. et al.: Advantages in the Use of Membrane Contactors for the Study of Gas-Liquid and Gas-Liquid-Solid Reactions. Ind. Eng. Chem. Res., 44 (25), pp. 9451-9460, 2005.

TSOTSIS, T. T., A. M. CHAMPAGNIE, R. G. MINET, P. K. T. LIU: "Catalytic Membrane Reactors," Computer-Aided Design of Catalysts, E. R. Becker and C. J. Pareira, eds., New York, Dekker (1993).

VERSTEEG, H. K., MALALASEKERA, W.: An introduction to computational fluid dinamics: the finite volume method. $2^{\text {nd }}$ Ed., Pearson Education Limited, 2007.

VINCENT M. J.; GONZALEZ, R. D.: Selective hydrogenation of acetylene through a short contact time reator. AIChE Journal, Vol. 48, №. 6, pp. 1257-1267, junho de 2002. 
WESTERMANN, T., MELIN, T.: Flow-through catalytic membrane reactorsPrinciples and applications. Chemical Engineering and Processing 48 (2009) pp. $17-28$.

WILEY, D. E., FLETCHER, D. F.: Techniques for computational fluid dynamics modeling of flow in membrane channels. Journal of Membrane Science $211 \mathrm{pp}$. 127-137, 2003.

ZHANG, L. et al.: Studies on the Hydrogenation of Cinnamaldehyde over Pd/C Catalysts. J. Chem. Technol. Biotechnol. 1998, 72, pp. 264-272. 


\section{ANEXO 1 Experimentos utilizados na determinação da cinética}

Reator de lama com membrana pulverizada (M184)

104,5 mL n-heptano, 5,5 mL COD, 10 bar, $50^{\circ} \mathrm{C}$
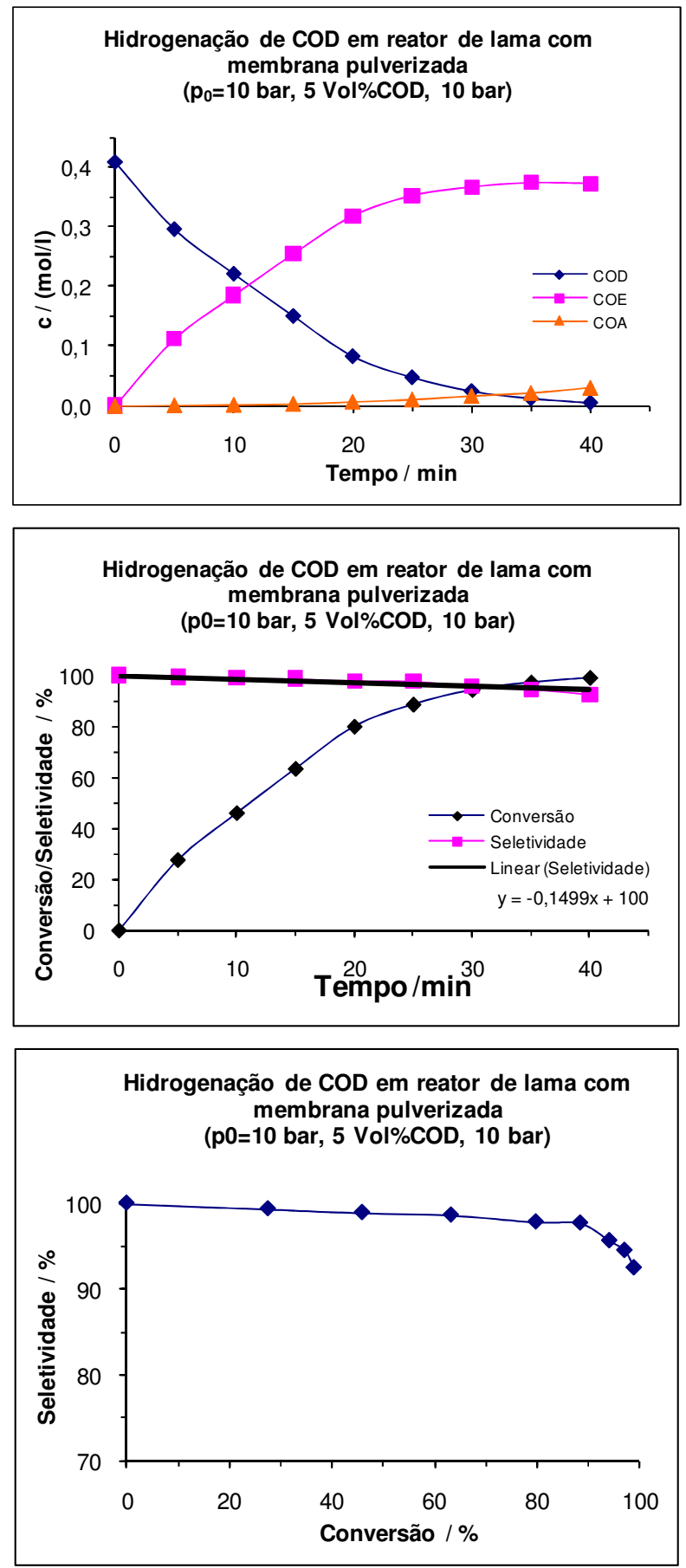

Fonte: Schmidt, 2007. 


\section{$\underline{\text { Reator de lama com catalisador "casca de ovo" }}$}

$70 \mathrm{~mL}$ heptano, $20 \mathrm{~mL}$ COD, $3 \mathrm{~g}$ catalisador
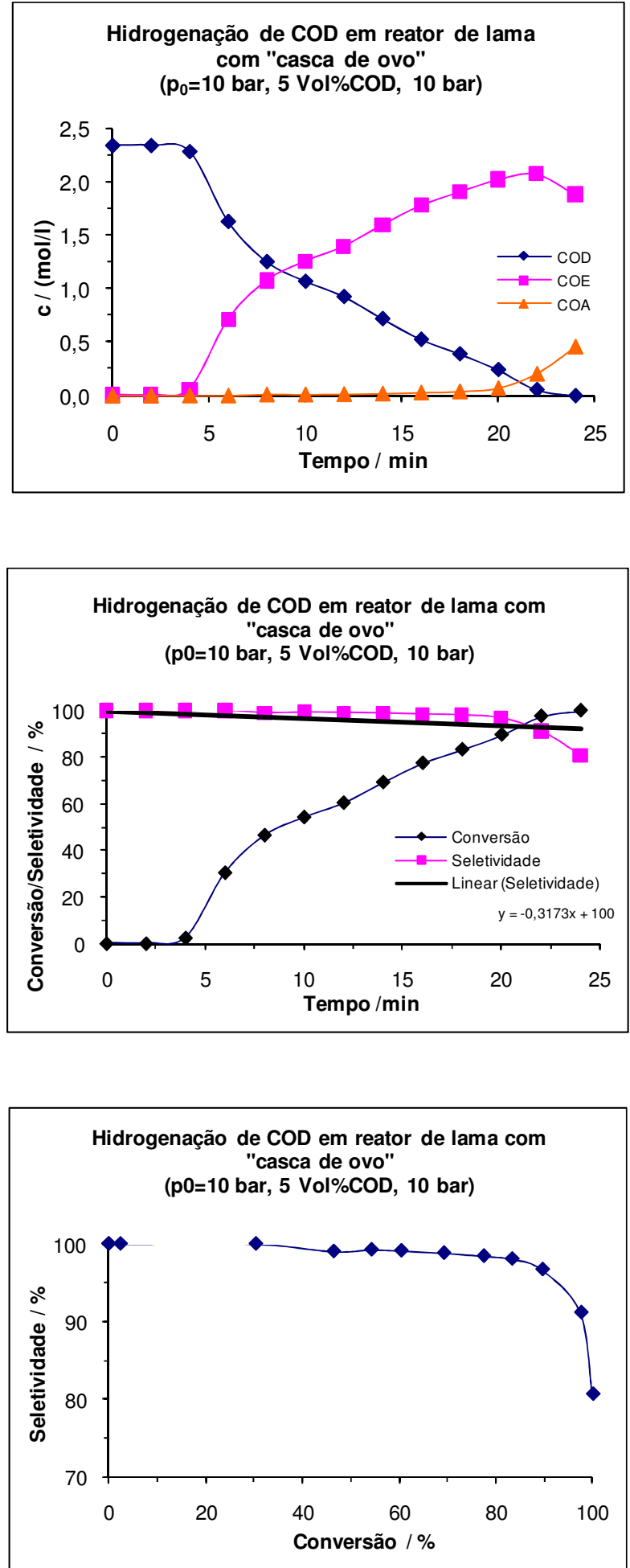

Fonte: Schmidt, 2007. 
$\underline{\text { Reator de lama com catalisador "casca de ovo" pulverizado }}$

$70 \mathrm{~mL}$ heptano, $20 \mathrm{~mL}$ COD, $3 \mathrm{~g}$ catalisador
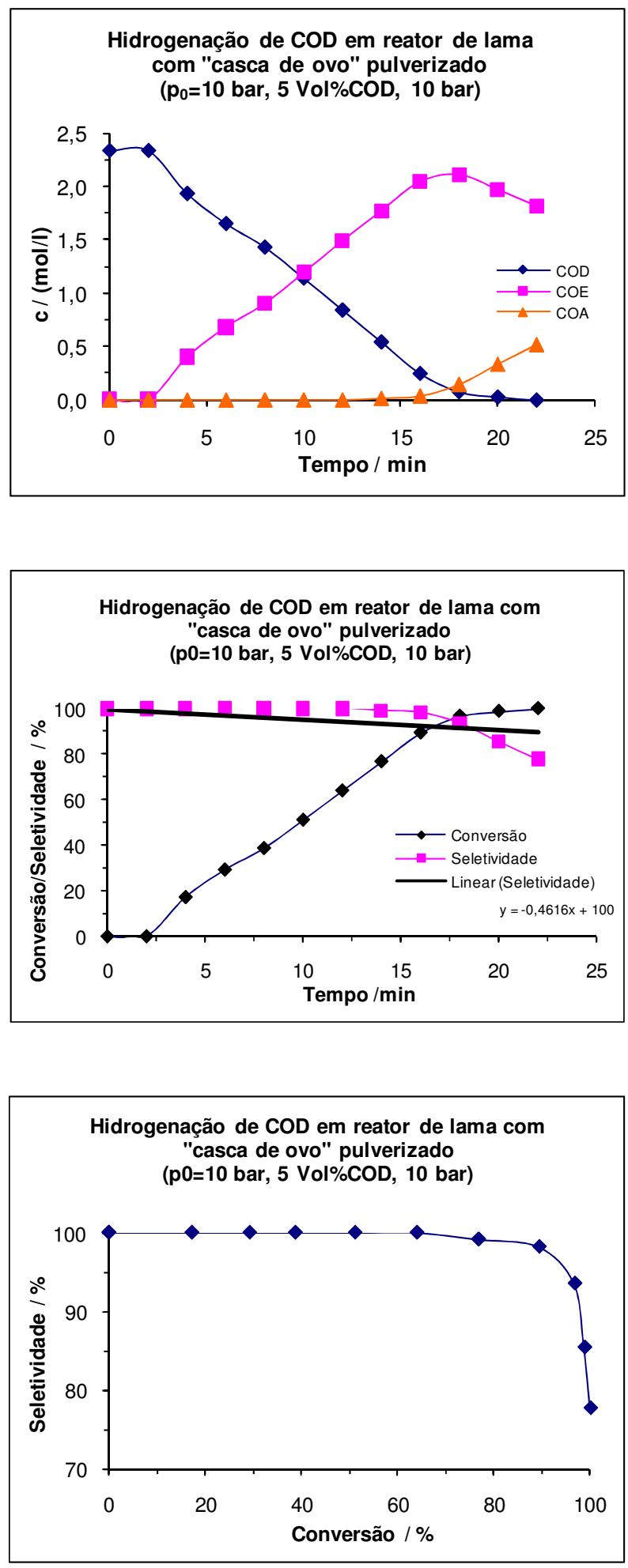

Fonte: Schmidt, 2007. 